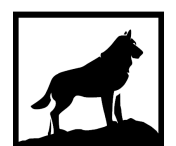

Michigan

Technological

18.5 University
Michigan Technological University

Digital Commons @ Michigan Tech

\title{
ASSESSMENT OF ANNULAR FLOW BOILING IN THE CONTEXT OF COMPUTATIONAL FLUID DYNAMICS (CFD) SIMULATIONS, EXPERIMENTS, AND EXISTING CORRELATIONS
}

HRISHIKESH PRASAD RANGA PRASAD

Michigan Technological University, hrangapr@mtu.edu

Copyright 2017 HRISHIKESH PRASAD RANGA PRASAD

Recommended Citation

RANGA PRASAD, HRISHIKESH PRASAD, "ASSESSMENT OF ANNULAR FLOW BOILING IN THE CONTEXT OF COMPUTATIONAL FLUID DYNAMICS (CFD) SIMULATIONS, EXPERIMENTS, AND EXISTING CORRELATIONS", Open Access Master's Thesis, Michigan Technological University, 2017.

https://doi.org/10.37099/mtu.dc.etdr/538

Follow this and additional works at: https://digitalcommons.mtu.edu/etdr

Part of the Heat Transfer, Combustion Commons 


\title{
ASSESSMENT OF ANNULAR FLOW BOILING IN THE CONTEXT OF COMPUTATIONAL FLUID DYNAMICS (CFD) SIMULATIONS, EXPERIMENTS, AND EXISTING CORRELATIONS
}

\author{
by \\ Hrishikesh Prasad Ranga Prasad
}

\begin{abstract}
A THESIS
Submitted in partial fulfillment of the requirements for the degree of MASTER OF SCIENCE in Mechanical Engineering
\end{abstract}

MICHIGAN TECHNOLOGICAL UNIVERSITY

2017

(C) 2017 Hrishikesh Prasad Ranga Prasad 
This thesis has been approved in partial fulfillment of the requirements for the Degree of MASTER OF SCIENCE in Mechanical Engineering.

Department of Mechanical Engineering - Engineering Mechanics

Thesis Advisor:

Committee Member:

Committee Member:

Department Chair:
Dr. Amitabh Narain

Dr. Kazuya Tajiri

Dr. Sunil Mehendale 


\section{Table of Contents}

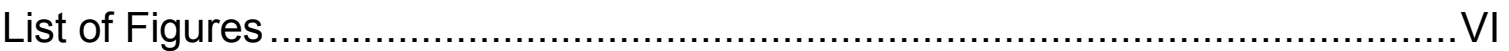

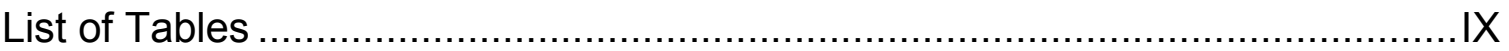

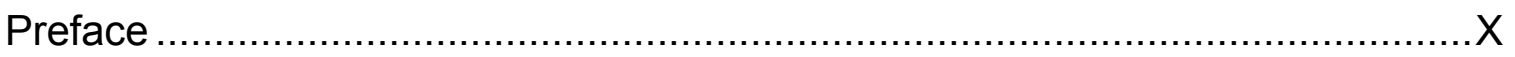

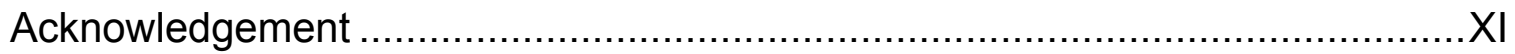

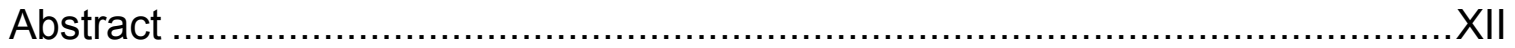

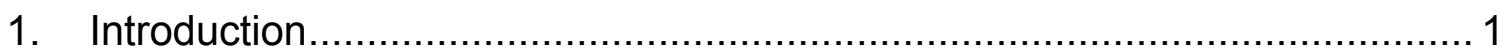

1.1 Traditional and Annular (Innovative) Flow-Boiling/Condensation ............... 2

1.2 Heat Transfer Coefficient (HTC) and Motivations for CFD Simulations of Flow-Boiling/Condensation ................................................................ 5

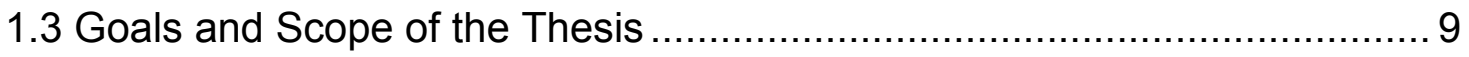

2. Basic variables and correlations of scientific and engineering interest and their relationship to one-dimensional (1-D) modeling of flow-boiling and flow-

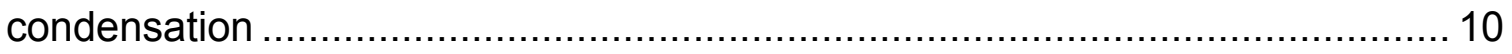

2.1 Basic variables and their correlations ................................................. 10

2.2 Other indirect variables and their influence on aforementioned key variables

2.3 Underlying one-dimensional (1-D) modeling approach to obtain spatial $x-$ variations of flow-variables that are known or correlated in terms of quality $\mathrm{X}$ and

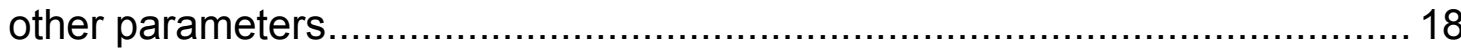

2.4 Use of Nux correlations covering all flow-regimes................................. 20 
3. Results and Correlations from Two-Dimensional (2-D) Laminar / Laminar CFD

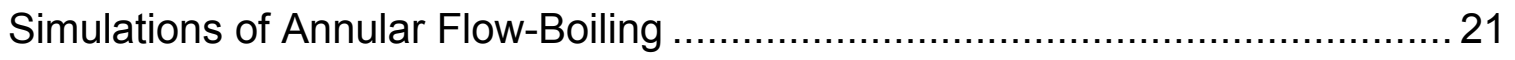

3.1 Important features of 2-D CFD Simulation of Annular Flow-Boiling .......... 21

3.2 Results and Correlation for Convective Boiling Component of Heat Transfer Coefficient..... 26

4. Use of Existing Correlations for Design of Annular Flow Boiling and Flow

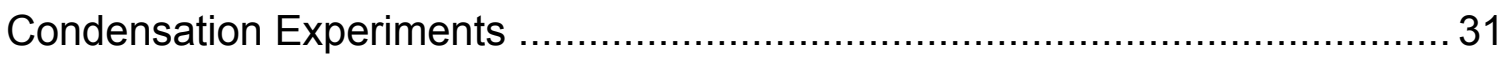

4.1 Design of Millimeter-Scale Annular Flow-Boilers .................................... 32

4.1.1 Desired specifications, constraints, and information/knowledge needed

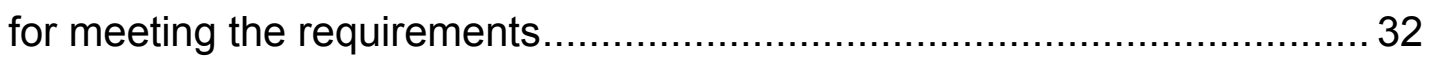

4.1.2 Implementation of a sample design methodology - meeting the requirements given in "Section 4.1.1" leading to results for steady annular

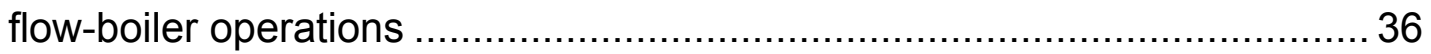

4.2 Design of millimeter-scale annular flow-condensers ............................. 46

4.2.1 Desired specifications, constraints, and information/knowledge needed

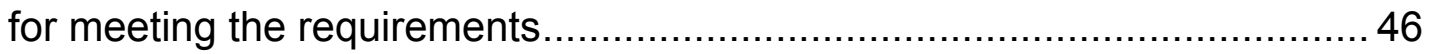

4.2.2 Implementation of a sample design methodology - meeting the requirements given in "Section 4.2.1" and leading to results for annular flow-

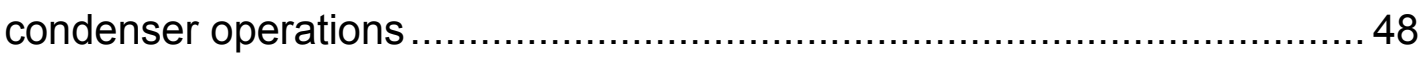

5. Modification of Design Methodology Discussed in Section 4.1 and Comparison of Experimental Results with that of CFD Simulations .................. 53

5.1 Modification of the Design Methodologies (Discussed in Section 4.1) for the

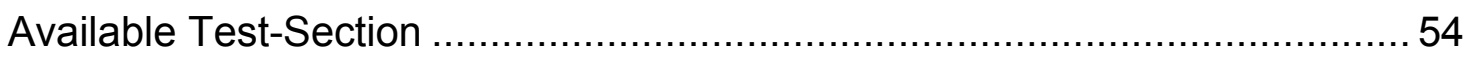


5.2 Suggested Operating Conditions Using the Modified Design Methodology

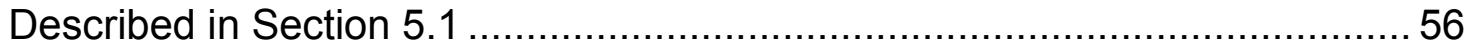

5.3 Comparison of Experimental Data and Correlation Developed using CFD Simulations of Laminar/Laminar Annular Flow-Boiling ................................ 58

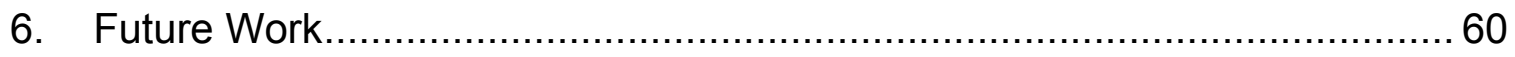

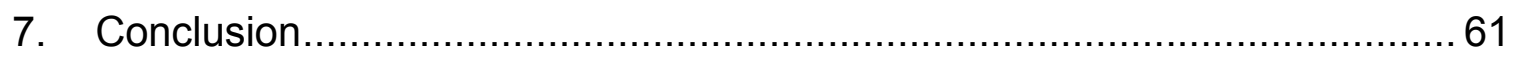

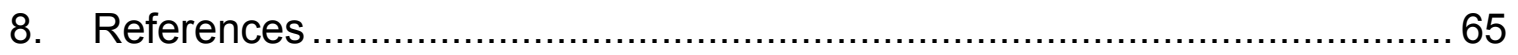




\section{List of Figures}

Fig 1.1: (a) Typical flow-regimes encountered in traditional operations dealing with saturated flow-boiling (with saturation conditions at $\mathrm{x}=0$ ) in a horizontal tube. The sequence of regimes are for cases where the average heat-flux $\overline{\mathrm{q}}_{\mathrm{w}}^{\prime \prime}$ for a given mass-flux $G$ is below a certain threshold. (b) Typical flow-regimes encountered in traditional operation of a horizontal flowcondenser.

Fig 1.2: (a) Innovative flow-boiler operations (b) Innovative flow-condenser operations.

Fig 2.1: A schematic of a control-volume between " $\mathrm{x}$ " and "x $+\Delta \mathrm{x}$ ". The heat-flux arrows, as shown, are positive for boiling. The negative values (reversed direction) are for flow-condensation

Fig 3.1: (a) Schematic of a representative suppressed nucleation case of annular flow-boiling in a channel. (b) Schematic of a representative instantaneous interface location showing the interfacial variables used as boundary conditions for the liquid and the vapor domains. The computational domain's exit at $x=$ $\mathrm{L}_{\text {comp }}$ in (b) is often slightly larger than the exit at $\mathrm{x}=\mathrm{L}$ in (a)

Fig 3.2: Representative film thickness profile for annular/stratified flow-boiling including "prior method of heating."

Fig 3.3: Representative wall temperature $\left(\mathrm{T}_{\mathrm{w}}(\mathrm{x})\right)$ (and heat-flux) values are prescribed as indicated for $\mathrm{x}^{\mathrm{p}} \geq 0$ and $-\mathrm{x}^{\mathrm{p}^{*}}<\mathrm{x}^{\mathrm{p}}<0$.

Fig 3.4: Plot of a steady film thickness profile for a horizontal case in the presence of transverse gravity. (Run parameters: Fluid is FC72, $U=1 \mathrm{~m} / \mathrm{s}, \mathrm{p}_{0}=$ $\left.105.1 \mathrm{kPa}, \Delta \mathrm{T}=10^{\circ} \mathrm{C}, \mathrm{h}=2 \mathrm{~mm}, \mathrm{G} \equiv \rho_{2} \mathrm{U}=13.98 \mathrm{~kg} / \mathrm{m}^{2} \mathrm{~s}\right)$.

Fig 3.5: Streamline patterns for $\overrightarrow{\mathrm{V}}_{\mathrm{I}}$, for $\mathrm{I}=1$ and 2 , are shown above for the flow in Fig. 3.4. The background shade representing magnitude of $\vec{v}_{\mathrm{I}}$, for $\mathrm{I}=$ "L" and "V", is the vertical axis on the right of the plot. (Run parameters: same as in Fig. 3.4)

Fig 3.6: (a) The $x$-variation of Wall heat-flux $q_{w}^{\prime \prime}\left(x^{p}\right)$ and convective heat transfer coefficient $h_{x \mid c b}\left(x^{p}\right)$. (b) Convective Heat transfer coefficient as a function of quality $\mathrm{X}, \mathrm{h}_{\mathrm{x} \mid \mathrm{cb}}(\mathrm{X})$. (Run parameters: same as in Fig. 3.4.)...................29 
Fig 3.7: Comparison between convective Nusselt number $\mathrm{Nu}_{\mathrm{x} \mid \mathrm{cb}, \mathrm{CFD}}$ calculated from Eq. 3.2 and from convective component of Nusselt number correlation proposed by Kim and Mudawar [17] $\mathrm{Nu}_{\mathrm{x} \mid \mathrm{cb}, \mathrm{KM}}$. (Run parameters: Fluid is FC72, $\left.\mathrm{p}_{0}=110.03 \mathrm{kPa}, \Delta \mathrm{T}=5^{\circ} \mathrm{C}, \mathrm{h}=2 \mathrm{~mm}, \mathrm{G} \equiv \rho_{2} \mathrm{U}=25.12 \mathrm{~kg} / \mathrm{m}^{2} \mathrm{~s}\right) \ldots \ldots \ldots \ldots \ldots . \ldots . .30$

Fig 4.1: Variation of quality $\mathrm{X}$ along the length of the channel.................42

Fig 4.2: Variation of heat transfer coefficients with quality - calculated using correlation proposed by Kim and Mudawar [17] along with the decomposition of $\mathrm{h}_{\mathrm{x}}$. The decomposition of $\mathrm{h}_{\mathrm{x}}$ using the correlation are given as $\mathrm{h}_{\mathrm{x} \mid \mathrm{nb}} \equiv \mathrm{h}_{\mathrm{x} \mid \mathrm{nb}-1}$ and $\mathrm{h}_{\mathrm{x} \mid \mathrm{cb}} \equiv \mathrm{h}_{\mathrm{x} \mid \mathrm{cb}-1}$. The component terms of $\mathrm{h}_{\mathrm{x}}$ after the introduction of correction factor $\alpha_{\mathrm{c}}$ are $\mathrm{h}_{\mathrm{x} \mid \mathrm{nb}-2}$ and $\mathrm{h}_{\mathrm{x} \mid \mathrm{cb}-2}$. The actual values of the $\mathrm{h}_{\mathrm{x} \mid \mathrm{nb}}$ are expected to lie between $h_{x \mid n b-1}$ and $h_{x \mid n b-2}$ while and $h_{x \mid c b}$ actual values of $h_{x \mid c b}$ are expected

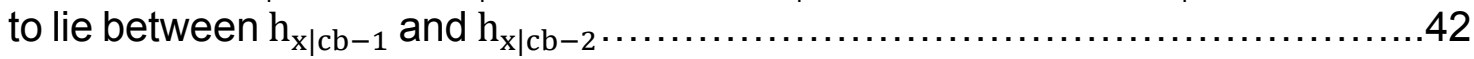

Fig 4.3: Variation of liquid film thickness $\Delta$ along the length of the channel calculated from void-fraction correlations and corrected convective boiling term

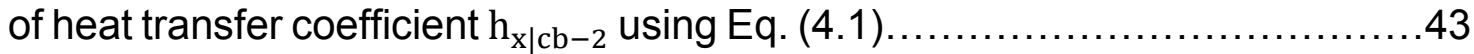

Fig 4.4: Variation of wall temperature $\mathrm{T}_{\mathrm{w}}(\mathrm{x})$ along the length of the channel calculated from total heat transfer coefficient using Eq. (2.4).

Fig. 4.5: (a) Variation of frictional pressure gradient along the length of the channel - calculated from Gronnerud [40], Friedel [39] and Lockhart \& Martinelli [41] pressure-drop correlations. (b) Variation of pressure - because of both frictional pressure drop and overall pressure drop - along the length of the channel. The three curves from the three models are closer together than in part (a). This is because of dominance of accelerational pressure-drop in Eq. (4.2). .46

Fig 4.6: Variation of heat transfer coefficients with quality - calculated using correlation proposed by Kim and Mudawar [34].

Fig 4.7: Variation of quality $\mathrm{X}$ along the length of the channel calculated using Eq. (2.18). .50

Fig 4.8: Variation of wall heat-flux $\mathrm{q}_{\mathrm{w}}^{\prime \prime}(\mathrm{x})$ along the length of the channel calculated from total heat transfer coefficient using Eq. (2.4). .51

Fig 4.9: (a) Variation of frictional pressure gradient along the length of the channel - calculated from Gronnerud [40], Friedel [39] and Lockhart \& Martinelli [41] frictional pressure-drop correlations. (b) Variation of pressure along the length of the channel due to both frictional pressure variation and total pressure 
variation. The overall pressure value rises with distance $\mathrm{x}$ for two of the three models. The total pressure variation values from the three models are higher than that of frictional pressure variation because of decelerational pressure

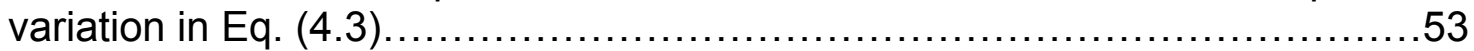




\section{List of Tables}

Table 3.1: Choices and ranges of physical flow variables for fluid flow conditions considered in 2-D CFD simulation of Annular Flow-Boiling

Table 4.1: Critical transition qualities from non-annular to annular flow-regime obtained using correlations for the channel height, $(\mathrm{h}=5 \mathrm{~mm}$, Fluid: R-123 \& operating conditions: $\left.p_{i n}=120 \mathrm{kPa} ; \mathrm{G}=300 \mathrm{~kg} / \mathrm{m}^{2} \mathrm{~s} ; \overline{\mathrm{q}}_{\mathrm{w}}^{\prime \prime}=50 \mathrm{~W} / \mathrm{cm}^{2}\right) \ldots \ldots \ldots . .38$

Table 5.1: Possible experimental run cases involving laminar liquid and laminar

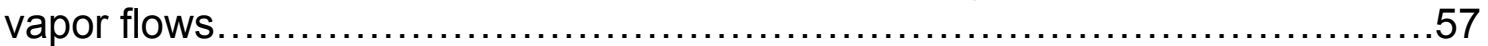

Table 5.2: Possible operating conditions to conduct experiments involving laminar liquid and turbulent vapor flows (some with near interface laminar flows) .........58

Table 5.3: Preliminary comparison of results from experiments (conducted from operating conditions proposed in Table 5.1) and correlation proposed by CFD simulation of annular flow-boiling (Eq. (3.2)) 


\section{Preface}

Figs. 1.1 - 1.2, Section 1.1, Section 2 and Section 4 (including figures, and tables) of this document have already been published in Section 2 and Section 4 of a book chapter:

Narain, A., H. Ranga Prasad and A. Koca, Internal Annular Flow-boiling and Flowcondensation: Context, Results and Recommendations, in Handbook of Thermal Science and Engineering, F.A. Kulacki, Editor. 2017, Springer International Publishing. p. 1-88.

Section 1.2 and Section 3 (including figures, table and the reported correlation) have already been published in:

Ranga Prasad, H., A. Narain, S.S. Bhasme and R.R. Naik, Shear-driven Annular Flow-boiling in Millimeter-scale channels: Direct Numerical Simulations for Convective Component of the Overall Heat Transfer Coefficient. International Journal of Transport Phenomena, 2017. 15(1): p. 1-35.

The copyright permissions to use the text, figures, tables and formulas have been obtained from Springer International Publishing and Old City Publishing respectively and included in Appendix A. 


\section{Acknowledgement}

I would like to thank my advisor, Prof. Amitabh Narain, for his guidance, support and motivation throughout the period of my research work at Michigan Technological University. I have learnt a lot from him that has helped me, and would help me, grow both in my professional and personal life.

I also would like to thank Dr. Kazuya Tajiri and Dr. Sunil Mehendale for agreeing to be in the committee and providing valuable feedback.

Next, I would like to thank Michigan Technological University and NSF (CBET1402702) for providing the opportunity and financial support.

I would like to thank the following members of the research group and friends for providing both professional and personal support at times of need: Amit Dev Vojini, Rutvi Thanki, Chirag Bangera, Nikhil Shinde, Soroush Sepahyar, Nook Gorgitrattanagul, Sathya, Venkatesh and Ekanth.

The 2-D CFD simulation of Annular Flow-Boiling (with assumed absence of nucleation), discussed in Section 3 here, was based on analogous work done for Annular Flow-Condensation by Dr. Ranjeet Naik. The early work on modifying and adapting the annular flow-condensation code to a flow-boiling simulation code was done by Sharayu Bhasme.

Finally, I would like to thank my parents and my brother for providing support and care all my life and for just being there at times of need. 


\section{Abstract}

The main objective of the current work is to achieve a better understanding through modeling and simulation/programming activities - of annular flow-boiling and its applications based on a synthesis of Computational Fluid Dynamics (CFD) simulations, existing correlations, and experiments. A unique and rigorous 2-D CFD simulations technique was developed for annular flow-boiling to propose a correlation for convective component of Heat Transfer Coefficient (HTC) - defined here as flow-boiling in the absence of nucleation. To provide a context for the correlation structure of convective component of HTC, flow-physics details of annular flow-boiling and correlation structure (based on fundamental considerations) for HTC have also been discussed. Further, other existing correlations for Nusselt number, void-fraction, flow-regime transition, and pressure-drop have been used to develop a general but first order engineering estimates-methodology for design of annular flow-boilers and flow-condensers. The first order estimates-methodology, thus developed for annular flow-boiler operations, was used to: (i) make a priori estimates of flow predictions towards choosing suitable instrumentations for the design of a particular test-section and associated flow-loop needed for a new high heat-flux flow-boiling experiments involving water as a working fluid), and (ii) define a range of experimental operating conditions - for a low heat-flux test-section and flow-loop (involving FC-72 as working fluid) facility from which experimental data needed to be obtained to throw light on the flow-physics being modeled by the CFD code. Furthermore, preliminary results from a different low heat-flux experiments are briefly discussed here and then compared with rigorous CFD simulations to achieve better understanding of the flow-physics. 


\section{Introduction}

Two-phase flow heat transfer employing boiling and condensation in macro/mini channel have become important because of their superior performance potential for cooling needs associated with applications in power generations sector, electronic/data center cooling, heating ventilation and air conditioning refrigeration, waste heat recovery, steam generation, etc. Many researchers are working on flow-boiling and flow-condensation because of the potentially large amount of heat transfer that is possible for a small temperature difference associated with phasechange. As engineering support for boiler and condenser operations in various macro-scale applications have matured, new challenges have emerged in the area of high heat flux (500-1000 W/cm ${ }^{2}$ or greater) cooling for data center, super computers, laser weapons, and other devices. One of these challenges is smallness of available space for device cooling (that must employ flow-boilers) and occasionally, also for heat rejection (for devices that must employ flowcondensers). The space restrictions and low pumping power needs often limit hydraulic diameter $\mathrm{D}_{\mathrm{h}}$ of the boiler/condenser tubes to be small but not too small (e.g. $100 \mu \mathrm{m} \leq \mathrm{D}_{\mathrm{h}} \leq 8 \mathrm{~mm}$ ) whereas safety and cost effectiveness issues restrict pure fluids to available refrigerants and/or water. The current focus is on the millimeter scale hydraulic diameter applications. However, there remains a need for high heat-flux boiling in micro-scale tubes (hydraulic diameter less than 100 $\mu \mathrm{m})$ as well - and active research in this area is going on (see, e.g., [1-3]).

Another challenge is a restriction on allowed boiling-surface and/or condensingsurface temperatures. For example, typically, $75-85{ }^{\circ} \mathrm{C}$ is the maximum allowed temperature for the boiler tube surfaces connected to cold plates used in electronic cooling [4]. Besides high heat removal capabilities at high heat-fluxes, there are other demands on effectiveness of such millimeter-scale boilers and condensers. For example, effectiveness often requires low pumping power consumption through manageable pressure drops - and, in case of high heat-flux flow-boilers, 
it may also mean an ability to recover large amounts of mechanical power available (associated with higher exiting vapor speeds from mm-scale ducts) at the exit.

Often effectiveness also requires avoidance of vapor compressibility related choking effects [5] and this, in turn, may require modest mass-fluxes $(G)$ in tubes of modest hydraulic diameters $\left(D_{h} \equiv 4 \mathrm{~A} / \mathrm{P}\right.$, where $\mathrm{A}$ and $\mathrm{P}$ respectively represent the cross-sectional area and perimeter of the tube/channel).

Unfortunately, established technologies such as an array of small diameter heat pipes or their Capillary and Looped heat pipe variations [6] are not the appropriate solutions for the increasing high heat-flux and heat-load needs of the electronic cooling applications [7, 8]. This is because, for these applications, direct use of heat pipes does not work well due to limitations arising from: necessarily large vapor speeds that are involved (sonic limits), wicking limits, and the need for large distances between boilers and condensers.

\subsection{Traditional and Annular (Innovative) Flow-Boiling/Condensation}

In a traditional flow-boiling process, the inlet sees an all-liquid flow at saturation temperature (occasionally sub-cooled). The liquid, typically, absorbs heat, gradually vaporizes and exits completely as a vapor. During the evaporation process, the boiling flow goes through multiple flow regimes. Transition from one flow regime to another, typically, depends on the heat absorbed at the boiling surface, fluid properties, local quality (ratio of mass flow rate of the vapor to the total mass flow rate) etc. Fig. 1.1 (a) shows the typical flow regimes in a traditional flow-boiling process.

Similarly, a traditional flow-condensation process sees an all vapor flow at the inlet in saturation conditions (occasionally super-heated). The vapor rejects heat, condenses into liquid along the length of the channel, and exit as saturated liquid. During condensation along the channel, the flow goes through multiple flow regimes. The transition process, as with boiling flows, depend on, heat rejected by 
the vapor, quality and the fluid properties. Fig. 1.1 (b) shows the typical flow regimes in a traditional flow-condensation process.

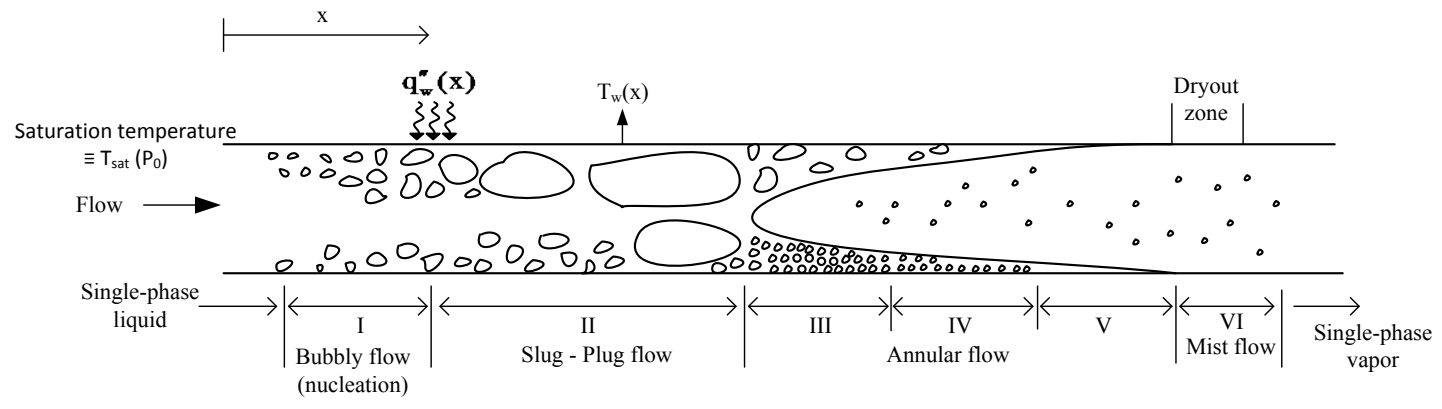

(a)

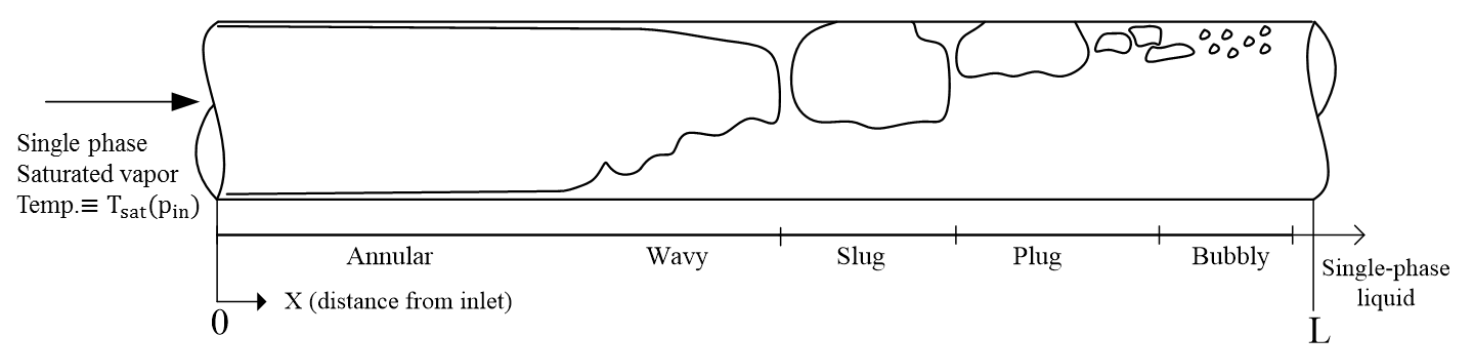

(b)

Fig 1.1: (a) Typical flow-regimes encountered in traditional operations dealing with saturated flowboiling (with saturation conditions at $x=0$ ) in a horizontal tube. The sequence of regimes are for cases where the average heat-flux $\overline{\mathrm{q}}_{\mathrm{w}}^{\prime \prime}$ for a given mass-flux $\mathrm{G}$ is below a certain threshold. (b) Typical flow-regimes encountered in traditional operation of a horizontal flow-condenser

However, it should be noted that the flow regimes shown in Fig. 1.1 (a), for flowboiling, are present only when the mean heat-flux $\overline{\mathrm{q}}_{w}^{\prime \prime}$ for a given mass flow rate $G$ is below a certain threshold value called the critical heat-flux $\overline{\mathrm{q}}_{\mathrm{CHF}}(\mathrm{CHF})$. Above this critical heat-flux value, the flow displays instabilities which may result in time varying dry spots on the heating surface (typically experiencing higher qualities) or, in some cases, it may lead to inverted annular flow where the flow has liquid flowing in the core region - with vapor flowing in the annulus region. See [9-11] etc. for detailed discussion on critical heat flux and related instabilities. 
The flow-regimes in horizontal configuration, shown in Fig. 1.1, would, typically be different from flow-regimes associated with downward or upward inclined (with respect to the gravity vector) tubes $[5,12]$. For modest to high mass-flux values of $G$ and millimeter-scale hydraulic diameters $D_{h}$, interfacial shear and pressure gradients may dominate effects of gravity and, therefore, even tubes at different inclinations may exhibit flow-regimes that are qualitatively close to the ones associated with the horizontal configuration (as shown in Fig. 1.1). This is because axial and transverse gravity components $g_{x}$ and $g_{y}$ may become effectively negligible compared to inertia forces (see definitions of Froude numbers in Section 2.1).

However, it should be noted that all flow regimes are not equally efficient for heat transfer, largely due to pressure drops associated with flow regimes occurring at lower qualities. Innovative operations (see Fig 1.2), in both flow-boiling and flowcondensation [13], have tackled this problem by controlling the inlet and/or exit quality, and consequently maintaining an efficient annular/stratified flow regime in a device of suitably chosen length (henceforth called Annular Flow-Boiling/FlowCondensation). In these operations, the inlet quality (in annular flow-boiling) and exit quality (in both annular flow-boiling and flow-condensation) are controlled to achieve annular flow throughout the length of the channel and to avoid dry-out in annular flow-boiling. This is done by carefully controlling the flow rates of liquid and vapor flowing into and out of the test section.

Annular flow-boiling and flow-condensation operations further enable various ways to take advantage of contact-line flow physics. One of them is by introducing acoustics-enabled large amplitude standing waves on the interface. Use of this method has resulted in a significant heat transfer enhancement for flowcondensation [13] and reasonably significant local heat transfer enhancement for flow-boiling [14]. 


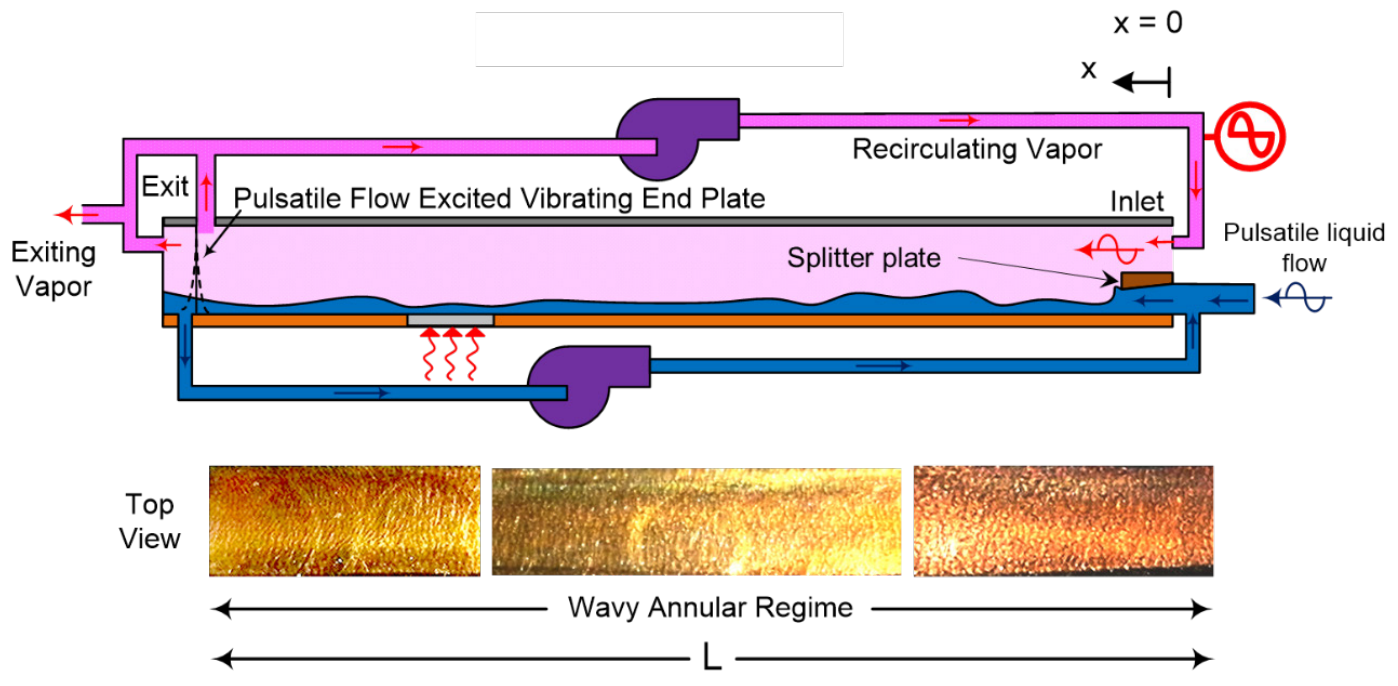

(a)

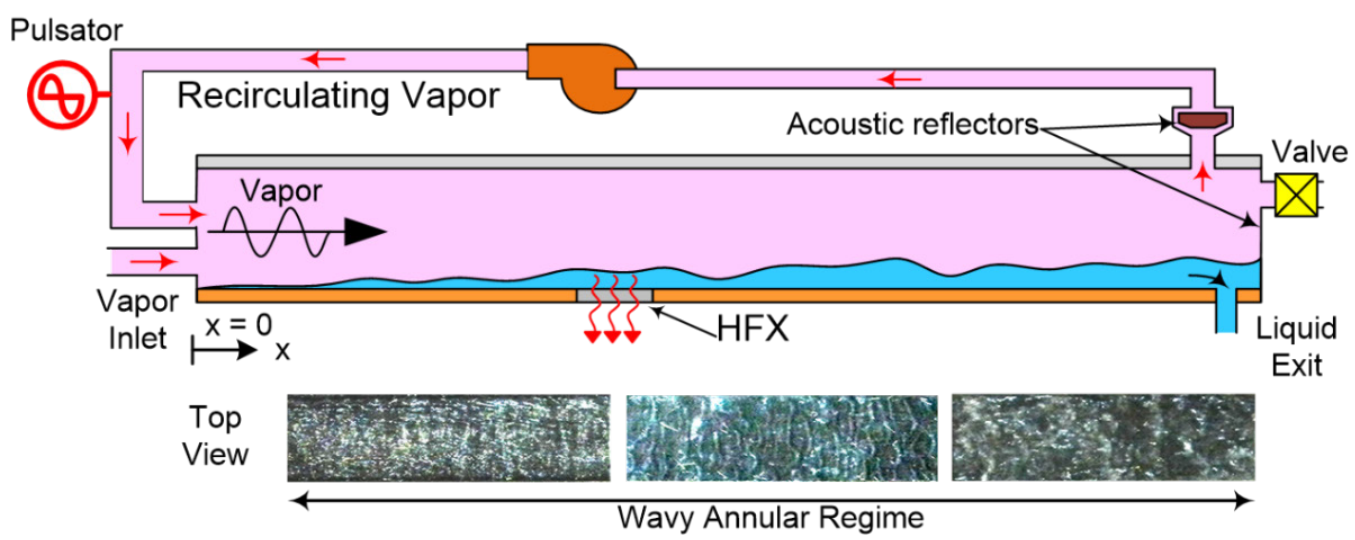

(b)

Fig 1.2: (a) Innovative flow-boiler operations (b) Innovative flow-condenser operations

\subsection{Heat Transfer Coefficient (HTC) and Motivations for CFD Simulations of Flow-Boiling/Condensation}

For flow-boiling and flow-condensation processes, Heat transfer Coefficient (HTC; denoted as $h_{x}$ ) is a partial measure of efficiency of the heat transfer process in the sense that higher local HTC means higher local heat-flux for lower local temperature difference between the heat-exchange surface and a representative saturation temperature. For a heat transfer process, definition of local HTC is given 
by the relationship: $\mathrm{q}_{\mathrm{w} \mid \text { total }}^{\prime \prime}(\mathrm{x}) \equiv \mathrm{q}_{\mathrm{w} \mid \text { Expt }}^{\prime \prime}(\mathrm{x}) \equiv \mathrm{h}_{\mathrm{x} \mid \text { total }} * \Delta \mathrm{T}(\mathrm{x})$ where, $\Delta \mathrm{T}(\mathrm{x})$ is the characteristic local excess temperature defined as " $\left|\mathrm{T}_{\mathrm{w}}(\mathrm{x})-\mathrm{T}_{\mathrm{sat}}\left(\mathrm{p}_{\mathrm{in}}\right)\right|, "$ with $\mathrm{T}_{\mathrm{w}}(\mathrm{x})$ being the local wall temperature and $\mathrm{T}_{\mathrm{sat}}\left(\mathrm{p}_{\mathrm{in}}\right)$ being the characteristic saturation temperature associated with channel inlet pressure $p_{\text {in }}$ at $x=0$ location in Figs. 1.1 and 1.2. Since, it is typically measured through experiments, it can also be referred to as $h_{x \mid \text { Expt }}$, or just $h_{x}$. Typical non-dimensional variables affecting HTC (or its non-dimensional equivalent, Nusselt number $\mathrm{Nu}_{\mathrm{x}}$ ) and its correlation structure are discussed in Section 2.

For flow-boiling processes, the overall HTC $h_{x \mid t o t a l}\left(\equiv h_{x \mid \text { Expt }} \equiv h_{x}\right)$ has contributions from convective boiling and nucleate boiling - typically referred to as convective boiling component $\left(\mathrm{h}_{\mathrm{x} \mid \mathrm{cb}}\right)$ and nucleate boiling component $\left(\mathrm{h}_{\mathrm{x} \mid \mathrm{nb}}\right)$ of overall HTC - with the simplest decomposition being, $h_{x \mid t o t a l} \equiv h_{x \mid c b}+h_{x \mid n b}[15$, 16]. This is based on the assertion that overall local heat-flux is the sum of contributions from nucleate boiling and convective boiling heat-flux values - i.e., $\mathrm{q}_{\mathrm{w} \mid \operatorname{Expt}}^{\prime \prime}(\mathrm{x}) \equiv \mathrm{q}_{\mathrm{w} \mid \text { total }}^{\prime \prime}(\mathrm{x}) \equiv \mathrm{q}_{\mathrm{w} \mid \mathrm{nb}}^{\prime \prime}(\mathrm{x})+\mathrm{q}_{\mathrm{w} \mid \mathrm{cb}} \mathrm{n}(\mathrm{x})$. Here this simple "superposition" definition of $\mathrm{h}_{\mathrm{x} \mid \text { total }}$ is preferred over other power-law forms in literature $[17,18]$. Detailed discussion on convective and nucleate boiling components of overall HTC, and their definitions can be found in [16].

In a traditional boiling flow process (Fig. $1.1 \mathrm{a}$ ), macro-scale nucleation is present at lower quality regime of the flow while it is gradually suppressed (at least visibly or macroscopically) at higher qualities as liquid film thickness is reduced. For annular flow-boiling cases (Fig. 1.2 b), there are three broad categories with regard to the presence or absence of contributions from nucleate boiling on overall HTC:

(i) Nucleate boiling is suppressed for the entire length ( $0 \leq x \leq L)$ of annular realization. This is likely if the boiling surface is machined smooth (e.g., with roughness less than $0.1 \mu \mathrm{m}$ and over $30 \mu \mathrm{m}$ apart, number of available nucleation sites become small), extremely low liquid film-thickness values 
(e.g. less than 10 micro-meters everywhere at high mass-flux $\mathrm{G}$ and high quality $\mathrm{X}$ ), and heating levels - in terms of average heat-flux or imposed temperature-difference values - being low to moderate (to allow stable thin film flows).

(ii) Contributions from nucleate boiling mechanisms $\left(\mathrm{h}_{\mathrm{x} \mid \mathrm{nb}}\right)$ - macro or microscale - is dominant in the overall HTC $\left(h_{x \mid \text { total }}\right)$, as discussed in [9], throughout $(0 \leq x \leq L)$ the length of the channel.

(iii) Nucleation (micro or macro-scale) is present in a certain upstream part (say, $0 \leq \mathrm{x} \leq \mathrm{x}^{*}$ ) of the annular flow-boiling channel (in Fig 1.1) and is effectively suppressed in the corresponding downstream part (say $\mathrm{x}^{*} \leq \mathrm{x} \leq \mathrm{L}$ ). This third category of realizations, which have been observed in [19], and the characterization of suppression of nucleation, require availability, definitions and comparison of $\mathrm{h}_{\mathrm{x} \mid \text { total }}$ with $\mathrm{h}_{\mathrm{x} \mid \mathrm{cb}}$ values over $0 \leq \mathrm{x} \leq \mathrm{L}$.

Corresponding to the three possible experimental realizations of annular flowboiling:

(i) For cases where nucleation is suppressed over the entire length of the channel, $\mathrm{h}_{\mathrm{x} \mid \text { total }} \approx \mathrm{h}_{\mathrm{x} \mid \mathrm{cb}}$.

(ii) For cases where nucleate boiling has a dominant or significant contribution, $\mathrm{h}_{\mathrm{x} \mid \text { total }} \approx \mathrm{h}_{\mathrm{x} \mid \mathrm{nb}}$ or $\mathrm{h}_{\mathrm{x} \mid \text { total }} \equiv \mathrm{h}_{\mathrm{x} \mid \mathrm{cb}}+\mathrm{h}_{\mathrm{x} \mid \mathrm{nb}}$.

(iii) For cases where nucleation is suppressed only in the downstream region (say, $\mathrm{x}^{*} \leq \mathrm{x} \leq \mathrm{L}$ ) $\mathrm{h}_{\mathrm{x} \mid \text { total }} \approx \mathrm{h}_{\mathrm{x} \mid \mathrm{cb}}$, and $\mathrm{h}_{\mathrm{x} \mid \text { total }}=\mathrm{h}_{\mathrm{x} \mid \mathrm{cb}}+\mathrm{h}_{\mathrm{x} \mid \mathrm{nb}}$ over the upstream locations (say $0 \leq \mathrm{x} \leq \mathrm{x}^{*}$ ).

The calculation of convective and nucleate boiling components in the literature are usually ad hoc in nature and typically fail to consider the contributions from micron/sub-micron scale nucleation (which are invisible to the naked eye). This, at times, results in power law forms for combining convective and nucleate boiling HTC values to calculate overall HTC, as mentioned above. The nature of the 
existing correlations, with various power law forms for combining convective and nucleate boiling components of HTC is ad hoc because only overall HTC values can be calculated through experiments - and there is no reliable way to directly calculate nucleate boiling contributions. However, through CFD simulation of annular flow-boiling, with a hypothetically assumed absence of nucleation, it is possible to calculate the convective boiling component of $\mathrm{HTC}\left(\mathrm{h}_{\mathrm{x} \mid \mathrm{cb}}\right)$. This was done through a 2-D CFD simulation [16], for flows involving laminar liquid and laminar vapor. Further, by comparing the convective component of HTC calculated either directly from CFD simulation or from a correlation obtained through the simulation - with the experimentally obtained values of overall HTC $\left(h_{x \mid t o t a l}\right.$ or $\left.h_{x}\right)$ - for the same location $x$, fluid properties, and inlet/wall boundary conditions (particularly representing experimental conditions, including wall temperatures); and obtaining the difference between the overall experimental and CFD predicted convective HTC, it is possible to ascertain the nucleate boiling component of HTC (i.e., $h_{x \mid n b}=h_{x \mid \text { total }}-h_{x \mid c b}$ ). Furthermore, if the local value of convective boiling $\mathrm{HTC}$ is approximately equal to the experimentally calculated local value of total HTC, it can be concluded that nucleation is suppressed (corresponding to either case (i) or downstream portion of case (iii) of annular boiling flow possibilities discussed above).

CFD analysis of steady annular flow-condensation, with laminar liquid and laminar vapor flows, was also done earlier by Dr. Narain's research group [20, 21]. However, absence of nucleation in condensing flows means that the HTC values calculated from the correlations developed through these analyses are the overall HTC values, as opposed to the annular flow-boiling cases where only the convective component of overall HTC can be calculated from such CFD analysis. 


\subsection{Goals and Scope of the Thesis}

The main goal of the current work is to contribute to an effectively synthesized understanding of annular flow-boiling with the help of CFD simulations, existing correlations, and experiments.

In order to provide context for correlations and correlation structures that would be discussed later, Section 2 explains various non-dimensional variables and how they affect overall heat transfer coefficient $h_{x}$ (or its non-dimensional equivalent $\mathrm{Nu}_{\mathrm{x}}$ ). It also explains, through energy balance, the variation of quality $\mathrm{X}$ with distance $\mathrm{x}$ for both known heat-flux and known wall temperatures "methods of heating."

Section 3.1 explains some of the salient and relevant features of the 2-D CFD simulation of annular flow-boiling with hypothetically assumed absence of nucleation, the motivations for which have been discussed above. The detailed problem statement along with the algorithm and discretization principles for the 2D CFD simulation have been discussed by Ranga Prasad et al [16]. Further, Section 3.2 presents a parameter range specific convective HTC correlation that has been developed using the data obtained from the simulation and compares its predictions with the convective component of HTC obtained from a popular correlation [17].

In Section 4, a general "order of magnitude" methodology for designing annular flow-boiling and annular flow-condensation experiments, using various correlations available in the literature, have been laid out. Some of these relevant correlations for heat transfer coefficient, void-fraction $(\epsilon)$, pressure drop, and flow regime transition have been discussed in detail elsewhere [9].

Section 5 shows how the "order of magnitude" methodology developed in Section 4 can be effectively used in designing specific flow-boiling experiments for some of the experimental setup already available in Dr. Narain's lab. It also shows some 
of the experiments, designed using the developed methodology, which involve both laminar liquid/laminar vapor and laminar liquid/turbulent vapor realizations. Preliminary results from experiments involving laminar liquid/laminar vapor have been shown and the data is compared with data from correlation obtained from the 2-D CFD simulation, and this is discussed in Section 3. Detailed discussion of the experimental results, modeling and processing of experimental data is taken up elsewhere $[14,22,23]$.

Sections 6 and 7 respectively discuss the scope for future work and the conclusions that can be drawn from this thesis.

\section{Basic variables and correlations of scientific and engineering interest and their relationship to one-dimensional (1-D) modeling of flow-boiling and flow-condensation}

\subsection{Basic variables and their correlations}

The primary focus of the current study is on the shear and pressure-drop driven annular flows inside tubes of circular (diameter $\mathrm{D}$ ) or rectangular (height $\mathrm{h}$ and width $\mathrm{w}$ ) cross-sections, including channels (i.e. h/w $\ll 1$ rectangular crosssections). Both traditional saturated flow-boiling and flow-condensation (Fig. 1.1) and innovative annular flow operations (Fig. 1.2) are of interest. A single characteristic length scale - popularly used in the hydrodynamics literature for defining pressure-drop and phase-specific Reynolds number, is used. This is the hydraulic diameter:

$$
\mathrm{D}_{\mathrm{h}} \equiv 4 \mathrm{~A} / \mathrm{P}
$$

where, $\mathrm{A}$ is the tube cross-sectional area and $\mathrm{P}=\mathrm{P}_{\mathrm{F}}$ is the wetted (by liquid or vapor) perimeter. For order of magnitude estimates of heat-transfer rates in tubes of different cross-sectional geometries but equivalent diameters, if curvature effects are secondary (which is not the case here), many Nusselt number definitions may prefer to use $D_{h}$ in Eq. (2.1) after replacing the perimeter $\mathrm{P}$ by $\mathrm{P}=$ 
$\mathrm{P}_{\mathrm{H}}$ in Eq. (2.1) where $\mathrm{P}_{\mathrm{H}}$ is the heated perimeter, which may only be a fraction of $\mathrm{P}_{\mathrm{F}}$. To address such a need, retaining the definition in Eq. (2.1), as needed, the value may be explicitly multiplied by the fraction " $\mathrm{fr}_{\mathrm{P}} \equiv \mathrm{P}_{\mathrm{H}} / \mathrm{P}_{\mathrm{F}}$." Furthermore, for present purposes, commercially smooth and hydrophilic heating/cooling surfaces (i.e. heat-exchange surfaces) are assumed for the flows in Figs. 1.1 and 1.2.

Commonly available pure fluids (refrigerants, fluorinert electronic cooling fluids, water, etc.) are the primary focus here - although the literature also shows a significant amount of interest in phase change flows with azeotropic and nonazeotropic fluid mixtures, nano-fluids, and phase change in the presence of noncondensable gases (see, [24-26] etc.).

The liquid and vapor phases in the flows of Figs. 1.1 and 1.2 are denoted with subscripts $\mathrm{I}=$ "L" and $\mathrm{I}=$ "V" respectively. Both phases are modeled as incompressible (i.e. vapor Mach numbers are low). The properties (density $\rho$, viscosity $\mu$, specific heat $C_{p}$, and thermal conductivity $k$ ) are denoted with subscript "I". The properties are to take their representative constant values for each phase $(\mathrm{I}=$ "L" or "V").

Let the temperature, pressure and velocity fields over the two phases - in the steady flows depicted in the Figs. 1.1 and 1.2 - be respectively denoted as $\mathrm{T}_{\mathrm{I}}, \mathrm{p}_{\mathrm{I}}$ and $\overrightarrow{\mathbf{v}}_{\mathrm{I}}=\mathrm{u}_{\mathrm{I}} \hat{\mathbf{i}}+\mathrm{v}_{\mathrm{I}} \hat{\mathbf{j}}$. Let $\mathrm{p}_{0}$ be the mean inlet pressure (or inlet pressure at a designated inlet location), $\mathrm{h}_{\mathrm{fg}}$ be the heat of vaporization at a local interfacial pressure $p$ or associated saturation temperature $T_{\text {sat }}(p), \bar{T}_{w}$ be the mean heatexchange surface temperature associated with steady but spatially varying wall temperature $\mathrm{T}_{\mathrm{w}}(\mathrm{x})$. Further, let $\Delta \mathrm{T}\left(\equiv\left|\mathrm{T}_{\mathrm{sat}}\left(\mathrm{p}_{0}\right)-\overline{\mathrm{T}}_{\mathrm{w}}\right|\right)$ be a representative controlling temperature difference between the fluid and the heat exchange surface, and $\dot{\mathrm{M}}_{\mathrm{in}}$ be the total steady mass flow rate $(\mathrm{kg} / \mathrm{s})$ through the tube. Furthermore, let $\dot{\mathrm{M}}_{\text {in }}$ consist of liquid mass flow rate $\dot{\mathrm{M}}_{\mathrm{L}}(\mathrm{x})$ and vapor mass flow rate $\dot{\mathrm{M}}_{\mathrm{v}}(\mathrm{x})$ at any distance "x" from the inlet - i.e. $\dot{\mathrm{M}}_{\mathrm{in}}=\dot{\mathrm{M}}_{\mathrm{L}}(\mathrm{x})+\dot{\mathrm{M}}_{\mathrm{v}}(\mathrm{x})$. Let $\mathrm{X}(\mathrm{x})(\equiv$ 
$\left.\dot{\mathrm{M}}_{\mathrm{V}}(\mathrm{x}) / \dot{\mathrm{M}}_{\mathrm{in}}\right)$ be the local quality, and $\mathrm{G}\left(\equiv \dot{\mathrm{M}}_{\mathrm{in}} / \mathrm{A}\right)$ be the mass-flux $\left(\mathrm{kg} / \mathrm{m}^{2} . \mathrm{s}\right)$, and let the overall characteristic speed be $\mathrm{U}\left(\equiv \mathrm{G} / \rho_{\mathrm{V}}\right)$. The "method of heating/cooling" for the flows in Figs. 1.1 and 1.2 can be specified by prescribing either the wall temperature values or the heat-flux values. The prescription choice depends on which of the two wall variables is experimentally known or is more conveniently assumed as a tentative prescription. A tentative prescription suffices if it is a conjugate problem and the boundary conditions for the surrounding environment are sufficiently known to find the assumed thermal boundary condition. It is common to replace wall temperature variations $\mathrm{T}_{\mathrm{w}}(\mathrm{x})$ by the characterizing temperature difference $\Delta \mathrm{T}(\mathrm{x})$.

Next, it is important to define the "level" of heating/cooling. Over the heating/cooling length "L" in Figs. 1.1 and 1.2, these "levels" are characterized by either the average temperature difference $\Delta \mathrm{T} \equiv\left|\mathrm{T}_{\mathrm{w}}-\mathrm{T}_{\mathrm{sat}}\left(\mathrm{p}_{0}\right)\right|$ between the saturation temperature $\mathrm{T}_{\text {sat }}\left(\mathrm{p}_{0}\right)$ and the axially averaged mean wall temperature $\overline{\mathrm{T}}_{\mathrm{w}} \equiv \frac{1}{\mathrm{~L}} \int_{0}^{\mathrm{L}} \mathrm{T}_{\mathrm{w}}(\mathrm{x})$. dx or the axially averaged mean wall heat-flux $\overline{\mathrm{q}}_{\mathrm{w}}^{\prime \prime} \equiv \frac{1}{\mathrm{~L}} \int_{0}^{\mathrm{L}} \mathrm{q}_{\mathrm{w}}^{\prime \prime}(\mathrm{x}) \cdot \mathrm{dx}$. Furthermore, a specific non-uniform "method of heating/cooling" is defined as $\theta_{\mathrm{w}}(\mathrm{x})$ or $\Psi_{\mathrm{q}}(\mathrm{x})$ through the relations:

$$
\Delta \mathrm{T}(\mathrm{x}) \equiv\left|\mathrm{T}_{\mathrm{w}}(\mathrm{x})-\mathrm{T}_{\mathrm{sat}}\left(\mathrm{p}_{0}\right)\right| \equiv \Delta \mathrm{T} \cdot \theta_{\mathrm{w}}(\mathrm{x})
$$

and

$$
\mathrm{q}_{\mathrm{w}}^{\prime \prime}(\mathrm{x})=\overline{\mathrm{q}}_{\mathrm{w}}^{\prime \prime} \cdot \Psi_{\mathrm{q}}(\mathrm{x})
$$

For non-uniform temperature-controlled heating/cooling, a specific $\theta_{\mathrm{w}}(\mathrm{x}) \neq 1$ over $0 \leq \mathrm{x} \leq \mathrm{L}$ defines a specific "method of heating/cooling," whereas for uniform temperature heating/cooling that specific function is $\theta_{\mathrm{w}}(\mathrm{x})=1$ over $0 \leq \mathrm{x} \leq \mathrm{L}$. Similarly, for a non-uniform wall heat-flux controlled heating/cooling, a specific $\Psi_{\mathrm{q}}(\mathrm{x}) \neq 1$ over $0 \leq \mathrm{x} \leq \mathrm{L}$ defines a specific "method of heating/cooling," whereas for uniform heat-flux heating/cooling that specific function is $\Psi_{\mathrm{q}}(\mathrm{x})=1$ over $0 \leq$ $\mathrm{x} \leq \mathrm{L}$. 
The heat transfer to or from heat-exchange surfaces for the phase-change flows in Figs. 1.1 and 1.2 are characterized by the value of local heat transfer coefficient $\mathrm{h}_{\mathrm{x}}$ defined as:

$$
\mathrm{q}_{\mathrm{w}}^{\prime \prime}(\mathrm{x}) \equiv \mathrm{h}_{\mathrm{x}} \cdot \Delta \mathrm{T}(\mathrm{x})=\mathrm{h}_{\mathrm{x}} \cdot\left|\mathrm{T}_{\mathrm{w}}(\mathrm{x})-\mathrm{T}_{\mathrm{sat}}\left(\mathrm{p}_{0}\right)\right|
$$

where, local heat transfer coefficient $h_{x}$ depends on the overall flow-specifying geometry and boundary conditions. Once it is assumed that straight ducts and their orientation with respect to gravity are of interest here, the local heat transfer coefficient $h_{x}$ depends on the following variables (assuming, as needed, an implicit dependence on solid-liquid-vapor interactions specifying parameters set $\left\{S^{*}\right\}$ ): distance " $\mathrm{x}$ " from the inlet, tube diameter $\mathrm{D}_{\mathrm{h}}$, inlet mass flow rate $\dot{\mathrm{M}}_{\mathrm{in}}$, relevant fluid properties, controlling thermodynamic variables for phase-change, the "level" and - for non-uniform "method of heating/cooling" - the functions $\theta_{w}(x)$ or $\Psi_{q}(x)$ at the tube walls, values of gravity components $g_{x}$ and $g_{y}$, and inlet quality $X_{i n}$. It should be noted that, $\mathrm{g}_{\mathrm{x}} \cong 0$ for the horizontal flow configurations of interest in Figs. 1.1 and 1.2 and the quality at the inlet $(x=0)$ is zero for saturated flow-boiling in Fig. 1.1a, unity for saturated flow-condensation in Fig. 1.1b, and $\mathrm{X}_{\text {in }}$ where, $0<\mathrm{X}_{\text {in }}<$ 1, for flows in Fig. 1.2. For traditional flows in Fig. 1.1 with known wall temperature "method of heating, " if " $\mathrm{x}$ " is lying in the convection-dominated plug/slug or annular regimes, this means that one can assume that the convective component of heat transfer coefficient $\mathrm{h}_{\mathrm{x} \mid \mathrm{cb}}$ (assuming micro-scale nucleation remains important) or total heat transfer coefficient $h_{x}$ (for flow-condensation and suppressed or negligible nucleation flow-boiling for which $h_{x}=h_{x \mid c b}$ ) has the dependence:

$$
\mathrm{h}_{\mathrm{x} \mid \mathrm{cb}} \equiv \mathrm{h}_{\mathrm{x} \mid \mathrm{cb}}\left(\mathrm{x}, \mathrm{G}, \mathrm{D}_{\mathrm{h}}, \Delta \mathrm{T}, \theta_{\mathrm{w}}(\mathrm{x}), \rho_{\mathrm{L}}, \rho_{\mathrm{V}}, \mu_{\mathrm{L}}, \mu_{\mathrm{V}}, \mathrm{C}_{\mathrm{pL}}, \mathrm{k}_{\mathrm{L}}, \mathrm{h}_{\mathrm{fg}}, \sigma,\left|\mathrm{g}_{\mathrm{x}}\right|,\left|\mathrm{g}_{\mathrm{y}}\right|\right)
$$

Similarly, for known wall heat-flux "method of heating/cooling," Eq. (2.5) for the flows in Fig. 1.1 is replaced by:

$$
\mathrm{h}_{\mathrm{x} \mid \mathrm{cb}} \equiv \mathrm{h}_{\mathrm{x} \mid \mathrm{cb}}\left(\mathrm{x}, \mathrm{G}, \mathrm{D}_{\mathrm{h}}, \overline{\mathrm{q}}_{\mathrm{w}}^{\prime \prime}, \Psi_{\mathrm{q}}(\mathrm{x}), \rho_{\mathrm{L}}, \rho_{\mathrm{V}}, \mu_{\mathrm{L}}, \mu_{\mathrm{V}}, \mathrm{C}_{\mathrm{pL}}, \mathrm{k}_{\mathrm{L}}, \mathrm{h}_{\mathrm{fg}}, \sigma,\left|\mathrm{g}_{\mathrm{x}}\right|,\left|\mathrm{g}_{\mathrm{y}}\right|\right)
$$

Heat transfer coefficient (just the convective component $\mathrm{h}_{\mathrm{x} \mid \mathrm{cb}}$ or total $\mathrm{h}_{\mathrm{x}}$ ) is typically non-dimensionalized as Nusselt number $\mathrm{Nu}_{\mathrm{x}}$ and is given below: 


$$
\mathrm{Nu}_{\mathrm{x}} \equiv \mathrm{h}_{\mathrm{x}} \cdot \frac{\mathrm{D}_{\mathrm{h}}}{\mathrm{k}_{\mathrm{L}}}
$$

At times, for channel flows, the channel height " $\mathrm{h}$ " is used as the characteristic length scale $[16,20,21]$ instead of the hydraulic diameter $D_{h}$. Also, elsewhere, for channel flows with only bottom-wall heating/cooling - as in $[16,20]-D_{h}=2 h$ in Eq. (2.7) has been replaced by $\widetilde{D}_{h} \equiv D_{h} \cdot f_{P}=4 h$ as the characteristic length in the $\mathrm{Nu}_{\mathrm{x}}$ definition.

Using the $\mathrm{Nu}_{\mathrm{x}}$ definition in Eq. (2.7), it is easily seen that the functional dependencies in Eqs. (2.5) - (2.6) can be non-dimensionalized, with the help of Pi-Theorem [27], in the following forms:

$$
\mathrm{Nu}_{\mathrm{x} \mid \text { conv }} \equiv \mathrm{Nu}_{\mathrm{x} \mid \operatorname{conv}}\left(\hat{\mathrm{x}}, \operatorname{Re}_{\mathrm{T}}, \mathrm{Ja}, \operatorname{Pr}_{\mathrm{L}}, \mathrm{We}, \mathrm{Fr}_{\mathrm{x}}^{-2}, \mathrm{Fr}_{\mathrm{y}}^{-2}, \frac{\rho_{\mathrm{V}}}{\rho_{\mathrm{L}}}, \frac{\mu_{\mathrm{V}}}{\mu_{\mathrm{L}}}, \theta_{\mathrm{w}}(\mathrm{x})\right)
$$

and

$$
\mathrm{Nu}_{\mathrm{x} \mid \text { conv }} \equiv \mathrm{Nu}_{\mathrm{x} \mid \operatorname{conv}}\left(\hat{\mathrm{x}}, \operatorname{Re}_{\mathrm{T}}, \mathrm{Bl}, \operatorname{Pr}_{\mathrm{L}}, \mathrm{We}, \mathrm{Fr}_{\mathrm{x}}^{-2}, \mathrm{Fr}_{\mathrm{y}}^{-2}, \frac{\rho_{\mathrm{V}}}{\rho_{\mathrm{L}}}, \frac{\mu_{\mathrm{V}}}{\mu_{\mathrm{L}}}, \Psi_{\mathrm{q}}(\mathrm{x})\right)
$$

In Eqs. (2.8) and (2.9), $\hat{\mathrm{x}} \equiv \mathrm{x} / \mathrm{D}_{\mathrm{h}}, \mathrm{Re}_{\mathrm{T}} \equiv \mathrm{GD}_{\mathrm{h}} / \mu_{\mathrm{V}}$, Ja $\equiv \mathrm{C}_{\mathrm{pL}} \Delta \mathrm{T} / \mathrm{h}_{\mathrm{fg}}, \operatorname{Pr}_{\mathrm{L}} \equiv \mu_{\mathrm{L}} \mathrm{C}_{\mathrm{pL}} / \mathrm{k}_{\mathrm{L}}$, $\mathrm{Fr}_{\mathrm{x}}^{-2} \equiv\left|\mathrm{g}_{\mathrm{x}}\right| \mathrm{D}_{\mathrm{h}} / \mathrm{U}^{2}, \mathrm{Fr}_{\mathrm{y}}^{-2} \equiv\left|\mathrm{g}_{\mathrm{y}}\right| \mathrm{D}_{\mathrm{h}} / \mathrm{U}^{2}, \mathrm{We} \equiv \rho_{\mathrm{L}} \mathrm{U}^{2} \mathrm{D}_{\mathrm{h}} / \sigma$ and $\mathrm{Bl} \equiv \overline{\mathrm{q}}_{\mathrm{w}}^{\prime \prime} / \mathrm{Gh}_{\mathrm{fg}}$. In Eqs. (2.8) and (2.9), we have not recommended use of $\mathrm{Ja}(\mathrm{x}) \equiv \mathrm{Ja} \cdot \theta_{\mathrm{w}}(\mathrm{x})$ and $\mathrm{Bl}(\mathrm{x}) \equiv$ $\mathrm{Bl} \cdot \Psi_{\mathrm{q}}(\mathrm{x})$ because often: (i) the non-dimensional spatial variation functions $\theta_{\mathrm{w}}(\mathrm{x})$ or $\Psi_{\mathrm{q}}(\mathrm{x})$ defining the "method of heating/cooling" are not known, or (ii) they are not "far," in an integral sense, from their corresponding uniform case value of "1." The total Reynolds number $\mathrm{Re}_{\mathrm{T}}$ simply represents non-dimensional value of mass-flux $\mathrm{G}$ - where its use of vapor viscosity $\mu_{\mathrm{V}}$ is more appropriate for traditional flowcondensation cases in Fig. 1.1b or innovative flow-boiling and flow-condensation cases in Fig. 1.2. For traditional flow-boiling case in Fig. 1.1a, it may be more appropriate to replace $\mathrm{Re}_{\mathrm{T}}$ in Eqs. (2.8) and (2.9) by $\widetilde{\mathrm{Re}}_{\mathrm{T}} \equiv \mathrm{Re}_{\mathrm{T}} \cdot \mu_{\mathrm{V}} / \mu_{\mathrm{L}}$. Nondimensional surface tension parameter Weber number (We) may also influence steady annular flows in Fig. 1.2, particularly if tube diameters are small and 
therefore interfacial curvatures are high (in different ways places for rectangular cross-section as opposed to circular cross-section).

For non-dimensional total heat transfer coefficient $h_{x}$ replacing $h_{x \mid c b}$ in Eqs. (2.5) and (2.6), particularly for annular regimes in Fig. 1.1a and Fig. 1.2a where there is significant presence of micro-scale nucleate boiling, the argument list on the right sides of Eqs. (2.8) and (2.9) will have additional dependence on non-dimensional parameter-set $\left\{S^{*}\right\}$ - that represent relevant vapor-liquid-solid interactions. In such cases, the presence of $\left\{S^{*}\right\}$ is tacitly assumed to be present and brought forth, as needed, when specific combination of fluid, solid, and solid-surface micro/nanostructures are being changed. For annular flow-boiling in Fig. 1.2a, the argument list in Eqs. (2.8) and (2.9) have direct additional dependence on inlet quality $\mathrm{X}_{\text {in }}$ [16]. That is, it should be noted that for annular flow-boiling with nucleation, Eqs. (2.8) and (2.9) only represent the structure for convective boiling component of the Nusselt number $\mathrm{Nu}_{\mathrm{x} \mid c \mathrm{cb}}[16]$.

The condensing/boiling flows of interest typically have a one-to-one correspondence because of monotonically decreasing/increasing values of quality $\mathrm{X}$ with distance $\mathrm{x}$ (or non-dimensional distance $\hat{\mathrm{x}}$ ). It is therefore possible and common to replace the non-dimensional distance $\hat{x} \equiv x / D_{h}$ in Eqs. (2.8) and (2.9) by the local quality $\mathrm{X}(\hat{\mathrm{x}})$ defined as:

$$
X(\hat{\mathrm{x}})=\frac{\dot{\mathrm{M}}_{\mathrm{v}}(\hat{\mathrm{x}})}{\dot{\mathrm{M}}_{\mathrm{in}}}
$$

One of several reasons for replacing distance $\hat{\mathrm{x}}$ with quality $\mathrm{X}$ is the expectation that its use, in place of " $\hat{\mathrm{x}}$ ", will allow more convenient and meaningful characterization of flow-regimes (except near transition boundaries) because of approximate similarities found among different flow-regimes encountered in phase-change flows (in Figs. 1.1 and 1.2) and those encountered for different realizations of adiabatic flows $[5,28]$. It should be noted that in adiabatic flows, a uniform quality $\mathrm{X}(\mathrm{x})=\mathrm{X}$ over $0 \leq \mathrm{x} \leq \mathrm{L}$ retains a value between zero and one. 
Another advantage of using $\mathrm{X}$ in place of $\hat{\mathrm{x}}-$ for developing the $\mathrm{Nu}_{\mathrm{x}}$ correlations in Eqs. (2.8) and (2.9) - is that it is likely to significantly weaken the influence of different functions $\theta_{\mathrm{w}}(\hat{\mathrm{x}})$ or $\Psi_{\mathrm{q}}(\hat{\mathrm{x}})$ that characterize the effects of spatially nonuniform methods of heating/cooling. For a certain class of annular flow-boiling, this fact has been verified by Ranga Prasad et al. in [16]. As a result of the above, it is a common practice to characterize heat-transfer for phase-change flow processes in horizontal tube configurations of Figs. 1.1 and 1.2 (where $g_{x}=0$ and effects of $\mathrm{g}_{\mathrm{y}}$ are often negligible within the plug-slug or annular regimes of interest but may affect the flow-regime transition boundaries) by seeking $\mathrm{Nu}_{\mathrm{x}}$ correlation for known wall temperature heating/cooling cases - using experiments or computations or their synthesis - in the simplified functional dependence structure of the form (or its equivalent):

$$
\mathrm{Nu}_{\mathrm{x}} \equiv \mathrm{Nu}_{\mathrm{x}}\left(\mathrm{X}, \mathrm{Ja}, \mathrm{Re}_{\mathrm{T}}, \operatorname{Pr}_{\mathrm{L}}, \mathrm{We}, \frac{\rho_{\mathrm{V}}}{\rho_{\mathrm{L}}}, \frac{\mu_{\mathrm{V}}}{\mu_{\mathrm{L}}}\right)
$$

For a known heat-flux specifying the "method of heating/cooling" of horizontal tubes, the Nusselt number dependence is of the simplified form (or its equivalent):

$$
\mathrm{Nu}_{\mathrm{x}} \equiv \mathrm{Nu}_{\mathrm{x}}\left(\mathrm{X}, \mathrm{Bl}, \mathrm{Re}_{\mathrm{T}}, \operatorname{Pr}_{\mathrm{L}}, \mathrm{We}, \frac{\rho_{\mathrm{V}}}{\rho_{\mathrm{L}}}, \frac{\mu_{\mathrm{V}}}{\mu_{\mathrm{L}}}\right)
$$

The non-dimensional arguments in Eqs. (2.8) and (2.9) or Eqs. (2.11) and (2.12) simply represent a broad structure, and may implicitly assume additional dependence, if it is relevant, on the earlier discussed non-dimensional parameterset $\left\{S^{*}\right\}$ representing relevant parameters characterizing vapor-liquid-solid interactions. While developing correlation(s), one may choose to simplify the dependences further or optimize for different equivalent combinations. For example, one may choose to limit mass-flux ( $G$ or speed $U \equiv G / \rho_{V}$ ) effects to Reynolds number $\mathrm{Re}_{\mathrm{T}}$ and replace Weber number We and Froude numbers $\left(\mathrm{Fr}_{\mathrm{x}}^{-2}\right.$ and $\left.\mathrm{Fr}_{\mathrm{y}}^{-2}\right)$ respectively by Suratman number $\mathrm{Su}\left(\equiv \sigma \rho_{\mathrm{V}} \mathrm{D}_{\mathrm{h}} / \mu_{\mathrm{V}}^{2}\right)$ and a pair of non-dimensional gravity numbers $\left(\mathrm{g}_{\mathrm{nd}-\mathrm{x}}\right.$ and $\mathrm{g}_{\text {nd-y }}$ where, $\mathrm{g}_{\mathrm{nd}-\mathrm{x}(\text { or } \mathrm{y})} \equiv$ $\left.\left|g_{\mathrm{x}(\text { or } y)}\right| \cdot \rho_{\mathrm{V}}^{2} \cdot \mathrm{D}_{\mathrm{h}}^{3} / \mu_{\mathrm{V}}^{3}\right)$. 
Furthermore, for thin film annular flows of Fig. 1.2, as established by several analyses [16, 29], independent dependences on Ja and $\operatorname{Pr}_{\mathrm{L}}$ on the right sides of Eqs (2.11) and (2.12) can be further simplified by a single parameter dependence on "Ja/ $\mathrm{Pr}_{\mathrm{L}}$." Thus, for thin steady annular flows of Fig. 1.2 restricted to mm-scale channels (curvature of the interface is negligible), effect of the surface tension parameters (We or $\mathrm{Su}$ ) can be assumed to be negligible and one can replace Eqs. (2.11) and (2.12) by their respective and further simplified forms - with the addition of inlet quality $\mathrm{X}_{\text {in }}$ (which is an independent additional variable only for innovative flow-boiling, as it equals 1 for innovative flow-condensation) - given below:

$$
\mathrm{Nu}_{\mathrm{x}}=\mathrm{Nu}_{\mathrm{x}}\left(\mathrm{X}, \mathrm{X}_{\mathrm{in}}, \operatorname{Re}_{\mathrm{T}}, \frac{\mathrm{Ja}}{\mathrm{Pr}_{\mathrm{L}}}, \frac{\rho_{\mathrm{V}}}{\rho_{\mathrm{L}}}, \frac{\mu_{\mathrm{V}}}{\mu_{\mathrm{L}}}\right)
$$

and

$$
\mathrm{Nu}_{\mathrm{x}}=\mathrm{Nu}_{\mathrm{x}}\left(\mathrm{X}, \mathrm{X}_{\mathrm{in}}, \mathrm{Bl}, \mathrm{Re}_{\mathrm{T}}, \operatorname{Pr}_{\mathrm{L}}, \frac{\rho_{\mathrm{V}}}{\rho_{\mathrm{L}}}, \frac{\mu_{\mathrm{V}}}{\mu_{\mathrm{L}}}\right)
$$

Again for annular flow-boiling with nucleation, Eqs. (2.13) and (2.14) only specify the structure for $\mathrm{Nu}_{\mathrm{x} \mid \mathrm{cb}}-$ i.e., convective component of HTC (see [16]) - unless an implicit dependence on the earlier alluded non-dimensional parameter-set $\left\{S^{*}\right\}$ is assumed. The goal is to carefully obtain correlations of the forms (or their equivalent) given in Eqs. (2.8) and (2.9) or (2.11) and (2.12) or (2.13) and (2.14), over a well-defined parameter space, by employing information obtained from: experiments, or accurate modeling/simulation techniques, or a synthesis of the two.

If $\mathrm{Nu}_{\mathrm{x}}$ correlations in the above form (or equivalent) could be reliably and completely obtained from experimental data obtained for flow-boilers and flowcondensers, such experimental correlations would already be consistent - at least approximately - with all the relevant laws of nature (mass, momentum, energy, etc.). This is because experimental realizations automatically satisfy all the relevant laws of nature. 


\subsection{Other indirect variables and their influence on aforementioned key variables}

Laminar or turbulent nature of flows: The total Reynolds number $\mathrm{Re}_{\mathrm{T}}$ cannot shed much light on the expected laminar or turbulent nature of the different phases in annular flows. Clearly laminar or turbulent nature of the flows impact heat transfer correlations for $\mathrm{Nu}_{\mathrm{x}}$ and most other variables of interest. For this assessment, one often uses "local" values of liquid and vapor Reynolds numbers $\left(\operatorname{Re}_{\mathrm{L}}(\mathrm{x})\right.$ and $\operatorname{Re}_{\mathrm{V}}(\mathrm{x})$ respectively) defined as:

$$
\operatorname{Re}_{\mathrm{L}} \equiv \frac{\mathrm{G} \cdot(1-\mathrm{X}(\mathrm{x})) \cdot \mathrm{D}_{\mathrm{h}}}{\mu_{\mathrm{L}}}
$$

and

$$
\mathrm{Re}_{\mathrm{V}} \equiv \frac{\mathrm{G} \cdot \mathrm{X}(\mathrm{x}) \cdot \mathrm{D}_{\mathrm{h}}}{\mu_{\mathrm{v}}}
$$

For separated annular flows, $\mathrm{Re}_{\mathrm{L}}$ (or $\mathrm{Re}_{\mathrm{V}}$ ) $<2000$ continue to indicate laminar nature of the flow in that phase. Similarly, $\operatorname{Re}_{\mathrm{L}}\left(\right.$ or $\left.\mathrm{Re}_{\mathrm{V}}\right) \gg 2000$ continue to indicate turbulent nature of flow in that phase, with $\mathrm{D}_{\mathrm{h}}$ based on wetted perimeter, as in Eq. (2.1), being used. In fact for thin film flows over a plate or in a channel, for which $\Delta \ll \mathrm{h}, \mathrm{Re}_{\Delta}\left(\equiv \mathrm{G} \cdot(1-\mathrm{X}(\mathrm{x})) \cdot 4 \Delta / \mu_{\mathrm{L}}\right)<1800$ is the more appropriate - and less conservative - thin film flow laminarity criteria [30] which is automatically satisfied, whenever $\mathrm{Re}_{\mathrm{L}}<2000$.

\subsection{Underlying one-dimensional (1-D) modeling approach to obtain spatial $x$-variations of flow-variables that are known or correlated in terms of quality $\mathrm{X}$ and other parameters}

For the flow-boiling and flow-condensation realizations in Figs. 1.1 and 1.2, onedimensional (1-D) Energy Balance can be applied to the control volume between any two arbitrary locations " $\mathrm{x}$ " and "x $+\Delta \mathrm{x}$ " (see Fig. 2.1).

It is easy to see that, in the limit of $\Delta x \rightarrow 0$, the energy balance yields: 


$$
\frac{\mathrm{dX}(\mathrm{x})}{\mathrm{dx}} \cong \pm \frac{\left|\mathrm{q}_{\mathrm{w}}^{\prime \prime}(\mathrm{x})\right| \cdot \mathrm{P}_{\mathrm{H}}}{\dot{\mathrm{M}}_{\mathrm{in}} \mathrm{h}_{\mathrm{fg}}\left(\mathrm{p}_{0}\right)}= \pm \frac{\mathrm{h}_{\mathrm{x}}\left|\mathrm{T}_{\mathrm{w}}(\mathrm{x})-\mathrm{T}_{\mathrm{sat}}\left(\mathrm{p}_{0}\right)\right| \cdot \mathrm{P}_{\mathrm{H}}}{\mathrm{G} \cdot \mathrm{A} \cdot \mathrm{h}_{\mathrm{fg}}}
$$

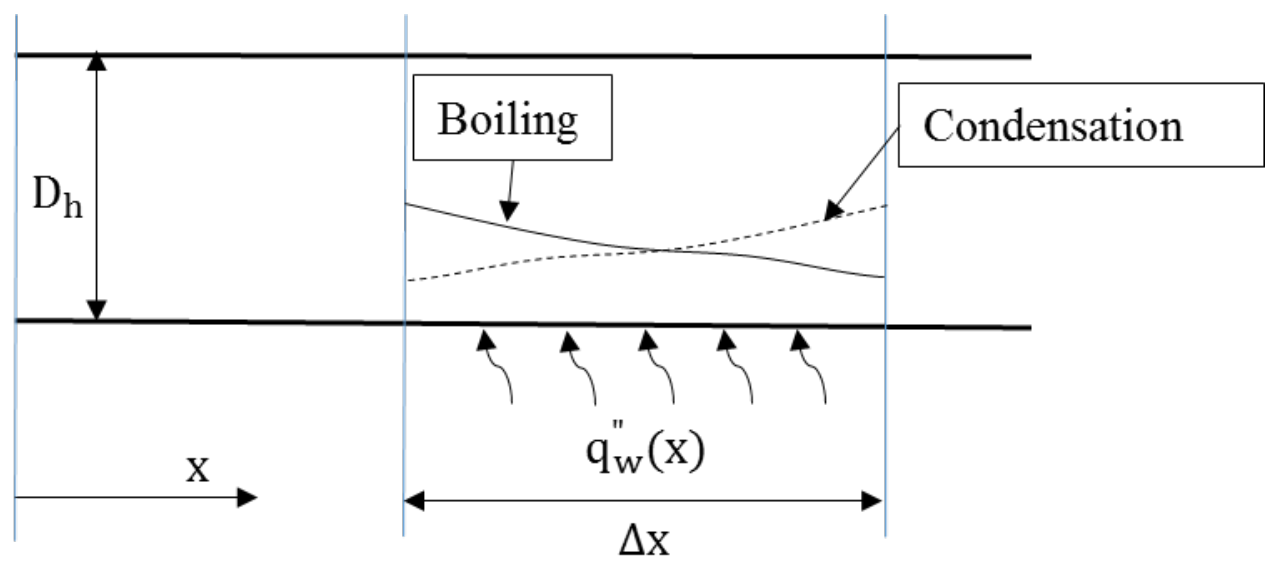

Fig 2.1: A schematic of a control-volume between " $\mathrm{x}$ " and " $\mathrm{x}+\Delta \mathrm{x}$ ". The heat-flux arrows, as shown, are positive for boiling. The negative values (reversed direction) are for flow-condensation.

Using the definitions given earlier: $\mathrm{P}_{\mathrm{H}}$ being the heated perimeter (potentially $a$ fraction $\mathrm{fr}_{\mathrm{P}} \equiv \mathrm{P}_{\mathrm{H}} / \mathrm{P}_{\mathrm{F}}$, where $\mathrm{P}_{\mathrm{F}}$ is the wetted - by liquid or vapor - perimeter), $\dot{\mathrm{M}}_{\mathrm{in}} \equiv$ $\mathrm{G} \cdot \mathrm{A}$, and the relevant non-dimensional variables and numbers as defined following Eq. (2.9); Eq. (2.17) can be non-dimensionalized as:

$$
\frac{\mathrm{dX}(\hat{\mathrm{x}})}{\mathrm{d} \hat{\mathrm{x}}}= \pm 4 \cdot \mathrm{fr}_{\mathrm{P}} \cdot \mathrm{Nu}_{\mathrm{x}} \frac{\mathrm{Ja}}{\operatorname{Pr}_{\mathrm{L}}} \cdot \frac{1}{\operatorname{Re}_{\mathrm{T}}} \cdot \frac{\mu_{\mathrm{L}}}{\mu_{\mathrm{V}}} \cdot \theta_{\mathrm{w}}(\mathrm{x})
$$

for known wall temperatures specifying the "method of heating/cooling."

For known heat-flux values specifying the "method of heating/cooling," Eq. (17) is non-dimensionalized as:

$$
\frac{\mathrm{dX}(\hat{\mathrm{x}})}{\mathrm{d} \hat{\mathrm{x}}}= \pm 4 . \mathrm{fr}_{\mathrm{P}} \cdot \mathrm{BI} . \Psi_{\mathrm{q}}(\mathrm{x})
$$

The "+" and "-" signs in Eqs. (2.17) - (2.19) are, respectively, for flow-boiling and flow-condensation. 


\subsection{Use of $\mathrm{Nu}_{\mathrm{x}}$ correlations covering all flow-regimes}

For known wall temperatures specifying the "method of heating/cooling," the nonlinear ordinary differential equation (ODE) in Eq. (2.18) may be solved over $0 \leq$ $\hat{\mathrm{x}} \leq \mathrm{L} / \mathrm{D}_{\mathrm{h}}$, in conjunction with a reliable $\mathrm{Nu}_{\mathrm{x}}$ correlation (covering all flow-regimes of saturated flow-boiling or flow-condensation in Fig. 1.1) given in the form of Eq. (2.11), or its equivalent, and subject to initial condition.

$$
X(0)= \begin{cases}0, & \text { for saturated flow }- \text { boiling } \\ 1, & \text { for saturated flow }- \text { condensation }\end{cases}
$$

For a known heat-flux value specifying the "method of heating/cooling," the ODE in Eq. (2.19) yields linear $X(\hat{x})$ variation if it is solved for a uniform heat-flux prescription (i.e. for $\Psi_{\mathrm{q}}(\mathrm{x}) \approx 1$ ) - over $0 \leq \hat{\mathrm{x}} \leq \mathrm{L} / \mathrm{D}_{\mathrm{h}}$ subject to the initial conditions in Eq. (2.20). If the overall $\mathrm{Nu}_{\mathrm{x}}$ correlation in Eq. (2.12) (or its equivalent) is known, it allows evaluation of $\mathrm{h}_{\mathrm{x}}$ under given values of $\overline{\mathrm{q}}_{\mathrm{w}}^{\prime \prime}, \mathrm{Bl}$, and $\mathrm{X}(\hat{\mathrm{x}})$ variation. Use of this $h_{x}$ in the defining relationship of Eq. (2.4) then yields the temperatures $T_{w}(x)$ over $0 \leq \mathrm{x} \leq \mathrm{L}$.

A more interesting and a relatively difficult case is when the $\mathrm{Nu}_{\mathrm{x}}$ correlation is available for known heat-flux "method of heating" - in the form of Eq. (2.9) or (2.12) or (2.14) as in [17] - and one wants to use/solve Eq. (2.18) to make $\mathrm{X}(\mathrm{x})$ and $\mathrm{q}_{\mathrm{w}} \mathrm{(x}$ ) predictions for a known wall temperature $\mathrm{T}_{\mathrm{w}}(\mathrm{x})$ case. In this case, preliminary reasonable guesses of $\overline{\mathrm{q}}_{\mathrm{w}}^{\prime \prime}$ and $\Psi_{\mathrm{q}}(\mathrm{x}) \cong 1$ are considered for use in Eq. (2.19) for the first iteration. The $\mathrm{X}(\mathrm{x})$ solution from Eq. (2.19) is used to calculate $\mathrm{Nu}_{\mathrm{x}}(\mathrm{x})$ for the first iteration. This process is iterated - though Eq. (2.18) for calculating $\mathrm{X}(\mathrm{x})$ and $\mathrm{Nu}_{\mathrm{x}}(\mathrm{x})$ in further iterations - to obtain $\left.\mathrm{q}_{\mathrm{w}}^{\prime \prime}(\mathrm{x})\right|_{\text {new }}$ and $\left.\Psi_{\mathrm{q}}(\mathrm{x})\right|_{\text {new }}$ until converged values of $\overline{\mathrm{q}}_{\mathrm{w}}^{\prime \prime}$ and $\Psi_{\mathrm{q}}(\mathrm{x})$ are obtained. 


\section{Results and Correlations from Two-Dimensional (2-D) Laminar I Laminar CFD Simulations of Annular Flow-Boiling}

The need and motivations for CFD simulation of flow-boiling (specifically annular flow-boiling) were discussed in Section 1.2. This section briefly describes some of the important features of the algorithm developed for 2-D CFD simulation of annular flow-boiling (for known wall temperature "method of heating") and reports some of the flow-physics results and the correlation for convective Nusselt number developed from the simulation. The detailed discussion of the algorithm, and results have been published in [16].

\subsection{Important features of 2-D CFD Simulation of Annular Flow-Boiling}

The computational algorithm and solutions presented in [16], and briefly discussed here, are for horizontal configurations of steady annular flow-boiling (under suppressed nucleation conditions) inside a channel, as shown in Fig 3.1 ( $\alpha=0$ for horizontal configurations). These boiling flows are achieved by heating the bottom wall and keeping the top wall at close to, or slightly above, local vapor saturation temperatures. The superscripts " $p$ " and "i," used for variables shown in Fig. 3.1, indicate "physical" dimensions and "interfacial" values respectively.

The 2-D computational approach employed to investigate annular flow-boiling inside channels and tubes is based on the full governing equations presented in $[16,31]$. Analogous flow-condensation approaches are given in [20, 21].

The flow-boiling simulations, emphasized in [16], assume laminar vapor and laminar liquid flows. For most shear-driven flows of interest to annular/stratified flow-boiling in mm-scale ducts, the laminar liquid flow assumption holds up to the end of the computational domain.

Within the vapor phase, for the refrigerants and $\mathrm{mm}$-scale ducts considered in [16], the inlet pressure is much less than the critical pressure (i.e., $p_{0} \ll p_{c r}$, where $p_{c r}$ 
is the critical pressure of the vapor). As a result, the changes in absolute pressure relative to the inlet pressure are big enough to affect vapor motion but, at the same time, they are usually too small to significantly affect saturation temperatures (except in micron-scale ducts and at high mass flux G values).

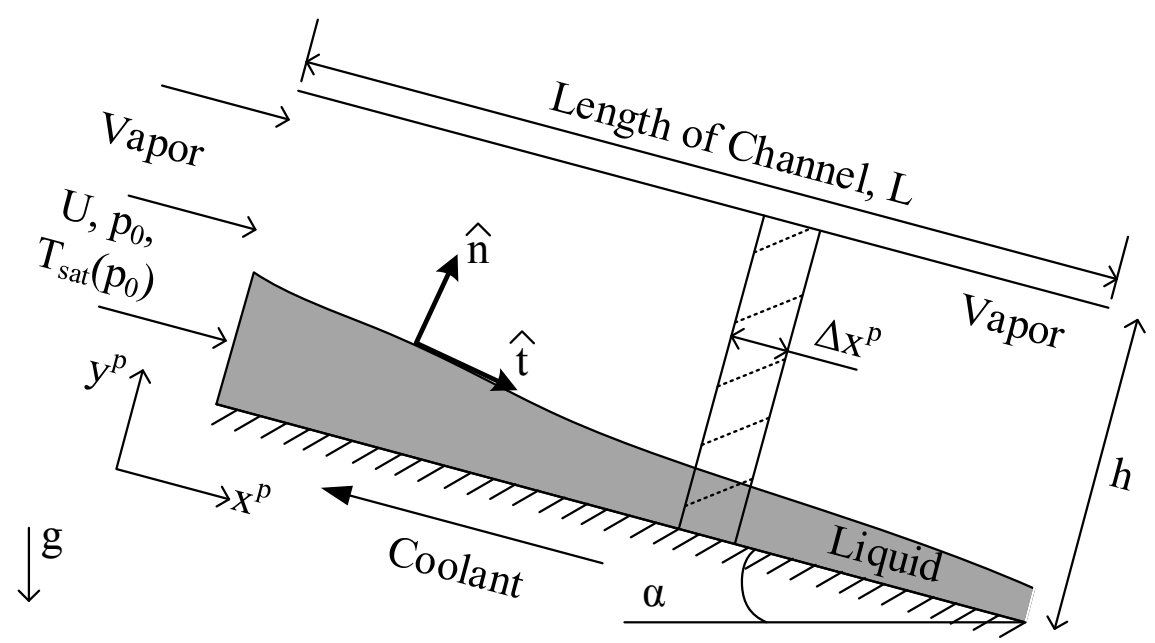

(a)

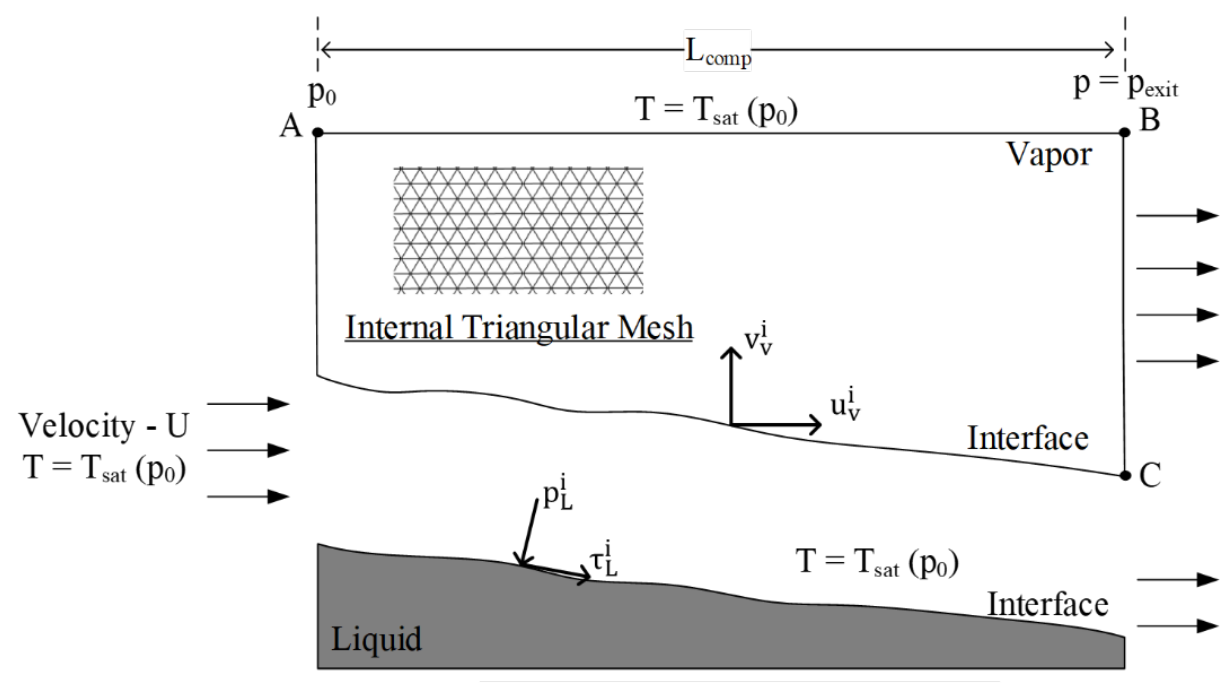

$\mathrm{T}_{\mathrm{w}}(\mathrm{x})$ or $\mathrm{q}_{\mathrm{w}}^{\prime \prime}(\mathrm{x})$ - heating condition

(b)

Fig 3.1: (a) Schematic of a representative suppressed nucleation case of annular flow-boiling in a channel. (b) Schematic of a representative instantaneous interface location showing the interfacial variables used as boundary conditions for the liquid and the vapor domains. The computational domain's exit at $\mathrm{x}=\mathrm{L}_{\text {comp }}$ in (b) is often slightly larger than the exit at $\mathrm{x}=\mathrm{L}$ in (a) 
The problem was computationally solved, subject to the boundary conditions shown on a representative, not-to-scale film profile in the vapor-liquid domain of Fig. 3.1b.

Top wall: The upper wall physical temperature $\mathrm{T}_{2}\left(\mathrm{x}^{\mathrm{p}}, \mathrm{h}\right)>\mathrm{T}_{\text {sat }}\left(\mathrm{p}_{0}\right)$ is at a superheated value (typically $5-10^{\circ} \mathrm{C}$ above saturation temperature) and this, along with the assumption that $\mathrm{p}_{0} \ll \mathrm{p}_{\mathrm{cr}}$, makes the vapor solutions almost indistinguishable from those that assume vapor phase temperature to be a uniform $\mathrm{T}_{\text {sat }}\left(\mathrm{p}_{0}\right)$.

Bottom wall: Besides the no-slip condition at the boiling surface, a steady boiling surface temperature $\mathrm{T}_{1}\left(\mathrm{x}^{\mathrm{p}}, 0\right)=\mathrm{T}_{\mathrm{w}}\left(\mathrm{x}^{\mathrm{p}}\right)\left(>\mathrm{T}_{\mathrm{sat}}\left(\mathrm{p}_{0}\right)\right)$ - or a steady wall heat-flux $\mathrm{q}_{\mathrm{w}}^{\prime \prime}(\mathrm{x})$ - define its thermal boundary condition. Also, as experimentally established [32], a specific choice for earlier defined non-dimensional temperature function:

$$
\theta_{\mathrm{w}}(\mathrm{x}) \equiv \theta_{1}(\mathrm{x}, 0)=\frac{\mathrm{T}_{1}(\mathrm{x}, 0)-\mathrm{T}_{\mathrm{sat}}\left(\mathrm{p}_{0}\right)}{\overline{\mathrm{T}}_{\mathrm{w}}-\mathrm{T}_{\mathrm{sat}}\left(\mathrm{p}_{0}\right)}
$$

for wall temperature $\mathrm{T}_{\mathrm{w}}(\mathrm{x})$ - or a specific $\Psi_{\mathrm{q}}(\mathrm{x})$ in case of wall heat flux prescription $\mathrm{q}_{\mathrm{w}}^{\prime \prime}(\mathrm{x}) \equiv \overline{\mathrm{q}}_{\mathrm{w}}^{\prime \prime} \cdot \Psi_{\mathrm{q}}(\mathrm{x})$ - define a specific "method of heating."

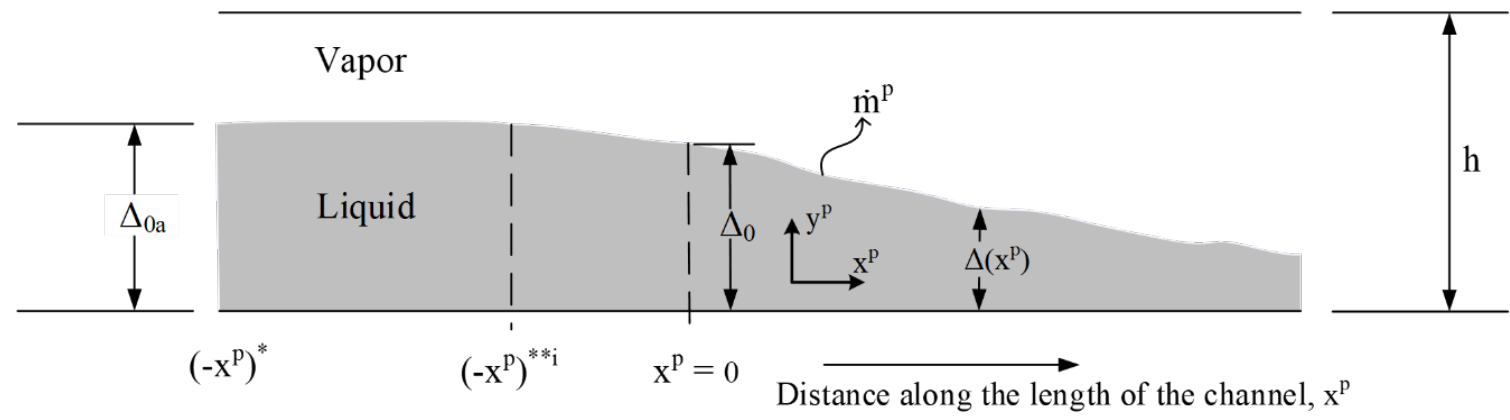

Fig 3.2: Representative film thickness profile for annular/stratified flow-boiling - including "prior method of heating."

Inlet conditions and significance of its resolution: At the inlet $\left(\mathrm{x}^{\mathrm{p}}=0\right)$, presence of evaporative annular/stratified flow-boiling (Fig. 3.1) is assumed and this requires, among other variables, a prescription of a finite non-zero film thickness, $\Delta(0)=\Delta_{0}$. 
Because of the finiteness of $\Delta_{0}$ (unlike $\Delta_{0} \approx 0$ in the onset of condensation condition discussed in $[20,21])$, this value had to be "special". Such restrictive compatibility requirements make full 2-D CFD simulation of annular flow-boiling a challenge. The challenges in prescribing non-zero inlet film thickness are discussed in detail in [16].

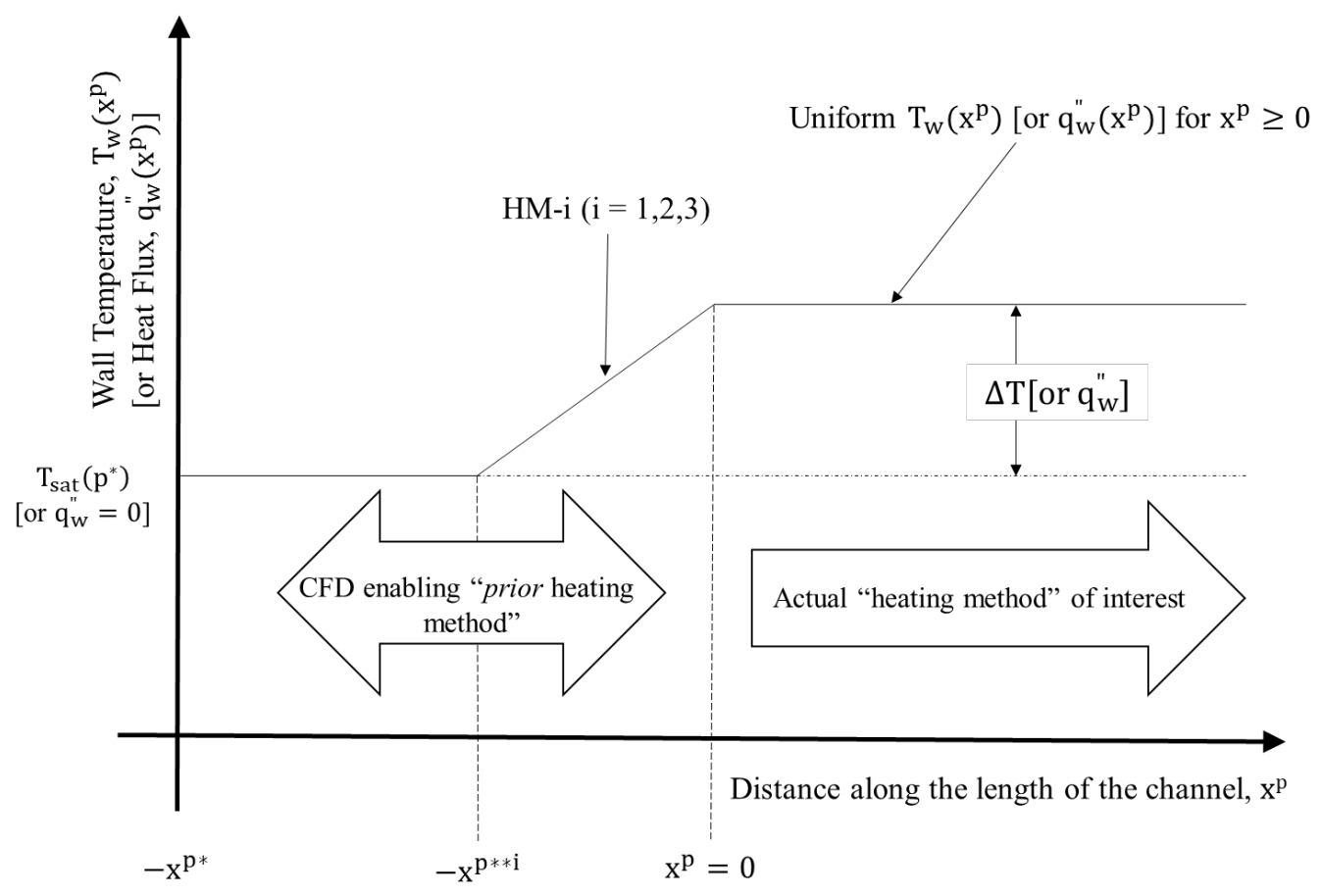

Fig 3.3: Representative wall temperature $\left(\mathrm{T}_{\mathrm{w}}(\mathrm{x})\right)$ (and heat-flux) values are prescribed as indicated for $\mathrm{x}^{\mathrm{p}} \geq 0$ and $-\mathrm{x}^{\mathrm{p}}<\mathrm{x}^{\mathrm{p}}<0$.

To benefit from detailed CFD solution and to address the needs of this rather restrictive specification of inlet conditions, the following enabling approach was used. The proposed enabling approach to deal with this situation was to assume a "prior" adiabatic laminar/laminar flow (see $-\mathrm{x}^{\mathrm{p}^{*}}<\mathrm{x}^{\mathrm{p}}<-\mathrm{x}^{\mathrm{p}^{* * i}}$ in Fig. 3.2, where "i" in $\mathrm{x}^{\mathrm{p}^{* * \mathrm{i}}}$ takes integer values $1,2,3$, etc. associated with different "prior" heating methods HM-i shown in Fig. 3.3) and, also, that a "prior" and spatially non-uniform "method of heating" be prescribed (see Fig. 3.3) for this part of $x^{p}<0$. Whether it is a wall temperature $\mathrm{T}_{\mathrm{w}}(\mathrm{x})$ or a wall heat-flux $\mathrm{q}_{\mathrm{w}}^{\prime \prime}(\mathrm{x})$ prescription, at a certain $\mathrm{x}^{\mathrm{p}}=$ $-\mathrm{x}^{\mathrm{p}^{*}}$, it is assumed that liquid and vapor enter the channel as adiabatic isothermal 
laminar/laminar flows (i.e., both phases are at same uniform temperature and experience no active heating over the adiabatic zone, viz. $\left.-\mathrm{x}^{\mathrm{p}^{*}}<\mathrm{x}^{\mathrm{p}}<-\mathrm{x}^{\mathrm{p} * \mathrm{i}}\right)$. For this adiabatic zone, "mutually consistent" analytical prescriptions for all required inlet conditions are available at $\mathrm{x}^{\mathrm{p}}=-\mathrm{x}^{\mathrm{p} *}$ (see Appendix A2 of [16]).

At the location $\mathrm{x}^{\mathrm{p}}=-\mathrm{x}^{\mathrm{p}^{*}}$ in Fig. 3.3, the fluid temperatures and wall temperatures all equal $\mathrm{T}_{\mathrm{sat}}\left(\mathrm{p}^{*}\right)$, where $\mathrm{p}^{*}$ is the absolute pressure assumed for the top wall location at $x^{p}=-x^{p^{*}}$. At $x^{p}=-x^{p^{*}}$, the consistent values of liquid and vapor phases' velocity, pressure and temperature profiles; interfacial stress vectors; and interfacial mass-flux are as given in Appendix A2 of [16]. For any assumed nonuniform "prior" heating method (denoted as "HM-i", i $=1,2 \& 3$ over $-\mathrm{x}^{\mathrm{p}^{* * \mathrm{i}}}<\mathrm{x}^{\mathrm{p}}<$ 0 , as in Fig. 3.3), mass flow rate $\dot{\mathrm{M}}_{\mathrm{in}}^{\prime}$, and suitably assigned inlet conditions such as quality values at $\mathrm{x}^{\mathrm{p}}=-\mathrm{x}^{\mathrm{p}^{*}}$ associated with liquid and vapor flow rates $\dot{\mathrm{M}}_{\mathrm{L}}^{\prime}\left(\mathrm{x}^{\mathrm{p}}=-\mathrm{x}^{\mathrm{p}^{*}}\right)$ and $\dot{\mathrm{M}}_{\mathrm{V}}^{\prime}\left(\mathrm{x}^{\mathrm{p}}=-\mathrm{x}^{\mathrm{p}^{*}}\right)$ respectively, the CFD solution over $\mathrm{x}^{\mathrm{p}}>-\mathrm{x}^{\mathrm{p}^{*}}$ automatically yields correct and consistent (with analytical solution in Appendix A2 of [16]) inlet conditions up to $x^{p}=-\left(x^{p}\right)^{* * i}$ followed by the transition heating zone of $-\left(x^{p}\right)^{* * 1}<x^{p}<0$ on to the uniform heating method zone of interest, which begins at $x^{p}=0$. The actual physical value of the steady pressure $p_{i n}\left(=p_{0}\right)$ at $\mathrm{x}^{\mathrm{p}}=0$ and $\mathrm{y}^{\mathrm{p}}=\mathrm{h}$ is not directly used in CFD but it indirectly appears through fluid properties and important thermodynamic properties such as $\mathrm{h}_{\mathrm{fg}}\left(\mathrm{p}_{2}^{\mathrm{i}}\right) \approx \mathrm{h}_{\mathrm{fg}}\left(\mathrm{p}_{0}\right)$ and $\mathrm{T}_{\mathrm{sat}}\left(\mathrm{p}_{2}^{\mathrm{i}}\right) \approx \mathrm{T}_{\mathrm{sat}}\left(\mathrm{p}_{0}\right)$.

Steady Exit conditions: For the steady problem, the flow is parabolic and no exit condition is needed. Pressure is not directly prescribed across the exit boundary for the computational simulations. Its arbitrary "reference" value $p_{\text {exit }}$ is specified, to begin with, in the vapor domain - at the corner point of the intersection of the exit and the top wall (point $B$ in Fig. 3.1b). This value is then re-adjusted to ensure a reference pressure value of $p_{\text {ref } \mid \mathrm{A}}=0$ for the reference location point $\mathrm{A}$ (at $\mathrm{x}=$ 0 in Fig. 3.1b). 
Initial Conditions: The steady problem needed no initial condition prescription as there are no time considerations. It does, however, require some reasonable but arbitrary initial guessed values for the first iteration, which are described in detail in [16].

\subsection{Results and Correlation for Convective Boiling Component of Heat Transfer Coefficient}

The steady flow simulations yield elucidating information on two-dimensional spatial variations of key flow variables of interest (I = "L" or "V"), viz. velocity components $\left(u_{1}, v_{l}\right)$, temperatures $\left(T_{1}\right)$, pressures $\left(p_{1}\right)$, streamlines etc.

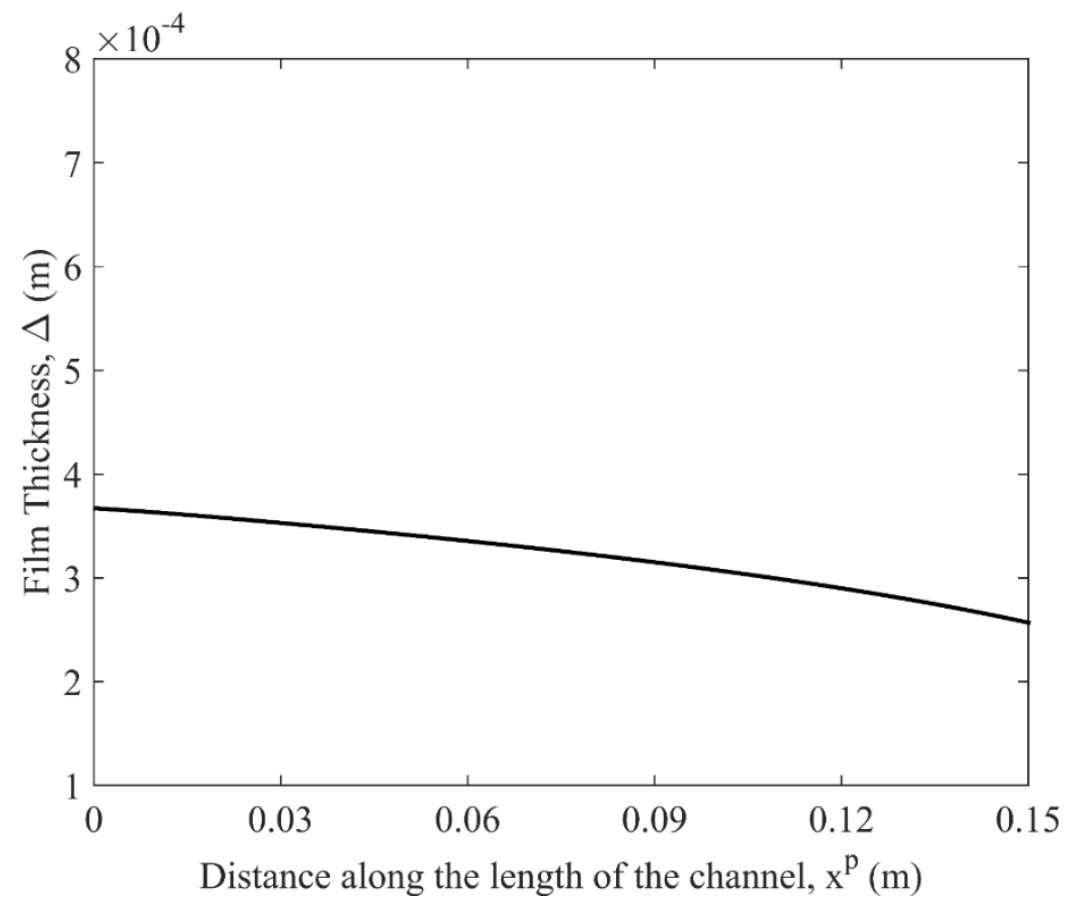

Fig 3.4: Plot of a steady film thickness profile for a horizontal case in the presence of transverse gravity. (Run parameters: Fluid is FC72, $U=1 \mathrm{~m} / \mathrm{s}, \mathrm{p}_{0}=105.1 \mathrm{kPa}, \Delta \mathrm{T}=10^{\circ} \mathrm{C}, \mathrm{h}=2 \mathrm{~mm}, \mathrm{G} \equiv$ $\left.\rho_{2} \mathrm{U}=13.98 \mathrm{~kg} / \mathrm{m}^{2} \mathrm{~s}\right)$

For a representative horizontal ( $\alpha=0$ ) flow situation in Fig. 3.1a (also see Fig. 3.2), and under a steady "method of heating" of the type defined in Fig. 3.3, the steady solution was obtained by the algorithm described in [16] and the plot for variation of film thickness $\Delta(\mathrm{x})$ along the length of the channel $\mathrm{x}^{\mathrm{p}}$ is shown in Fig. 3.4 (the 
run parameters are as given in the figure caption). Other results including crosssectional profiles of: $x$-component of liquid and vapor interfacial velocities $u_{I}^{p}, y-$ component of liquid and vapor interfacial velocities $v_{I}^{p}$, Temperature $T_{I}\left(x^{*}, y\right)$ and Pressure $p_{1}\left(x^{*}, y\right)$ (for $I=" L " \&$ "V") versus $y$, for a representative $x=x^{*}$, are not shown here for brevity but have been shown in [16].

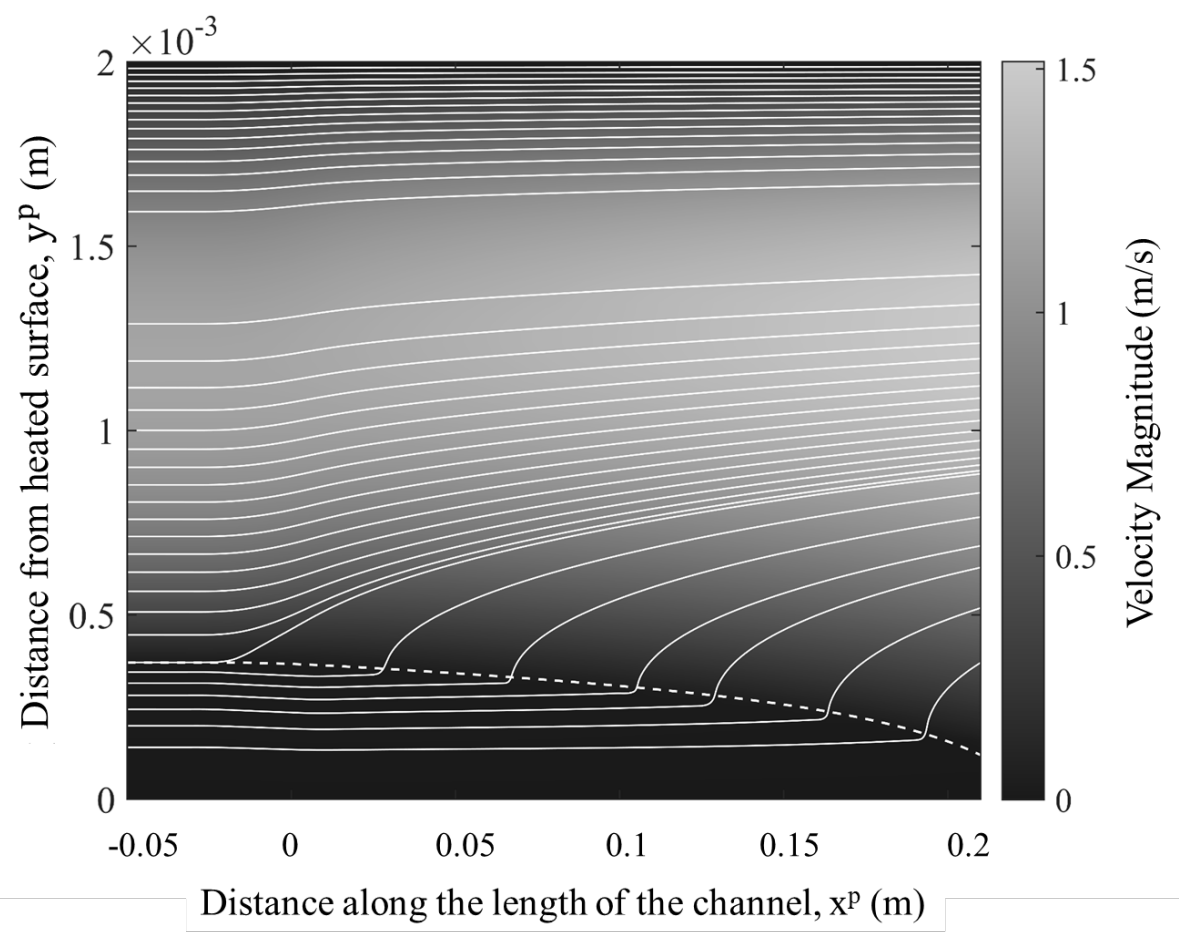

Fig 3.5: Streamline patterns for $\overrightarrow{\mathbf{v}}_{\mathrm{I}}$, for $\mathrm{I}=1$ and 2, are shown above for the flow in Fig. 3.4. The background shade representing magnitude of $\overrightarrow{\mathbf{v}}_{\mathrm{I}}$, for I = "L" and "V", is the vertical axis on the right of the plot. (Run parameters: same as in Fig. 3.4).

The stream line patterns for a particular run case is shown in Fig. 3.5. The starting points of the streamlines were chosen at $x^{p}=-x^{p *}=-0.05$ (for both liquid and vapor mass phases) in a fashion so as to yield equal mass flow rates between each streamline - and hence the streamlines are spatially unequally distributed at $\mathrm{x}^{\mathrm{p}}=-\mathrm{x}^{\mathrm{p} *}$. It is significant to note that Fig. 3.5 clearly demonstrates how evaporated vapor of laminar liquid flow pushes the incoming vapor away from the interface region into the core region. As a result, for thin film flows of interest here, even in the presence of non-deterministic interfacial waves, the liquid flow remains 
laminar - dominated by viscous forces (with negligible inertia) - and at most exhibits wavy laminar interfacial turbulence. Fig. 3.5 also shows that even if vaporphase Reynolds number is sufficiently high (i.e., $2000 \leq \operatorname{Re}_{V}\left(\equiv \mathrm{GXh} / \mu_{2}\right) \leq 10000$, or much higher depending on the flow specifics), classical turbulence will be restricted to the vapor core and would only affect pressure drop predictions (associated with changes in vapor phase velocity away from the interface) - not the liquid flow's predicted dynamics, thickness, and associated heat transfer rates.

Fig. 3.6a shows the variation of heat-flux $\mathrm{q}_{\mathrm{w}}^{\prime \prime}$ and convective $\mathrm{HTC} \mathrm{h}_{\mathrm{x} \mid \mathrm{cb}}$ along the length of the channel, while Fig. 3.6b shows the variation of convective HTC $h_{x \mid c b}$ with quality X. In Figs. 3.6a-b, the drop in $\mathrm{h}_{\mathrm{x} \mid \mathrm{cb}}$ immediately after the beginning of uniform heating (over $0 \leq \mathrm{x}^{\mathrm{p}} \leq \mathrm{x}_{\mathrm{e}}^{\mathrm{p}}$ ) is essentially a "thermal entry zone" effect and after that prior non-uniform heating methods become unimportant and the flow behaves as if it has been exposed to uniform heating alone. To avoid the effects due to "thermal entry zone," while obtaining the correlation for convective HTC $\mathrm{h}_{\mathrm{x} \mid \mathrm{cb}}$ (or convective Nusselt number $\mathrm{Nu}_{\mathrm{x} \mid \mathrm{cb}}$ ), only data points after the minimum $h_{x \mid c b}$ value (i.e., $x^{p} \geq x_{e}^{p}$ in Fig. 3.6a) are considered.

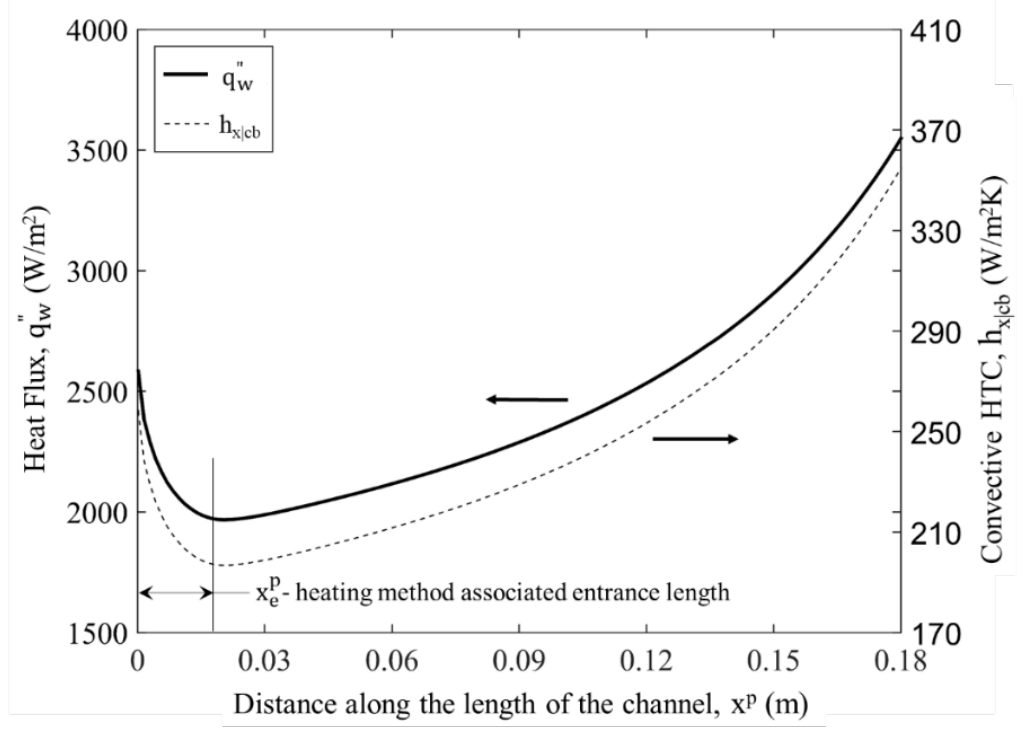

(a) 


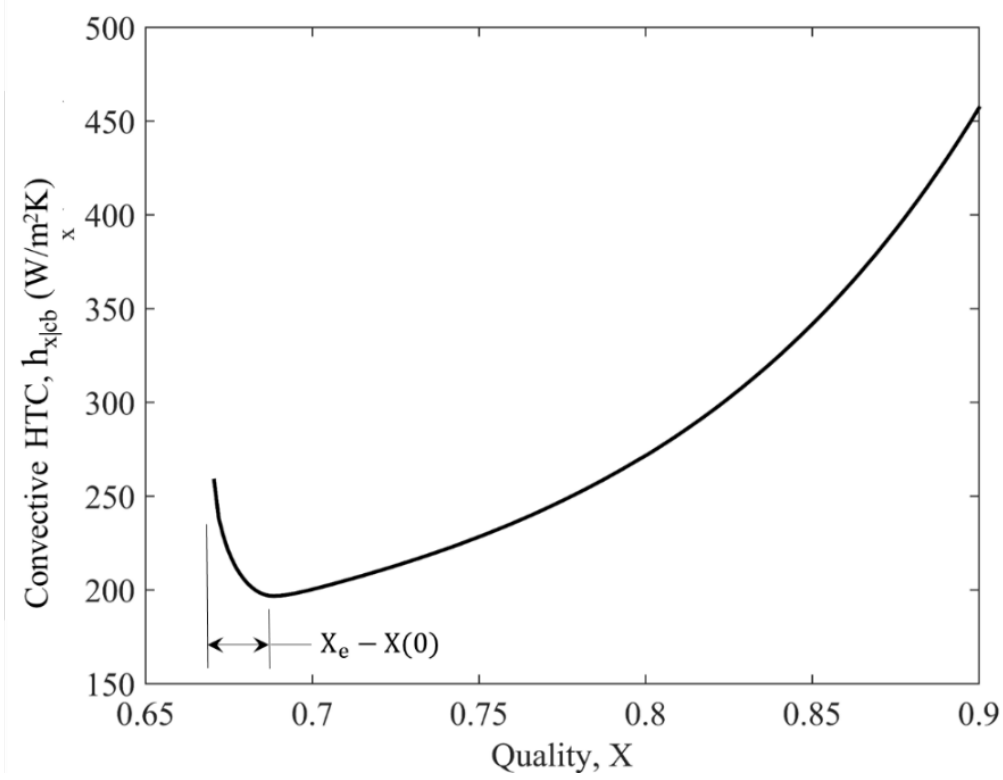

(b)

Fig 3.6: (a) The $x$-variation of Wall heat-flux $q_{w}^{\prime \prime}\left(x^{p}\right)$ and convective heat transfer coefficient $\mathrm{h}_{\mathrm{x} \mid \mathrm{cb}}\left(\mathrm{x}^{\mathrm{p}}\right)$. (b) Convective Heat transfer coefficient as a function of quality $\mathrm{X}, \mathrm{h}_{\mathrm{x} \mid \mathrm{cb}}(\mathrm{X})$. (Run parameters: same as in Fig. 3.4.)

For choices of physical variables and ranges associated with the flow conditions listed in Table 3.1, a $\mathrm{Nu}_{\mathrm{x} \mid \mathrm{cb}}$ correlation - for just the convective component of overall HTC and for uniform wall-temperature "method of heating" or actual suppressed annular flow-boiling - is sought in the form given by the right side of Eq. (2.14).

Table 3.1: Choices and ranges of physical flow variables for fluid flow conditions considered in 2D CFD simulation of Annular Flow-Boiling.

\begin{tabular}{|c|c|c|c|}
\hline Working fluids & FC-72 & R-113 & R-123 \\
\hline Inlet pressure, $\mathrm{p}_{0}(\mathrm{kPa})$ & 105.1 & $105.1-200$ & 105.1 \\
\hline Channel Height, $\mathrm{h}(\mathrm{mm})$ & 2 & 2 & 2 \\
\hline Mass Flux, $\mathrm{G}\left(\equiv \rho_{2} \mathrm{U}\right)\left(\mathrm{kg} / \mathrm{m}^{2} \mathrm{~s}\right)$ & $7-35$ & $3.8-56.3$ & $3.4-26.8$ \\
\hline Transverse Gravity, $\mathrm{g}_{\mathrm{y}}\left(\mathrm{m} / \mathrm{s}^{2}\right)$ & -9.81 & -9.81 & -9.81 \\
\hline Average Inlet Vapor Speed, $\mathrm{U}(\mathrm{m} / \mathrm{s})$ & $0.5-2.5$ & $0.5-4$ & $0.5-4$ \\
\hline Temperature Difference, $\Delta \mathrm{T}\left({ }^{\circ} \mathrm{C}\right)$ & $5-25$ & $5-25$ & $5-25$ \\
\hline Inlet Quality, $\mathrm{X}_{\mathrm{in}}$ & $0.5-0.8$ & $0.5-0.8$ & $0.5-0.8$ \\
\hline
\end{tabular}


Based on the physical parameter ranges mentioned in Table 3.1 several simulation cases were run and the data was used to correlate the dependence of convective boiling Nusselt number. The resulting correlation is of the form:

$$
\mathrm{Nu}_{\mathrm{x} \mid \mathrm{cb}} \equiv \frac{\mathrm{h}_{\mathrm{x} \mid \mathrm{cb}} * \mathrm{~h}}{\mathrm{k}_{\mathrm{L}}}=5.58 * \mathrm{X}^{1.61} \mathrm{X}_{\mathrm{in}}^{0.128} \widetilde{\mathrm{Re}}_{\mathrm{T}-\mathrm{V}}^{0.0284}\left(\frac{\mathrm{Ja}}{\mathrm{Pr}_{\mathrm{L}}}\right)^{-0.0583}\left(\frac{\rho_{\mathrm{V}}}{\rho_{\mathrm{L}}}\right)^{-0.399}\left(\frac{\mu_{\mathrm{V}}}{\mu_{\mathrm{L}}}\right)^{0.454}
$$

where, $0.5 \leq \mathrm{X}_{\mathrm{in}} \leq 0.8,616.5 \leq \widetilde{\mathrm{Re}}_{\mathrm{T}-\mathrm{V}} \leq 9880.7,0.0048 \leq \mathrm{Ja} / \mathrm{Pr}_{1} \leq 0.0424$, $0.00466 \leq \rho_{2} / \rho_{1} \leq 0.0097,0.0216 \leq \mu_{2} / \mu_{1} \leq 0.0295$. The linear regression fit associated with Eq. (3.2) yielded a mean error of $4.95 \%$. It should be noted that total vapor Reynolds number $\widetilde{R e}_{\mathrm{T}-\mathrm{V}}$ is defined here - like the convective Nusselt number $\mathrm{Nu}_{\mathrm{x} \mid \mathrm{cb}}$ and unlike $\mathrm{Re}_{\mathrm{T}}$ defined after Eq. (2.9) - with height of the channel $\mathrm{h}$ as the characteristic length - i.e., $\widetilde{\mathrm{Re}}_{\mathrm{T}-\mathrm{V}} \equiv \mathrm{Gh} / \mu_{\mathrm{V}}$.

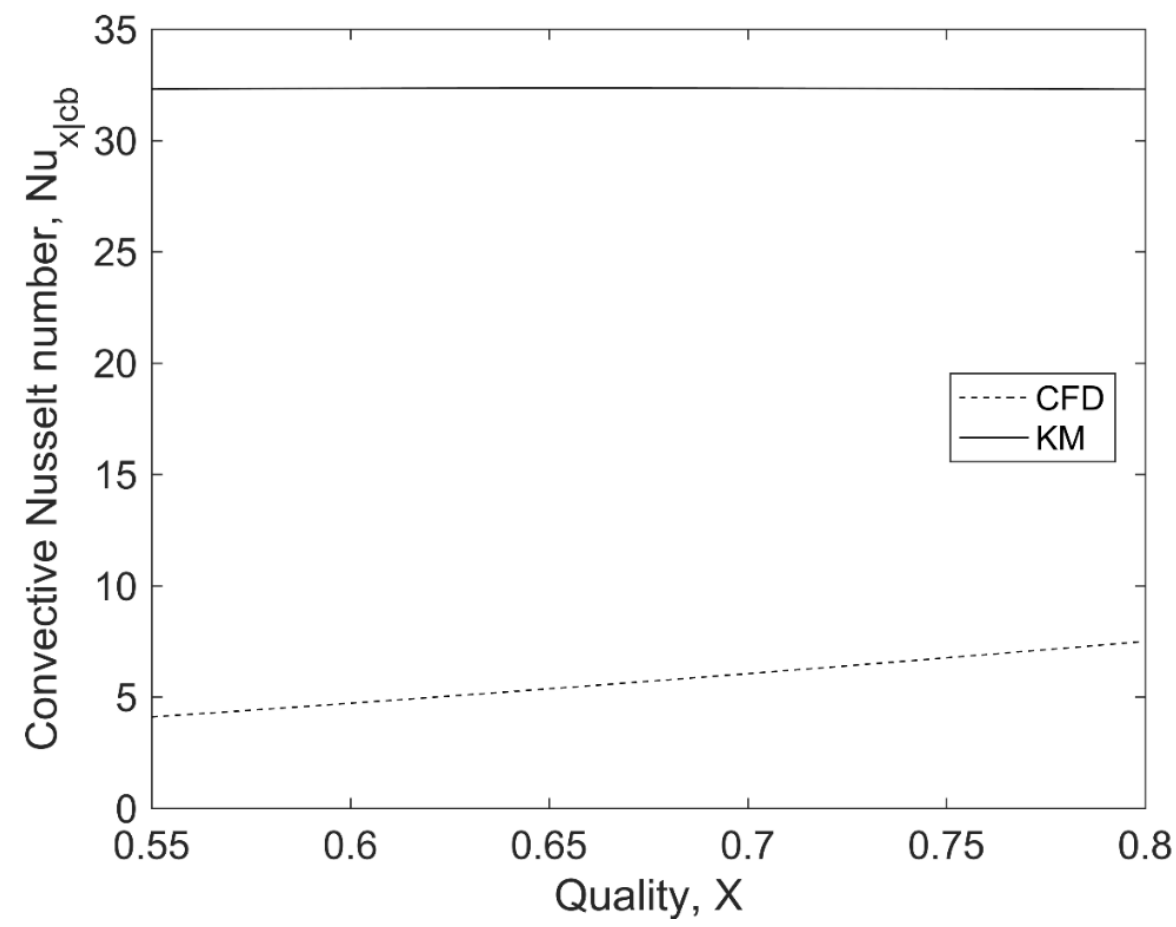

Fig 3.7: Comparison between convective Nusselt number values calculated from Eq. 3.2 (CFD) with convective component of Nusselt number correlation proposed by Kim and Mudawar [17] (KM). (Run parameters: Fluid is FC72, $\mathrm{p}_{0}=110.03 \mathrm{kPa}, \Delta \mathrm{T}=5^{\circ} \mathrm{C}, \mathrm{h}=2 \mathrm{~mm}, \mathrm{G}=25.12 \mathrm{~kg} / \mathrm{m}^{2} \mathrm{~s}$ ). 
Fig. 3.7 shows a comparison between convective Nusselt number $\mathrm{Nu}_{\mathrm{x} \mid \mathrm{cb}, \mathrm{CFD}}$ calculated from Eq. 3.2 and convective component of a popular Nusselt number correlation proposed by Kim and Mudawar [17] $\mathrm{Nu}_{\mathrm{x} \mid \mathrm{cb}, \mathrm{KM}}$ for an arbitrary run parameters (described in the figure caption) and an arbitrary range of quality.

It can be seen that the convective Nusselt number as predicted by the Kim and Mudawar correlation $\left(\mathrm{Nu}_{\mathrm{x} \mid \mathrm{cb}, \mathrm{KM}}\right)$ is higher than the one predicted by Eq. 3.2 $\left(\mathrm{Nu}_{\mathrm{x} \mid \mathrm{cb}, \mathrm{CFD}}\right)$. This is because of the ad hoc nature of splitting the overall HTC (or Nusselt number) into convective and nucleate boiling components and/or underestimation of the contributions from nucleate boiling (by not considering contributions from micron/sub-micron scale nucleation), which would consequently show a higher contribution of convective component of Nusselt number; both these possible reasons were discussed in Section 1.2.

\section{Use of Existing Correlations for Design of Annular Flow Boiling and Flow Condensation Experiments}

The correlation structures discussed in Section 2 supported the specific correlation reported in Section 3. The specific correlation in Section 3 was developed with the help of data obtained from 2-D CFD simulations. However, typically the correlations are developed with the help of experiments (often flow-regime transition and pressure-gradient correlations use adiabatic flow-regime maps). The correlation structures discussed in Section 2 were developed with the aid of theory underlying non-dimensionalization processes and some understanding of the physics that underlie these phase-change flows. Design of new experiments or new systems for a given working fluid and a range of operating conditions can develop such correlations. This, in turn, requires preliminary - but mutually consistent - "order of magnitude" estimates for values of variables (such as: liquid and vapor flow rates, wall heat-flux or wall temperature values, inlet pressure, length and hydraulic diameter of the device, heat transfer coefficient values, 
pressure-drop values, liquid film thickness values, etc.) which make device operations possible. To begin with, until better correlations or experimentally obtained refinements for the existing correlations become available, correlations that are presently available need to be judiciously used to define the experimental and/or design operating conditions and associated instrumentation requirements.

Use of existing correlations are shown here with the help of two specific examples. The first example is that of a preliminary design of a millimeter-scale flow-boiler operating in a steady annular/stratified regime with thin liquid film flows (Fig. 1.2a) - either in the presence of nucleation (most likely with micron and sub-micron scale bubble diameters) or under suppressed nucleation conditions. The second example is that of a preliminary design of a millimeter-scale flow-condenser for a steady annular/stratified film-wise condensation on a hydrophilic surface (see Fig. $1.2 \mathrm{~b})$. In both the examples, it is assumed here that the fluid flows through a horizontal duct of rectangular cross-section with high aspect ratio (adequately modeled as a channel) - with the heat-exchange surface being the bottom plate.

\subsection{Design of Millimeter-Scale Annular Flow-Boilers}

The next sub-section discusses some of the desired specifications and constraints for the design of an innovative flow-boiler operating in the annular flow-regime. It should be noted that these constraints are specific to a particular application and a different application would require a different set of constraints. The current set of constraints have been decided assuming an application for electronic cooling.

4.1.1 Desired specifications, constraints, and information/knowledge needed for meeting the requirements

A pure working fluid should be chosen such that it has a saturation temperature in $30-90{ }^{\circ} \mathrm{C}$ range for operating inlet pressures in $100-110 \mathrm{kPa}$ range.

(i) The inlet quality (at $x=0$ in Fig $1.2 a$ ) should be higher than the critical quality of transition from non-annular to annular flow-regimes - ensuring 
annular flow realization. For this, it is important to know, approximately, the quality at which the flow-regime transition occurs with estimates coming from different flow-regime transition maps. The required scientific structures for this, and the status of available knowledge have been discussed in [9]. These estimates are sought to be within a reasonable range of values that would suffice, with trial-and-error experimental adjustments, for present purposes. It is hoped that, in future, such estimates could be further improved (i.e., made more accurate) through a proper synthesis of experiments and modeling.

(ii) The inlet film thickness $\Delta_{\text {in }}$, the liquid film thickness just downstream of the splitter plate in Fig. 1.2a, is desired to be around $300 \mu \mathrm{m}$. This is, presumably, neither too thin nor too thick and it is important for subsequent and possible transitioning of the steady operations to pulsatile operations which were briefly discussed in Section 1.1 and discussed in detail elsewhere $[9,13]$. The control of inlet liquid film thickness by recirculating vapor is essential because, otherwise, the liquid film thickness may change abruptly to an undesirable range, as it exits the splitter plate in Fig. 1.2a. Thickness, at or below $300 \mu \mathrm{m}$, are needed to keep the films stable - with or without micron/sub-micron diameters nucleating bubbles - even when large amplitude standing waves are superposed on the interface. For such a design, a correlation for inlet film thickness with dependence on inlet quality is required as input. Since this is a stratified/annular flow through a rectangular channel, with nearly adiabatic self-seeking free-surface locations immediately downstream of the inlet splitter plate (see Fig. 1.2a), a set of void-fraction $(\epsilon)$ correlations for adiabatic flows (discussed in [9]) could be used to obtain a good range of appropriate inlet quality and associated inlet film thickness values.

(iii) To avoid dry-out related CHF instabilities at or near the exit, the exit quality should be less than 1 and the heat-flux at the exit should be less than the 
available order of magnitude estimates for CHF associated with dry-out instability $\left(\mathrm{q}_{\mathrm{w} \mid \text { exit }}<\mathrm{q}_{\mathrm{CHF} \mid \mathrm{dry}-\mathrm{out}}\right)$. For this, an estimate of a dry-out related $\mathrm{CHF}$, obtained from correlation(s), such as the ones presented by $\mathrm{Qu}$ and Mudawar [10], may be used. However, instead, the following more conservative constraint is recommended. As a safety measure, it is required that the film thickness at the exit, estimated in different ways, be equal to or greater than one-fifth of the inlet film thickness (i.e., $\Delta_{\text {out }} \geq \Delta_{\text {in }} / 5 \geq \mathrm{O}$ (50 $\mu \mathrm{m})$ ). This constraint is also helpful in ensuring that inlet vapor speeds (or qualities $X_{\text {in }}$ ) are not too large, as entrainment of liquid into the vapor needs to be minimized.

(iv) Some of the important information that are required for this design are the Reynolds numbers: Reynolds numbers based on total mass-flux $\operatorname{Re}_{\mathrm{T}}$ (三 $\left.\mathrm{GD}_{\mathrm{h}} / \mu_{\mathrm{V}}\right)$, liquid Reynolds number $\mathrm{Re}_{\mathrm{L}}\left(\equiv \mathrm{G}(1-\mathrm{X}) \mathrm{D}_{\mathrm{h}} / \mu_{\mathrm{L}}\right)$, and vapor Reynolds number $\operatorname{Re}_{\mathrm{V}}\left(\equiv \mathrm{GXD}_{\mathrm{h}} / \mu_{\mathrm{V}}\right)$. The first Reynolds number is typically used in evaluating Nusselt number correlations for saturated flow-boiling covering annular regimes (over appropriate range of qualities). Meanwhile, the second and third Reynolds numbers are often needed for assessing whether the liquid and vapor flows are laminar or turbulent and, accordingly, for selecting constants in sub-correlations (either directly for Nusselt number correlations or indirectly for related pressure drop correlations). The knowledge of the laminar/turbulent nature of liquid and vapor flows are also useful in choosing appropriate correlation(s) that are available for different void-fraction models.

(v) Since there are separate inlet channels for liquid and vapor, and a splitter plate is used (as in the experiments of Kivisalu et al. [13]) to ensure that the liquid and vapor do not mix before they enter the test-section (as shown in the Fig. 1.2a), the cross-sectional area for vapor flow just before the inlet (locations $\mathrm{x}<0$ ) is different from the cross-sectional area for the vapor flow within the test-section (locations $x \geq 0$ ). Furthermore, because of non-zero 
vapor inflow rate at the inlet and its subsequent acceleration associated with flow-boiling, the vapor speed at the exit of the test-section would be higher (much higher for higher heat-fluxes) than it is at the inlet of the test section. To avoid compressibility related choking effects [5], it is required that the vapor speeds at both the inlet and the exit be, approximately, less than $1 / 3^{\text {rd }}$ of the speed of sound for saturated vapor operating at pressures that are at or below the inlet pressure value.

(vi) The inlet pressure $p_{\text {in }}$ is required to be above atmospheric pressure such that, despite the pressure-drop along the length of the channel, the exit pressure is also higher than the atmospheric pressure (i.e., $p_{\text {out }}>p_{\text {atm }}$ ). This requirement is to make the design simpler, so that the system does not have to exhibit stringent and prolonged tolerance to vacuum pressures. For systems operating below atmospheric pressure, even small leaks of air can, over time, lead to substantial buildup of non-condensable air into the system and then this system-design, based on pure vapor and pure liquid flowphysics assumption and associated correlations, as proposed, will fail.

(vii) Further, despite the pressure-drop between the inlet and the exit of the channel, mechanical power in the vapor at the exit is likely to be much more than the incoming power at the inlet - i.e., for exiting vapor speeds relative to the inlet, it is expected that $P_{V, \text { out }}\left(\equiv p_{\text {out }} \cdot v_{V, \text { out }} \cdot A_{\text {out }}\right)>P_{V, \text { in }}(\equiv$ $\left.\mathrm{p}_{\text {in }} \cdot \mathrm{v}_{\mathrm{V}, \text { in }} \cdot \mathrm{A}_{\mathrm{in}}\right)$. The net power out $\left(\mathrm{P}_{\mathrm{V}, \text { out }}-\mathrm{P}_{\mathrm{V}, \text { in }}\right)$ has to be maximized for high heat-flux cases. This is to ensure that only minimal additional power is needed for the vapor-phase compressor (in Fig. 1.2a). Note that the liquid pump already consumes insignificant power.

(viii) For a known uniform heat-flux specifying the "method of heating," Eq. (2.19) yields linear quality variations and, subsequently, order of magnitude estimate of the heat transfer coefficient $h_{x}$ can be obtained from a Nusselt number correlation - which is only needed for assessing wall temperature $\mathrm{T}_{\mathrm{w}}(\mathrm{x})$ variations associated with the boiling surface. It is required that the 
design be such that the mean wall temperature $\bar{T}_{w}$ be not too high and remain below a certain threshold value.

(ix) The key parameters whose desired ranges need to be recommended, or chosen, to propose a design that satisfies the above conditions are: massflux $G$, length of the channel $L$, height of the channel $h$, inlet pressure $p_{i n}$, and inlet quality $X_{\text {in }}$.

\subsubsection{Implementation of a sample design methodology - meeting the requirements} given in "Section 4.1.1" leading to results for steady annular flow-boiler operations

A range of inlet pressures $\mathrm{p}_{\text {in }}$, total mass fluxes $\mathrm{G}$, and mean heat-flux $\overline{\mathrm{q}}_{\mathrm{w}}^{\prime \prime}$ (or mean wall temperatures $\bar{T}_{\mathrm{w}}$, depending on what is known or preferred assumption about the "method of heating") are initially chosen and considered. They are then optimized to satisfy most of the constraints mentioned in the above-described design requirements. Subsequently, the length $\mathrm{L}$ of the flow-boiler may also be adjusted to satisfy the remaining constraints. This is a reasonable approach because of the flexibility to stack these flow-boilers in series and/or in parallel arrangements towards a feasible solution for a new system, that covers a designated cooling area of design interest.

Towards achieving this design, to begin with, one particular combination of inlet pressure, total mass-flux, and mean heat-flux (or mean wall temperature) is defined as a specific initial operating condition for a given channel height $h$ and a single flow-boiler design. For this, towards meeting the remaining design requirements, the channel height is chosen to be $5 \mathrm{~mm}$, the working fluid to be R123 , and the tentative choices for the remaining steady operating conditions are as follows: inlet pressure $p_{\text {in }}=120.1 \mathrm{kPa}$; total mass-flux $G=300 \mathrm{~kg} / \mathrm{m}^{2}-\mathrm{s}$; and mean heat-flux $\overline{\mathrm{q}}_{\mathrm{w}}^{\prime \prime}=50 \mathrm{~W} / \mathrm{cm}^{2}=500 \mathrm{~kW} / \mathrm{m}^{2}$.

(i) For any chosen operating condition, the first step is to find the critical quality for transition from non-annular to annular flow-regimes $\left(\mathrm{X}_{\mathrm{cr} \mid \mathrm{NA}-\mathrm{A}}\right)$ through 
available maps for traditional Fig. 1.1a operations, so an inlet quality $X_{\text {in }}>$ $\mathrm{X}_{\mathrm{cr|NA}-\mathrm{A}}$ can be chosen for Fig. 1.2a operations. This is accomplished by using approximate flow-regime transition maps. A few appropriate flowregime transitions maps should be chosen, based on hydraulic diameter $D_{h}$, fluid, orientation (horizontal, in this case) of the channel/tube, etc. Since the flow-regime transition maps are semi-empirical in nature (i.e., correlated using data from either existing experiments or modeling/simulations), as a conservative measure, it is recommended that the critical quality for transition from non-annular to annular flow-regime $\mathrm{X}_{\mathrm{cr} \mid \mathrm{NA}-\mathrm{A}}$ be obtained from at least three different flow-regime transition maps and the highest of those qualities be used. For the flow-boiler design under consideration, flow-regime transition maps proposed by Harirchian and Garimella [33], Kim and Mudawar [34], and Mandhane et al. [35] were considered here to be approximate and relevant ones for further evaluations. Even though the map by Mandhane et al. [35] was developed for adiabatic flows, its use in the present scenario is justified because the flow will be approximately adiabatic immediately after it exits the splitter plate at the inlet (Fig. 1.2a). The transition qualities obtained using the correlations are tabulated in Table 4.1. It can be noticed that the critical transition qualities obtained from correlations proposed by Kim and Mudawar [34] and Harirchian and Garimella [33] are quite low and less likely to be applicable to the present design estimates. It was further noticed that, for low values of mass-flux ( $\left.\mathrm{G}<30 \mathrm{~kg} / \mathrm{m}^{2} \mathrm{~s}\right)$, Kim and Mudawar [34] correlation provided higher values of critical transition quality while the critical transition qualities obtained from correlation by Harirchian and Garimella [33] and flow-regime map by Mandhane et al. [35] were quite low $(<0.1)$. For the initial conservative estimate, it is then decided to set $X_{\text {in }}>$ 0.3 (as implied by flow-regime map of Mandhane et al. [35]). 
Table 4.1: Critical transition qualities from non-annular to annular flow-regime obtained using correlations for the channel height, $\left(h=5 \mathrm{~mm}\right.$, Fluid: $\mathrm{R}-123$ \& operating conditions: $\mathrm{p}_{\text {in }}=120 \mathrm{kPa}$; $\mathrm{G}=300 \mathrm{~kg} / \mathrm{m}^{2} \mathrm{~s} ; \overline{\mathrm{q}}_{\mathrm{w}}^{\prime \prime}=50 \mathrm{~W} / \mathrm{cm}^{2}$ )

\begin{tabular}{|c|c|}
\hline Flow regime transition correlations & Transition quality, $\mathrm{X}_{\mathrm{cr} \mid \mathrm{NA}-\mathrm{A}}$ \\
\hline Harirchian and Garimella [33] & 0.028 \\
\hline Kim and Mudawar [34] & 0.0483 \\
\hline Mandhane et al. [35] & 0.307 \\
\hline
\end{tabular}

(ii) For approximately realizing the assumed inlet film thickness $\Delta_{\text {in }}$ of around 300 $\mu \mathrm{m}$, first the vapor Reynolds number $\operatorname{Re}_{\mathrm{V}}\left(\equiv \mathrm{GXD}_{\mathrm{h}} / \mu_{2}\right)$ is calculated with $\mathrm{X}_{\mathrm{cr} \mid \mathrm{NA}-\mathrm{A}}$ as the initial guess of inlet quality $\mathrm{X}_{\mathrm{in}}$. This is to check if the vapor flow is laminar or turbulent. If the vapor flow is turbulent (and it is ensured that the liquid flows are still laminar), the adiabatic void-fraction correlations proposed by Zivi [36] and Rouhani and Axelsson [37] (with modifications for horizontal flows proposed by Steiner [38]) are used to calculate film thickness (note that void-fraction at the inlet $\epsilon_{\text {in|correlation }}=\left(\mathrm{h}-\Delta_{\text {in }}\right) / \mathrm{h}$ ). If the vapor flow is also laminar, void-fraction correlation proposed by Ranga Prasad et al. [16] may be used along with the ones mentioned earlier. Although all these above mentioned void-fraction correlations were originally proposed for adiabatic flows, their use in this case is, once again, justified since the flow is approximately adiabatic immediately after the splitter plate at the inlet (Fig. 1.2a). Using $X_{\mathrm{cr} \mid \mathrm{NA}-\mathrm{A}}$ as the first guess, the corresponding film thicknesses values are calculated using the above mentioned void-fraction correlations. Next, the inlet quality value is typically increased to values higher than $\mathrm{X}_{\mathrm{cr} \mid \mathrm{NA}-\mathrm{A}}$ until the mean film thickness calculated from the chosen correlations gives a value of around $300 \mu \mathrm{m}$ or less. However, since these are semiempirical correlations with large uncertainties, the mean of the different film thicknesses obtained from the three different correlations above is actually considered the final film thickness value. The final inlet film thickness value, 
for this example, is estimated to be $299.9 \mu \mathrm{m}$ and the corresponding inlet quality is found to be $0.405\left(>X_{\text {cr|NA-A }}\right)$.

(iii) For this inlet quality, using the space available for the vapor flow above the splitter plate (3.7 $\mathrm{mm}$ for the current case), the vapor velocity and its ratio relative to the speed of sound is calculated. For the current case, it is found to be 0.17 . If the ratio of inlet vapor speed to the speed of sound is more than 0.28 (conservatively chosen to be less than 0.33 ), it is suggested that, initially, the mass-flux $\mathrm{G}$ be reduced (which essentially means changing the initially guessed operating condition) and steps (i) to (ii) be repeated. If that is not feasible, the height of the channel may also be increased so that the ratio of the vapor speed to sound speed is reduced.

(iv) If the compressibility effect constraint (i.e., Mach number $<0.28$ ) is satisfied at the inlet, assuming an arbitrarily high exit quality (say, 0.98 ) for a sufficiently long boiler, and then using Nusselt number correlation(s), the heat transfer coefficient values for a linear range of qualities (implied by Eq. (2.19) and uniform heat-flux assumptions) are calculated, along with their nucleate boiling $\left(\mathrm{h}_{\mathrm{nb}}\right)$ and convective boiling $\left(\mathrm{h}_{\mathrm{cb}}\right)$ components. For the current design problem, the correlation proposed by Kim and Mudawar [17] is used. The total heat-transfer coefficient $h_{x}$ for the full range of quality is calculated. The film thickness values for these qualities can be estimated by neglecting micronucleation effects on mean film thickness (these effects are included in $\mathrm{h}_{\mathrm{x} \mid \mathrm{cb}}(\mathrm{x})$ ) and ignoring macro-nucleation effects (modeled by $\mathrm{h}_{\mathrm{x} \mid \mathrm{nb}}$ ) by using the formula:

$$
\Delta(\mathrm{x}) \cong \frac{\mathrm{k}_{\mathrm{L}}}{\mathrm{h}_{\mathrm{x} \mid \mathrm{cb}}(\mathrm{x})}
$$

provided $\mathrm{h}_{\mathrm{x} \mid \mathrm{cb}}$ values proposed by Kim and Mudawar [17] can be trusted (Eq. (3.2) provides a scientifically more accurate estimation of $h_{x \mid c b}$ ). However, it should be noted that, this correlation (in fact most correlations) is semi- 
empirical in nature and obtained from curve-fitting available data for the total $h_{x}$ values. So, while the total heat transfer coefficient $h_{x}$ value might be approximately correct to within a certain percentage, the nucleate boiling and convective boiling term decomposition making up the total is arbitrary and (as discussed in Sections 1.2 and 3.2 and by Ranga Prasad et al. [16]) in all likelihood not correct. See Fig. 4.2a for such an initial decomposition provided by correlation from Kim and Mudawar [17]. Therefore, a correction factor is introduced. The correction factor $\alpha_{c}$ is defined as the ratio of inlet film thickness calculated using void-fraction models (in step (ii)) and the inlet film thickness calculated using convective boiling heat transfer coefficient term $\mathrm{h}_{\mathrm{x} \mid \mathrm{cb}}$ (as in Eq. (4.1) i.e., $\alpha_{\mathrm{c}} \equiv \Delta_{\mathrm{in} \text {-void-fraction-method }} / \Delta_{\mathrm{in}-\mathrm{h} \mid \mathrm{x}-\mathrm{cb}}$ ). This is done because it is assumed that the void-fraction models provide more reliable estimate of film thickness value at the inlet because of the presence of adiabatic type conditions. For the present case, the correction factor $\alpha_{c}$ was found to be 7.55. It is then assumed that this can be used to better evaluate the convective component of heat transfer coefficient at the inlet (through $\mathrm{h}_{\mathrm{x} \mid c \text { b,in-2 }} \cong \mathrm{k}_{\mathrm{L}} / \Delta_{\text {in-void-fraction-method }}$ ) because this is a more reliable order of magnitude estimate. Therefore, the convective boiling term $\mathrm{h}_{\mathrm{x} \mid \mathrm{cb}}$ in the correlation proposed by Kim and Mudawar [17] is only approximate and can vary within a range bounded by the second estimate of $\mathrm{h}_{\mathrm{x} \mid \mathrm{cb}-2}=\mathrm{h}_{\mathrm{x} \mid \mathrm{cb}} / \alpha_{\mathrm{c}}$ - as obtained by correcting the Kim and Mudawar [17] values by simply dividing it by correction factor $\alpha_{c}$. The nucleate boiling contribution term is calculated assuming that the total heat transfer coefficient, which is experimentally known to be of reasonable accuracy, through relations such as: $h_{x \mid n b-2}=$ $\mathrm{h}_{\mathrm{x}}-\mathrm{h}_{\mathrm{x} \mid \mathrm{cb}-2}$ or $\mathrm{h}_{\mathrm{x} \mid \mathrm{nb}-2}=\sqrt{\mathrm{h}_{\mathrm{x}}^{2}-\mathrm{h}_{\mathrm{x} \mid \mathrm{cb}-2}^{2}}$ depending on whether $\mathrm{n}=1$ or $\mathrm{n}=2$ was originally used to decompose $h_{x}$ between $h_{x \mid n b}$ and $h_{x \mid c b}$. 
(v) Using the new corrected convective boiling $\mathrm{h}_{\mathrm{x} \mid \mathrm{cb}-2}$ term, still for the whole range of quality set in step (iv), the new corresponding film thickness $\Delta_{2}(\mathrm{x})$ values are calculated (using Eq. (4.1) given in step (iv)) as a function of quality $X$. Further, using the vapor height above the exit film thickness $\left(\Delta_{\text {exit }}=\Delta_{2}(\mathrm{~L})\right)$, the vapor speed and its ratio with respect to the speed of sound are calculated for the exit location $\mathrm{x}=\mathrm{L}$. Now with the knowledge of film thickness as a function of quality and quality variation along the length of the channel, this step is iterated until an exit quality and a corresponding length $\mathrm{L}$ is found such that, the Mach number at the exit is equal to or less than 0.28 and the exit film thickness is greater than or equal to one-fifth of inlet film thickness $\left(\Delta_{\text {in }} / 5\right)$. This quality is considered as maximum exit quality and the corresponding channel length, is considered the maximum possible length $\mathrm{L}_{\max }$. The exit quality and maximum length thus calculated for the present design problem are 0.89 and $0.24 \mathrm{~m}$ respectively. The variation of quality along the length of the channel is plotted in Fig. 4.1. The heat transfer coefficient values, for the range of qualities between the inlet and the exit, along with the two estimates of their component terms $\left(\mathrm{h}_{\mathrm{x} \mid \mathrm{nb}}\right.$ and $\left.\mathrm{h}_{\mathrm{x} \mid \mathrm{cb}}\right)$, are plotted in Fig. 4.2. The film thickness values along the length of the channel (for the same quality range), calculated using convective boiling heat transfer coefficient $h_{x \mid c b-2}$ term, are plotted in Fig. 4.3. Using total heat transfer coefficient values, wall temperature values are calculated using Eq. (2.4) and are plotted in Fig. 4.4.

A few important points to note are as follows:

(a) It is first assumed that the pressure drop is quite low compared to the inlet pressure and therefore the speed of sound at the exit is calculated using the inlet pressure.

(b) The length calculated here is the maximum permissible length that would satisfy the constraints. However, as a conservative measure, it is 
suggested that the length of the channel could be a fraction (say, 0.7) of the maximum length $L_{\max }$ calculated earlier and that fraction should be further reduced with increasing mean heat-flux $\left(\overline{\mathrm{q}}_{\mathrm{w}}^{\prime \prime}\right)$ values.

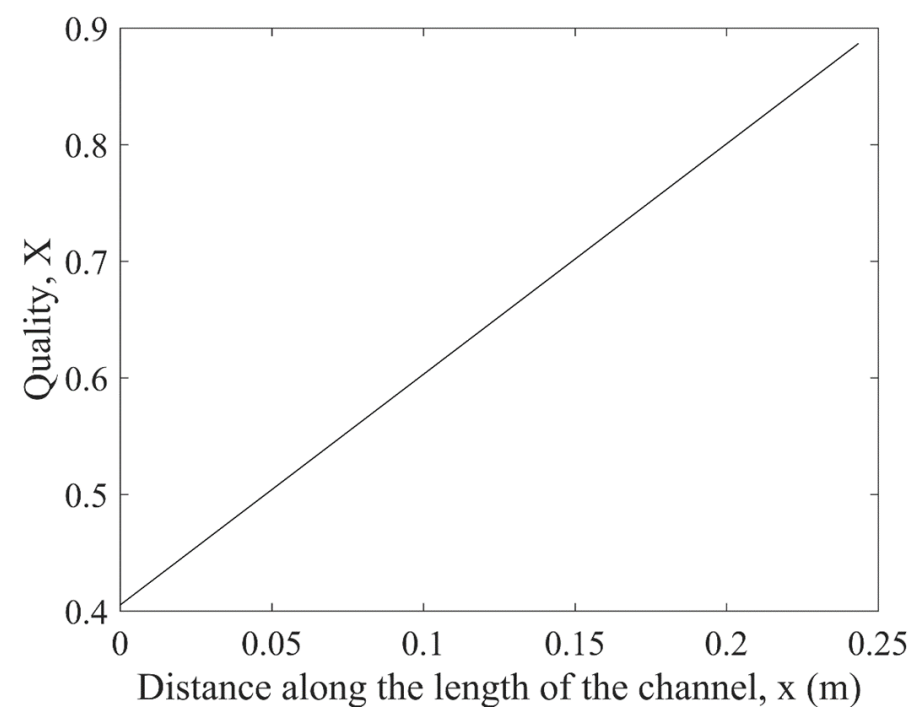

Fig 4.1: Variation of quality $\mathrm{X}$ along the length of the channel.

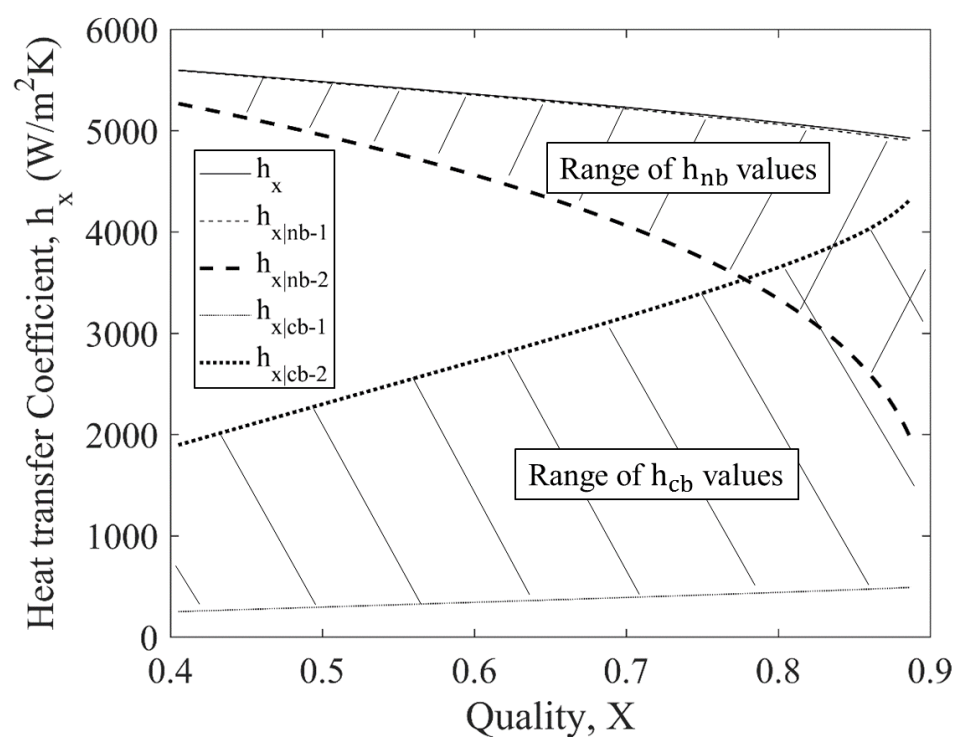

Fig 4.2: Variation of heat transfer coefficients with quality - calculated using correlation proposed by Kim and Mudawar [17] along with the decomposition of $h_{x}$. The decomposition of $h_{x}$ using the correlation are given as $\mathrm{h}_{\mathrm{x} \mid \mathrm{nb}} \equiv \mathrm{h}_{\mathrm{x} \mid \mathrm{nb}-1}$ and $\mathrm{h}_{\mathrm{x} \mid \mathrm{cb}} \equiv \mathrm{h}_{\mathrm{x} \mid \mathrm{cb}-1}$. The component terms of $\mathrm{h}_{\mathrm{x}}$ after the introduction of correction factor $\alpha_{c}$ are $h_{x \mid n b-2}$ and $h_{x \mid c b-2}$. The actual values of the $h_{x \mid n b}$ are expected to lie between $h_{x \mid n b-1}$ and $h_{x \mid n b-2}$ while and $h_{x \mid c b}$ actual values of $h_{x \mid c b}$ are expected to lie between $\mathrm{h}_{\mathrm{x} \mid \mathrm{cb}-1}$ and $\mathrm{h}_{\mathrm{x} \mid \mathrm{cb}-2}$. 


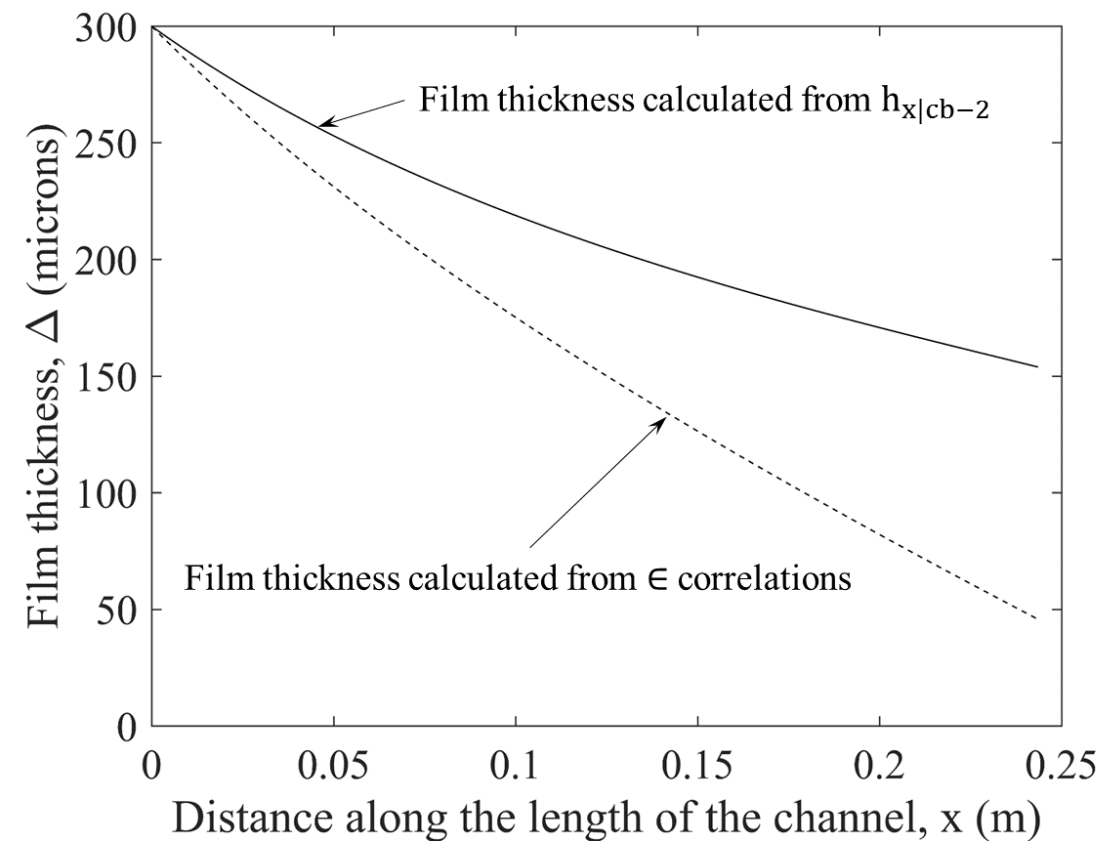

Fig 4.3: Variation of liquid film thickness $\Delta$ along the length of the channel - calculated from voidfraction correlations and corrected convective boiling term of heat transfer coefficient $\mathrm{h}_{\mathrm{x} \mid \mathrm{cb}-2}$ using Eq. (4.1).

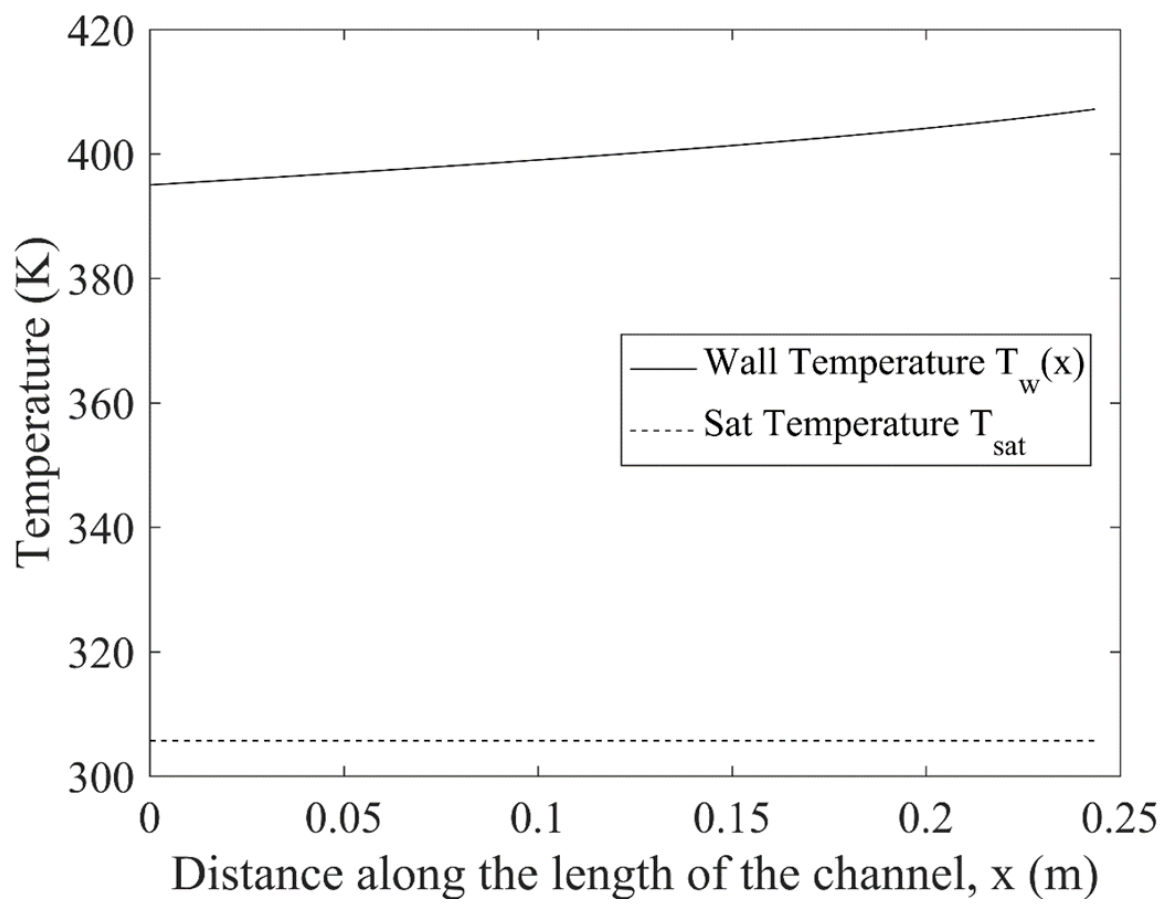

Fig 4.4: Variation of wall temperature $\mathrm{T}_{\mathrm{w}}(\mathrm{x})$ along the length of the channel - calculated from total heat transfer coefficient using Eq. (2.4). 
(vi) Pressure drop calculations usually involve three different components and the total pressure drop $\Delta \mathrm{p}_{\mathrm{T}}$ is the sum of Accelerational (or decelerational) pressure drop $\Delta \mathrm{p}_{\text {acc }}$, Frictional pressure drop $\Delta \mathrm{p}_{\text {fric }}$ and gravitational pressure drop $\Delta \mathrm{p}_{\mathrm{g}}$ (as given in Eq. (4.2)).

$$
\Delta \mathrm{p}_{\mathrm{T}} \equiv \int_{0}^{\mathrm{L}}\left(-\frac{\partial \mathrm{p}}{\partial \mathrm{x}}\right)_{\text {fric }} \cdot \mathrm{dx}+\int_{0}^{\mathrm{L}}\left(-\frac{\partial \mathrm{p}}{\partial \mathrm{x}}\right)_{\mathrm{g}} \cdot \mathrm{dx}+\int_{0}^{\mathrm{L}}\left(-\frac{\partial \mathrm{p}}{\partial \mathrm{x}}\right)_{\mathrm{acc}} \cdot \mathrm{dx} \equiv \Delta \mathrm{p}_{\text {fric }}+\Delta \mathrm{p}_{\mathrm{g}}+\Delta \mathrm{p}_{\text {acc }}
$$

The Gravitational component of pressure drop is calculated only for vertical (upward or downward) flows and doesn't contribute to overall pressure drop for horizontal flows of interest here. The accelerational pressure drop is calculated using Eq. (4.3) given below and is dependent on the choice of voidfraction $\epsilon$ correlation (Zivi [36] in this case) and not on $\mathrm{Nu}_{\mathrm{x}}$ correlation, as this case involves uniform heat-flux with linear $\mathrm{X}(\mathrm{x})$ variations.

$$
\left(-\frac{\partial \mathrm{p}}{\partial \mathrm{x}}\right)_{\mathrm{acc}}=\mathrm{G}^{2} \frac{\mathrm{d}}{\mathrm{dx}}\left[\frac{\mathrm{X}(\mathrm{x})^{2}}{\rho_{\mathrm{V}} \cdot \epsilon}+\frac{(1-\mathrm{X}(\mathrm{x}))^{2}}{\rho_{\mathrm{L}} *(1-\epsilon)}\right]
$$

The frictional pressure drop is calculated using three different correlations viz. Friedel [39], Grönnerud [40] and Lockhart and Martinelli [41]. This is done to get a range of possible frictional pressure gradient values which, as seen in Fig. $4.5 \mathrm{a}$, have wide variations despite the fact that they are based on the easier correlations of experimental data obtained from adiabatic two-phase flows. For the calculated/identified quality variations between the inlet and the exit, both acceleration and frictional pressure drops are calculated along the length of the channel. The total and their corresponding frictional pressure drop values (relative to the inlet pressure) along the length of channel are plotted in Fig. 4.5b. For present purposes, it is assumed that using flowboiling based $\mathrm{X}(\mathrm{x})$ values in these adiabatic flows based frictional pressuregradient correlations, will suffice for order of magnitude estimates. However, for further calculations, as a conservative measure, the highest of the 
frictional pressure-drop values is chosen. The final exit pressure (including momentum/acceleration pressure drop) is, for this example, $107.93 \mathrm{kPa}$.

(vii) Using the chosen inlet pressure and the exit pressure, along with vapor velocities (calculated in steps (iii) and ( $v$ ) for the inlet and the exit respectively), and the corresponding cross-sectional areas; net output power per unit channel width for the test section (as discussed in constraint (vi) of Section 4.1.1) is calculated and is found to be $9.3 \mathrm{~kW} / \mathrm{m}$. The vapor compressor power per unit width of the section is conservatively estimated as $1.2 \times\left[p_{\text {in }}-p_{\text {out }}\right] \times v_{\text {in }} * h \cong 1.6 \mathrm{~kW} / \mathrm{m}$. Since the net mechanical power input from the compressor is less than the mechanical power output, the flowboiler design operation is considered energy efficient.

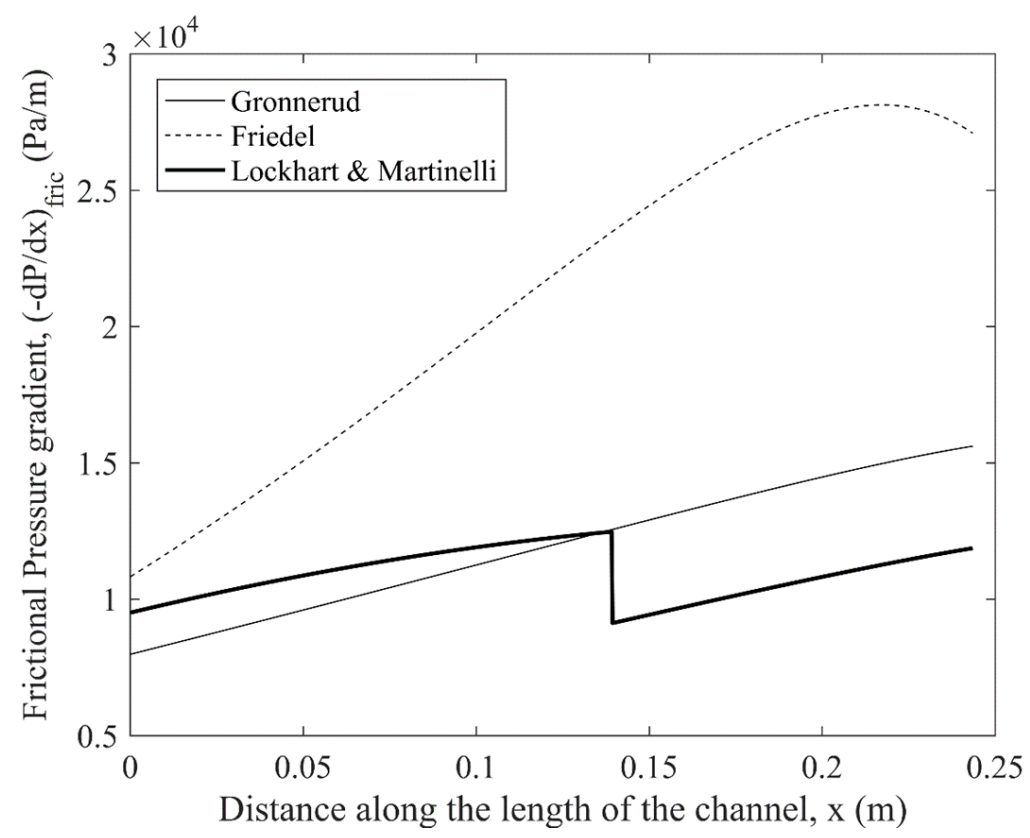

(a) 


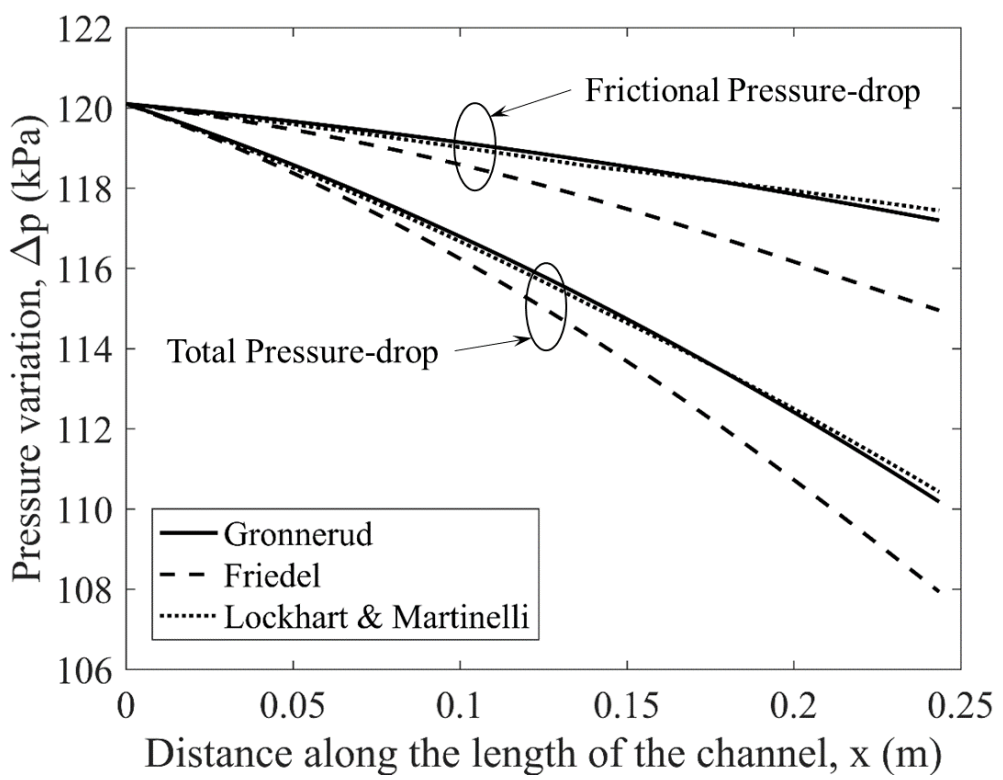

(b)

Fig. 4.5: (a) Variation of frictional pressure gradient along the length of the channel - calculated from Gronnerud [40], Friedel [39] and Lockhart \& Martinelli [41] pressure-drop correlations. (b) Variation of pressure - because of both frictional pressure drop and overall pressure drop - along the length of the channel. The three curves from the three models are closer together than in part (a). This is because of dominance of accelerational pressure-drop in Eq. (4.2).

\subsection{Design of millimeter-scale annular flow-condensers}

Design of the steady annular innovative operation of condenser shown in Fig. 1.2b is discussed in this section. Because of factors such as absence of CHF, inlet quality of vapor flows being $X \cong 1$, etc., the number of constraints in the design of steady annular flow-condenser operations is relatively less as compared to that of steady annular flow-boiler operations.

4.2.1 Desired specifications, constraints, and information/knowledge needed for meeting the requirements

This section discusses some of the constraints involved in the design of flowcondensers that may be required to operate in the thin liquid steady annular flowregime. Such condensers can, in principle, be converted to high heat-flux compact devices by superposing a pulsatile flow-physics - described in [9]. 
(i) It is important to know the transition quality from annular to non-annular flowregimes so that the exit quality can be adjusted and kept above the transition quality, with the help of the passively recirculating vapor as in Fig. 1.2b. Using this strategy, non-annular flow regimes (associated with high pressure drop and poorer heat transfer rates) can be avoided - all the way up to the exit of the condenser in Fig. 1.2b. For this, some appropriate flow-regime maps, as in Section 4.1.2, are used.

(ii) The total inlet Reynolds number $\left(\operatorname{Re}_{\mathrm{in}}=\mathrm{Re}_{\mathrm{T}} \equiv \mathrm{GD}_{\mathrm{h}} / \mu_{\mathrm{V}}\right)$ needs to be computed for the chosen mass-flux $G$. This number is directly or indirectly required to evaluate any of the suitable Nusselt number correlations for flow-condensers, and, obtain quality variations along the length of the channel for, say, a known wall temperature case for specifying the "method of cooling." Further, for the known temperature specifying the "method of cooling," appropriate local Nusselt number correlation(s) would be required and should be used to get an order of magnitude estimate of the local heat transfer coefficient $h_{x}$, local heat flux $\mathrm{q}_{\mathrm{w}}^{\prime \prime}(\mathrm{x})$, and the quality $\mathrm{X}(\mathrm{x})$ variations along the length of the channel (obtained from using Eq. (2.18)).

(iii) Unlike the earlier case of flow-boiling, the mechanical power in the vapor flow at the exit is, typically, lower than the mechanical power available in the vapor flow at the inlet. This is because of reduction in velocity along the length of the channel. However, the design should be optimized such that the reduction in velocity is minimal, and, consequently the loss in mechanical power in vapor is also reduced - which is a relatively easy task for these millimeter-scale steady annular operations.

(iv) The length L of the condenser should be chosen such that exit liquid film thickness $\Delta(\mathrm{L})$ is less than say, $200 \mu \mathrm{m}$.

(v) Some of the parameters that are to be initially chosen and then varied to optimize the design are as follows: mass flux $\mathrm{G}$, height of the channel $\mathrm{h}$, length of the channel $\mathrm{L}$, inlet pressure $\mathrm{p}_{\mathrm{in}}$, wall temperature $\mathrm{T}_{\mathrm{w}}=\overline{\mathrm{T}}_{\mathrm{w}}$, etc. 
4.2.2 Implementation of a sample design methodology - meeting the requirements given in "Section 4.2.1" and leading to results for annular flow-condenser operations

For a chosen working fluid, a range of inlet pressures $\mathrm{p}_{\mathrm{in}}$, mass fluxes $\mathrm{G}$, and mean wall temperatures $\bar{T}_{w}$ are to be initially considered. These can later be optimized, based on constraints mentioned above or based on other specific and additional design requirements. However, similar to the flow-boiling design methodology, a particular combination of inlet pressure, total mass-flux and mean wall temperature is initially chosen as a specific operating condition around which all variations are to be considered. For the present case, the following parameters are chosen: Fluid is R-123; Channel height is $\mathrm{h}=5 \mathrm{~mm}$; Inlet pressure is $\mathrm{p}_{\text {in }}=105.1 \mathrm{kPa}$; Total mass-flux is $G=300 \mathrm{~kg} / \mathrm{m}^{2} \mathrm{~s}$; and the mean wall temperature is $\bar{T}_{\mathrm{w}}=382 \mathrm{~K}$, which corresponds to a cooling temperature difference of $\Delta \mathrm{T}=60 \mathrm{~K}$.

(i) For the chosen operating condition, the critical quality of transition from annular to non-annular flow regimes $\left(\mathrm{X}_{\mathrm{cr} \mid \mathrm{NA}-\mathrm{A}}\right)$ is calculated from available flow regime maps, some of which have been discussed in [9]. Flow regime transition maps should be appropriately chosen with the working fluid, the orientation (horizontal, vertical or inclined) of the channel, and $\mathrm{mm} / \mathrm{\mu m}$ hydraulic diameter scale of the channel considered for selecting relevant maps in the literature. For the present case, flow-regime transition criterion proposed by Kim and Mudawar [34] and flow regime map proposed by Mandhane et al. [35] have been used. The critical transition qualities obtained from these flow-regime criteria are 0.046 and 0.273 respectively. Again, as in the design of annular flow- boilers (in Section 4.1.2), the value obtained from the criterion proposed by Kim and Mudawar [34] is unacceptably low for this high mass-flux case even though the same correlation was found to have yielded reasonable estimates for the lower mass-fluxes $\left(\mathrm{G}<50 \mathrm{~kg} / \mathrm{m}^{2} \mathrm{~s}\right)$. The highest of the qualities obtained from these two criteria is tentatively 
considered as the critical quality of transition from annular to non-annular flow-regime. Furthermore, as a conservative measure, since the exit quality should be more than the critical transition quality, an even higher value (say, by $\Delta \mathrm{X}=0.05$ to 0.1 ) than the estimated critical value of transition quality is chosen to be the exit quality (i.e., say $X_{\text {out }} \cong X_{\text {cr|NA-A }}+0.1$ ). The chosen exit quality for the present case, at this step, is 0.373 .

(ii) Assuming an inlet quality of 1 (or slightly less, say 0.99) and using the knowledge of the exit quality calculated/identified from step (i) above, the local heat transfer coefficient values for qualities between the inlet and exit qualities can be obtained by using Nusselt number correlation(s) - similar to the ones proposed by Kim and Mudawar [34] - which can be directly evaluated and plotted (see Fig. 4.6) with values of $X$ varying between the inlet and the exit qualities. The kink in Fig. 4.6, which in reality will be a gradual smoothed curve, is due to reduction in vapor quality from its inlet value of 1 and is associated with vapor-phase transitioning from turbulent to laminar. The Nusselt number correlations, along with inlet and exit qualities can also be used to calculate the length of the channel $\mathrm{L}$, by obtaining quality versus distance $X(x)$ variations by integrating Eq. (2.18) subject to the inlet value of $X(0)=X_{i n}$. For the chosen exit quality $X(L)=X_{\text {out }}$, $L$ is found to be $0.59 \mathrm{~m}$. However, it should be noted that this would be the maximum possible length of the channel and considerations should be given to the fact that it is to operate in the annular flow-regime, preferably with negligible entrainment. In addition, the test-section might have to operate for multiple operating conditions and all of the conditions should be taken into consideration before finally deciding on the length of the channel. For the chosen operating condition, however, the variation of quality along the length of the channel, as obtained from integrating Eq. (2.18), is shown in Fig. 4.7. The heat transfer coefficient values calculated above (see Fig. 4.6) can also be used to 
calculate the local wall heat-flux $\left(\mathrm{q}_{\mathrm{w}}^{\prime \prime}(\mathrm{x})\right)$ values, by using Eq. (2.4). This is done and the results are plotted in Fig. 4.8.

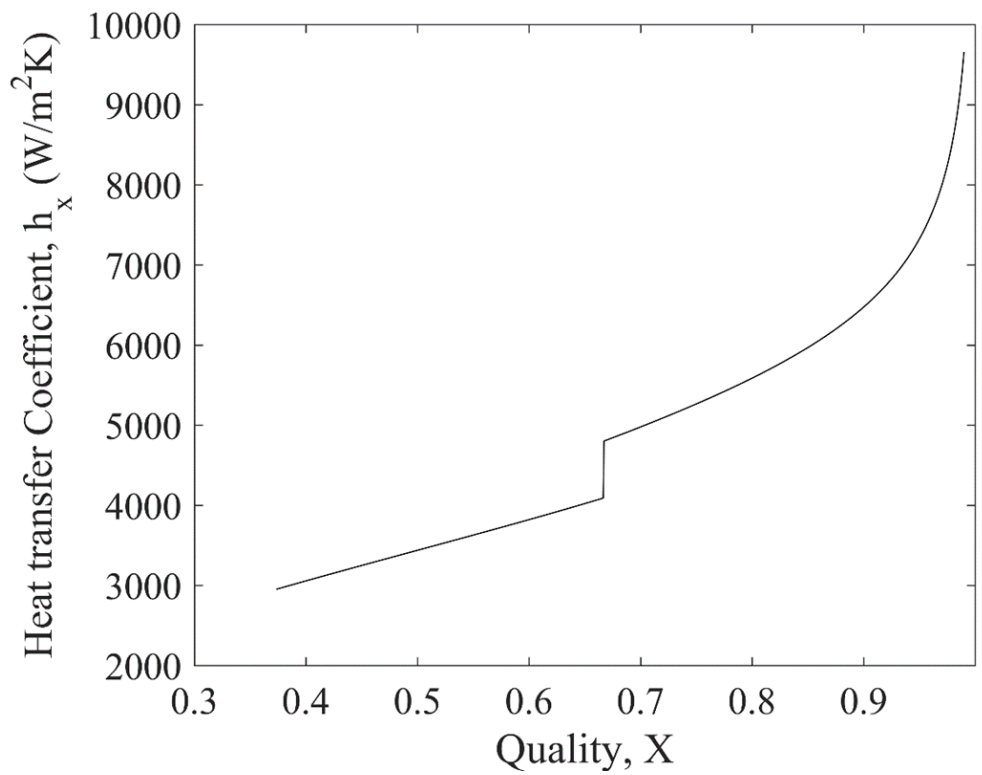

Fig 4.6: Variation of heat transfer coefficients with quality - calculated using correlation proposed by Kim and Mudawar [34].

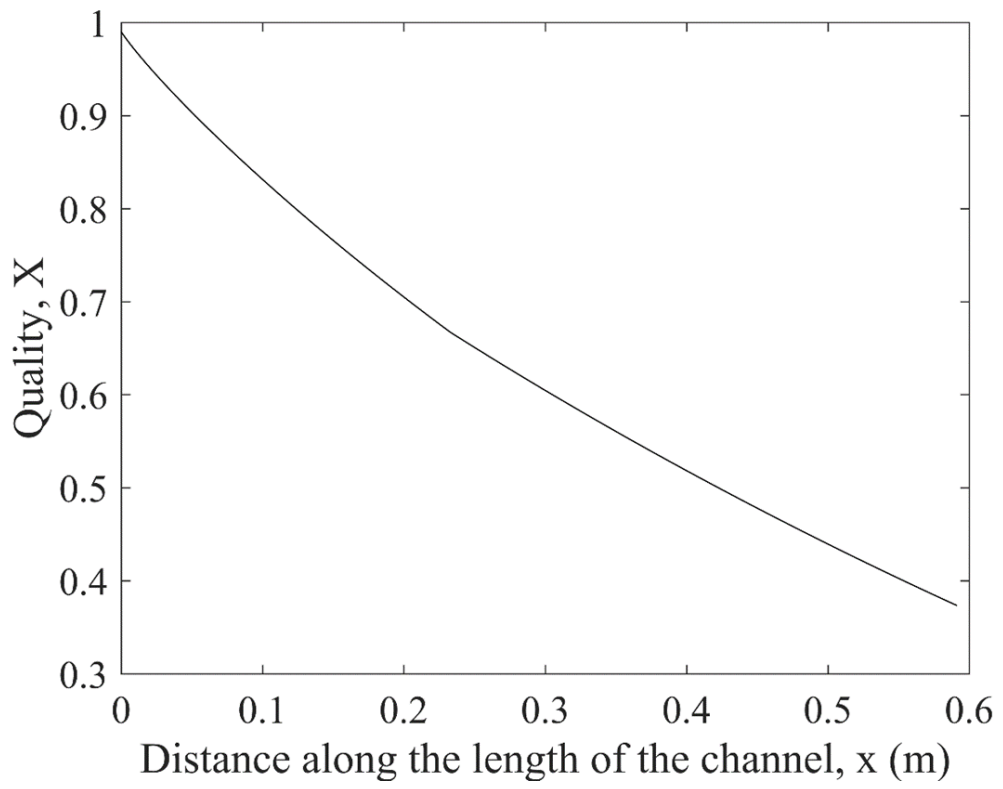

Fig 4.7: Variation of quality $X$ along the length of the channel calculated using Eq. (2.18). 


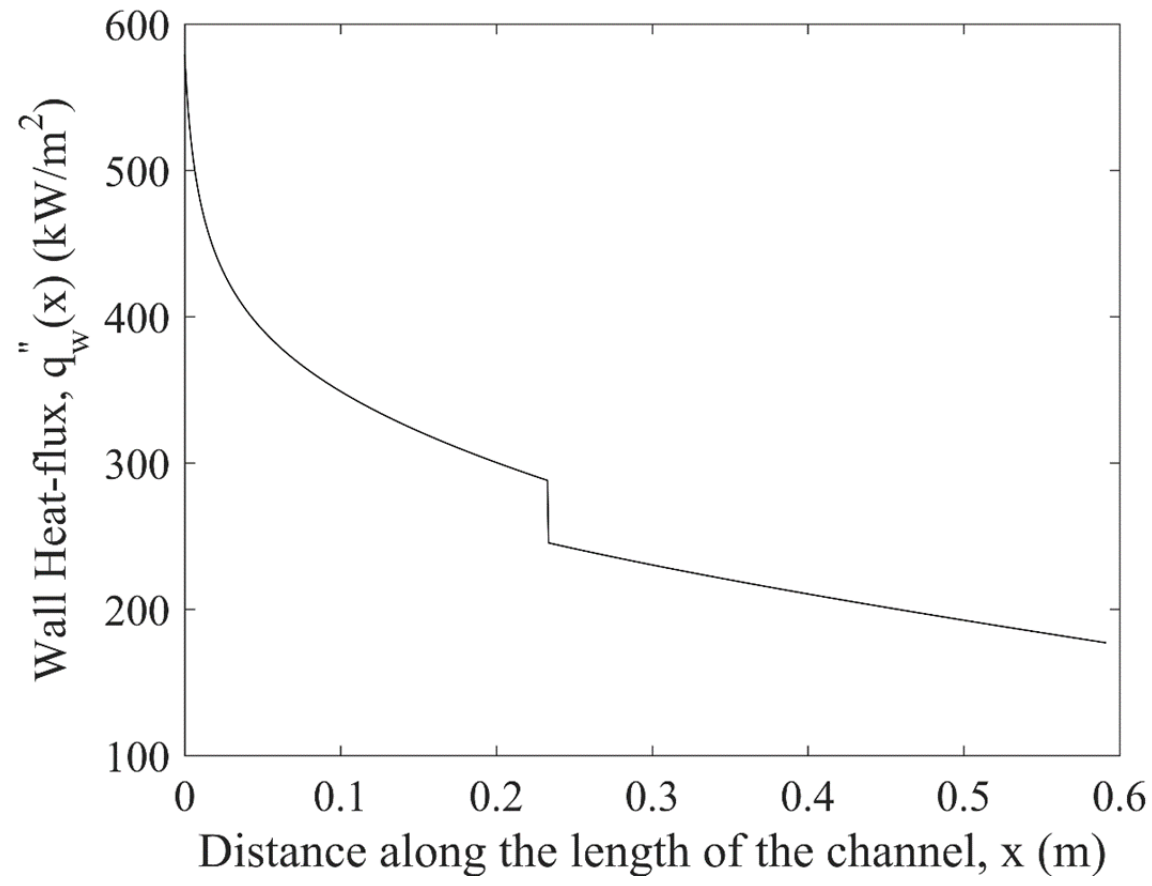

Fig 4.8: Variation of wall heat-flux $\mathrm{q}_{\mathrm{w}}^{\prime \prime}(\mathrm{x})$ along the length of the channel - calculated from total heat transfer coefficient using Eq. (2.4).

(iii) Using the inlet and the exit qualities, the pressure-drop/rise can be calculated using appropriate correlation(s). For this design, to get an estimate of changes in pressure along the length of the channel, frictional pressure drop correlations proposed by Friedel [39], Grönnerud [40] and Lockhart and Martinelli [40] were chosen and used. The accelerational pressure variation is calculated using Eq. (4.3). The reasons for the variations in frictional pressure gradient estimates of different models, as shown in Fig. 4.9 a, are the same as those discussed for Fig. 4.5a. The net pressure variations (and its frictional component) along the length of the channel, calculated using the three chosen correlations for frictional pressure are plotted in Fig. 4.9b. The final exit pressure, for $\mathrm{L}=0.59 \mathrm{~m}$, is found, by considering the maximum (Friedel correlation [39]) of the three total (frictional + accelerational) pressure drop values, to be approximately $102.8 \mathrm{kPa}$. However, it can be seen in Fig. $4.9 \mathrm{~b}$ that the other two pressure drop models predict pressure rise. Such rise 
in pressures (given $\mathrm{p}_{\text {in }}=105.1 \mathrm{kPa}$ ) are possible in condensing flow operations due to vapor deceleration effects. However, as mentioned in Section 4.2.1, the design calculations should be done for different operating conditions and pressure-drop (or rise) may be optimized, if needed, to minimize the reduction in mechanical power in the vapor (along with any other specific design constraint (s) that may also need to be imposed).

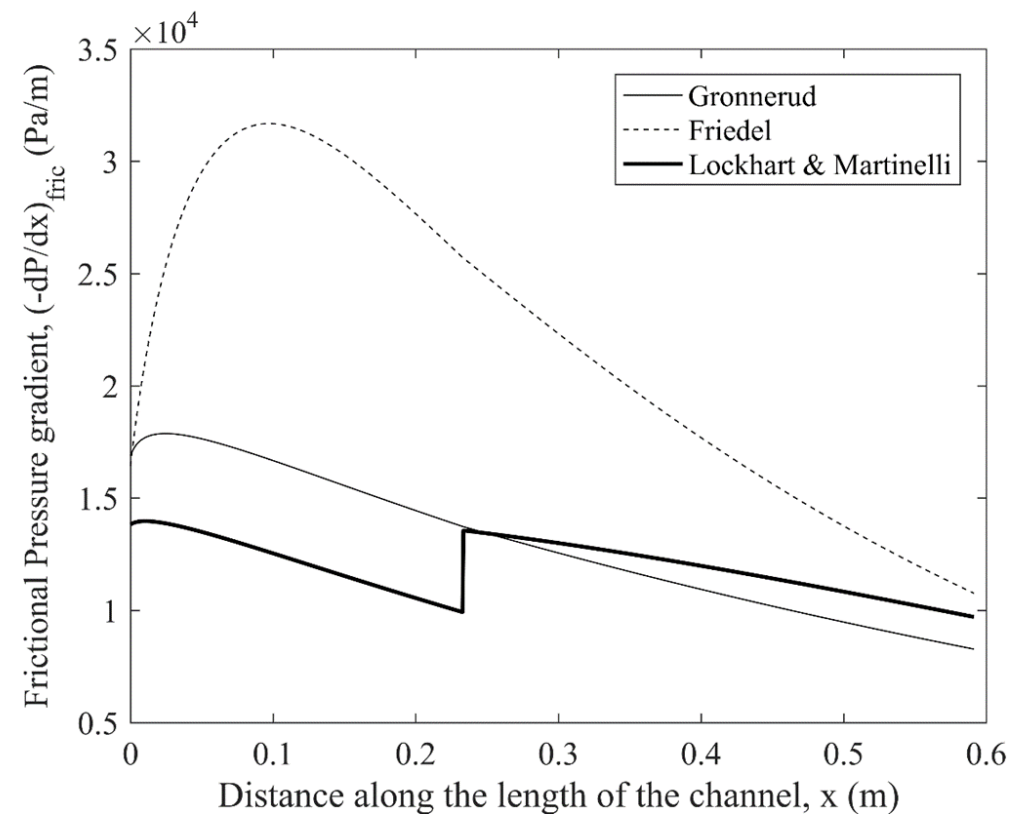

(a) 


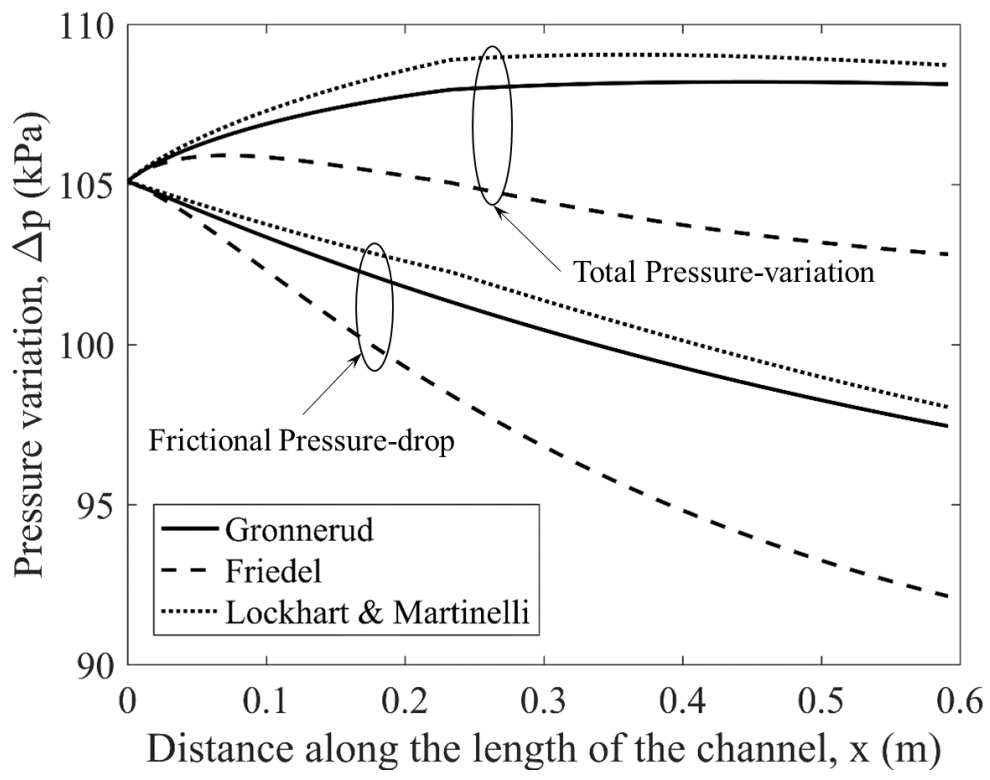

(b)

Fig 4.9: (a) Variation of frictional pressure gradient along the length of the channel - calculated from Gronnerud [40], Friedel [39] and Lockhart \& Martinelli [41] frictional pressure-drop correlations. (b) Variation of pressure along the length of the channel due to both frictional pressure variation and total pressure variation. The overall pressure value rises with distance $\mathrm{x}$ for two of the three models. The total pressure variation values from the three models are higher than that of frictional pressure variation because of decelerational pressure variation in Eq. (4.3).

\section{Modification of Design Methodology Discussed in Section 4.1 and Comparison of Experimental Results with that of CFD Simulations}

In Section 3, features of 2-D CFD simulation of annular flow-boiling, with hypothetically assumed suppression of nucleation, were discussed. Some of the preliminary results and correlations developed from the simulation were shown later on in the section.

In Section 4, general first order estimates-methodologies for design of annular flow-boilers and flow-condensers were discussed.

Present section discusses some of the ways to use (and modify, if required) the design methodologies discussed in Section 4.1 - to design experiments using 
appropriate operating conditions and the correlation reported in Eq. (3.2) - to evaluate the data gathered from such experiments.

\subsection{Modification of the Design Methodologies (Discussed in Section 4.1) for the Available Test-Section}

The methodologies for designing of annular flow-boilers, presented in Section 4.1, were generic in nature. For a particular operating condition - a combination of inlet pressure $p_{i n}$, mass-flux $G$ and mean heat-flux $\bar{q}_{w}^{\prime \prime}$ or mean wall temperature $\bar{T}_{w}$ (depending on the "method of heating") - the design allowed the calculation of maximum possible length $\mathrm{L}_{\max }(\operatorname{step}(\mathrm{v})$ in Section 4.1 ) and the range of qualities within which the test-section can be operated. However, if the length of the channel is fixed and/or if other constraints/limitations are present, the methodologies would have to be modified to address the differences. One such experimental test-section and necessary modifications to choose appropriate operating conditions to conduct flow-boiling experiments using that test-section are discussed below.

The test-section is a channel with rectangular cross-section and has a length $\mathrm{L}$ of $0.5 \mathrm{~m}$, width w of $15 \mathrm{~mm}$, height $\mathrm{h}$ of $2 \mathrm{~mm}$ and the heat-exchange surface is the bottom plate. Typically, FC-72 is used as the working fluid for the test-section. Apart from the fact that length of the current test-section is fixed, a major difference between the current test-section and the one used for discussions in Section 4.1 is the "method of heating." In the current test-section, the "method of heating" is defined by known wall temperatures, while the design methodology in Section 4.1 assumed known heat-flux "method of heating." Further, a major limitation of the current experimental test-section is the temperature difference $\Delta \mathrm{T}$, and consequently the heat-flux $\overline{\mathrm{q}}_{\mathrm{w}}^{\prime \prime}$, that it is designed to handle. The instrumentation in the experimental set-up, and the test section itself, can only handle lower values of heat-flux $\bar{q}_{w}^{\prime \prime}$ and consequently the flow variables/operating conditions for the experiments have to be chosen accordingly. Other details of test-section along with the whole experimental setup are discussed in [13, 22, 32]. 
While all the constraints and most of the steps in design methodologies discussed in Section 4.1 hold true for the current test-section, some of the modifications necessary to address the differences in "method of heating" and the fixed length of test-section are as follows:

(i) The "method of heating" used in design methodology discussed in Section 4.1 was defined by known-heat-flux values and thus resulted in linear quality variation (see Step (iv) of Section 4.1.2 and Fig. 4.1) as implied by Eq. (2.19). However, for the current test-section, as mentioned earlier, the "method of heating" is defined by known wall-temperature values and thus the variation of quality with distance $\mathrm{X}(\mathrm{x})$ will be dictated by Eq. (2.18), which will not necessarily be linear. Also, because of the known wall temperature "method of heating," the operating condition for the current test-section is defined by a combination of inlet pressure $p_{\text {in }}$, mass-flux $G$, and mean wall temperature $\overline{\mathrm{T}}_{\mathrm{w}}$.

However, incorporating Eq. (2.18) to calculate quality variations is not straight forward since Eq. (2.18) includes Nusselt number values in the formula and most Nusselt number correlations are only available for known heat-flux "method of heating" and are typically of the form of Eq. (2.9) or (2.12) or (2.14). This gives rise to a difficult case where it is necessary to use Nusselt number correlation of the form of Eq. (2.14) or equivalent (i.e., a function of heat-flux $\bar{q}_{w}^{\prime \prime}$ or its non-dimensional equivalent Boiling number $\mathrm{Bl}$ ) for a "method of heating" defined by known wall temperature (and thus unknown heat-flux $\bar{q}_{\mathrm{w}}^{\prime \prime}$ ). This requires an initial assumption of mean heatflux that is constant throughout the test section. Further, as discussed earlier, the test section was designed to handle only lower values of heatflux and thus this initial assumption of mean heat-flux $\overline{\mathrm{q}}_{\mathrm{w}}$, should be chosen accordingly. The algorithm for using such cases was discussed towards the end of Section 2.4. Such a solution was implemented for designing the 
experiments, and choosing the appropriate flow variables for the current test section.

(ii) The length of the current test-section is fixed at $0.5 \mathrm{~m}$, while the design methodology in Section 4.1 calculated the maximum possible length of the test-section for a particular operating condition. Therefore, in the design methodology for the current test-section, only the operating conditions that yield a value of maximum length higher than that of the length of the testsection are considered for further steps - i.e., $\mathrm{L}_{\max }>\mathrm{L}$.

Once the maximum possible length is calculated, and found to be less than the length of the channel, the inlet quality, calculated in Step (ii) of Section 4.1.2, would become the minimum inlet quality $X_{\mathrm{in} \text {,min }}$ and the exit quality, calculated in Step (v) of Section 4.1.2 would become the maximum exit quality $\mathrm{X}_{\text {out,max }}$. The minimum exit quality $\mathrm{X}_{\mathrm{out} \text {,min }}$ and maximum inlet quality $X_{\text {in,max }}$, corresponding to minimum inlet quality $X_{i n, m i n}$ and maximum exit quality $\mathrm{X}_{\text {out,max }}$ respectively, can then be calculated with the knowledge of length of the test-section L and energy balance (either Eq. (2.18) in the present case). This would effectively give a range of inlet qualities (and a corresponding range of exit qualities) for a given operating condition. However, it is suggested, as a conservative measure, that the minimum quality or a quality value near the minimum quality be chosen for any particular experiment.

\subsection{Suggested Operating Conditions Using the Modified Design Methodology Described in Section 5.1}

The design methodology discussed in Section 4.1 and the modifications discussed in the previous section were used to choose the operating conditions and the corresponding range of inlet qualities to conduct experiments using the test-section described in Section 5.1. 
Table 5.1 shows some of the operating conditions that were chosen to conduct experiments with flows involving laminar liquid and laminar vapor. These were chosen to ultimately compare the experimental data with the correlation (Eq. (3.2)) obtained from 2-D CFD simulation of annular flow-boiling. A preliminary comparison is done in Section 5.3 and a detailed comparison is reported elsewhere [23].

Table 5.1: Possible operating conditions to conduct experiments involving laminar liquid and laminar vapor flows.

\begin{tabular}{|c|c|c|c|c|c|c|c|}
\hline Case & $\begin{array}{c}\text { Inlet pressure, } \\
\mathrm{p}_{\text {in }}(\mathrm{kPa})\end{array}$ & $\begin{array}{c}\text { Mass-flux, } \\
\mathrm{G}\left(\mathrm{kg} / \mathrm{m}^{2} \mathrm{~s}\right)\end{array}$ & $\begin{array}{c}\text { Mean } \\
\text { temperature } \\
\text { difference, } \Delta \mathrm{T} \\
\left({ }^{\circ} \mathrm{C}\right)\end{array}$ & $\begin{array}{c}\text { Mean heat- } \\
\text { flux, } \overline{\mathrm{q}}_{\mathrm{W}}^{\prime \prime} \\
\left(\mathrm{W} / \mathrm{cm}^{2}\right)\end{array}$ & $\begin{array}{c}\text { Inlet } \\
\text { quality, } \\
\mathrm{X}_{\text {in }}\end{array}$ & $\begin{array}{c}\text { Inlet Liquid } \\
\text { Mass flow-rate, } \\
\dot{\mathrm{M}}_{\mathrm{L}, \text { in }}(\mathrm{g} / \mathrm{s})\end{array}$ & $\begin{array}{c}\text { Inlet Vapor } \\
\text { mass flow-rate, } \\
\dot{\mathrm{M}}_{\mathrm{V}, \text { in }}(\mathrm{g} / \mathrm{s})\end{array}$ \\
\hline 1 & 110.04 & 21.175 & 1.50 & 0.635 & 0.614 & 0.245 & 0.390 \\
\hline 2 & 109.94 & 21.826 & 1.56 & 0.655 & 0.594 & 0.266 & 0.389 \\
\hline 3 & 109.97 & 22.659 & 1.49 & 0.680 & 0.571 & 0.291 & 0.388 \\
\hline 4 & 109.70 & 23.747 & 1.55 & 0.712 & 0.543 & 0.326 & 0.387 \\
\hline 5 & 110.03 & 25.123 & 1.54 & 0.754 & 0.566 & 0.327 & 0.427 \\
\hline
\end{tabular}

As can be seen from Table 5.1, lower mass-flux G values were deliberately chosen to achieve laminar flows in both liquid and vapor phases. While a range of inlet qualities were obtained from the modified design methodology, the minimum inlet quality or an inlet quality value close to the minimum inlet quality were chosen for the actual experiment. Mass-flux $\mathrm{G}$, inlet quality $\mathrm{X}_{\mathrm{in}}$ and the area of cross-section of the channel were used to calculate the liquid and vapor mass flow-rates at the inlet $\left(\dot{\mathrm{M}}_{\mathrm{L}, \text { in }}\right.$ and $\dot{\mathrm{M}}_{\mathrm{V} \text {,in }}$ respectively).

Table 5.2 shows some of the operating conditions that were chosen to conduct experiments with flows involving turbulent (or laminar) liquid and turbulent vapor. These were chosen to ultimately compare the steady experimental data with the experimental data that involve pulsatile flows. Pulsatile flows are achieved by inducing pulsations in liquid and/or vapor phases and enable large amplitude standing interfacial waves that enhance heat transfer in both flow-boilers and flowcondenser. The heat transfer enhancement in flow-condensation has been 
reported by Kivisalu et al in [13]. The heat transfer enhancement in flow-boiling is being reported in [14, 22].

Table 5.2: Possible operating conditions to conduct experiments involving laminar liquid and turbulent vapor flows (some with near interface laminar flows).

\begin{tabular}{|c|c|c|c|c|c|c|c|}
\hline Case & $\begin{array}{c}\text { Inlet pressure, } \\
\mathrm{p}_{\text {in }}(\mathrm{kPa})\end{array}$ & $\begin{array}{c}\text { Mass-flux, G } \\
\left(\mathrm{kg} / \mathrm{m}^{2} \mathrm{~s}\right)\end{array}$ & $\begin{array}{c}\text { Mean } \\
\text { temperature } \\
\text { difference, } \Delta \mathrm{T} \\
\left({ }^{\circ} \mathrm{C}\right)\end{array}$ & $\begin{array}{c}\text { Mean heat- } \\
\text { flux, } \overline{\mathrm{q}}_{\mathrm{w}}^{\prime} \\
\left(\mathrm{W} / \mathrm{cm}^{2}\right)\end{array}$ & $\begin{array}{c}\text { Inlet } \\
\text { quality, } \\
\mathrm{X}_{\mathrm{in}}\end{array}$ & $\begin{array}{c}\text { Inlet Liquid } \\
\text { Mass flow- } \\
\text { rate, } \dot{\mathrm{M}}_{\mathrm{L}, \text { in }} \\
\mathrm{g} / \mathrm{s})\end{array}$ & $\begin{array}{c}\text { Inlet Vapor } \\
\text { mass flow-rate, } \\
\dot{\mathrm{M}}_{\mathrm{V}, \text { in }}(\mathrm{g} / \mathrm{s})\end{array}$ \\
\hline 1 & 109.33 & 66.626 & 3.81 & 0.791 & 0.202 & 1.595 & 0.403 \\
\hline 2 & 112.95 & 81.197 & 3.89 & 0.992 & 0.343 & 1.600 & 0.836 \\
\hline 3 & 114.94 & 90.172 & 3.77 & 1.112 & 0.408 & 1.600 & 1.105 \\
\hline 4 & 118.69 & 95.020 & 3.94 & 1.233 & 0.434 & 1.613 & 1.237 \\
\hline 5 & 123.05 & 111.341 & 3.76 & 1.405 & 0.516 & 1.618 & 1.722 \\
\hline
\end{tabular}

It can be seen that mass-flux G values in Table 5.2 are reasonably higher than the ones in Table 5.1, indicating turbulent flows, especially in the vapor phase. Further, the inlet qualities in Table 5.2 are lower than the ones in Table 5.1. This is because, for flows involving high mass-flow rates (typically turbulent flows), annular flowregime is reached at a lower quality and film thicknesses are, usually, less even at lower qualities.

\subsection{Comparison of Experimental Data and Correlation Developed using CFD Simulations of Laminar/Laminar Annular Flow-Boiling}

This section shows some preliminary comparison of data obtained from experiments and the correlation reported in Eq. (3.2). Table 5.3, which contains the results from experiments conducted using the operating conditions proposed in Table 5.1, shows the nucleate boiling components of HTC $\left(\mathrm{h}_{\mathrm{x} \mid \mathrm{nb}-40}\right)$ at a particular location $(\mathrm{x}=40 \mathrm{~cm}=0.4 \mathrm{~m})$ and thus consequently shows the contributions of nucleate boiling ( $\% \mu \mathrm{nb})$. This was computed by first calculating convective boiling components of $\mathrm{HTC}$ at $\mathrm{x}=40 \mathrm{~cm}\left(\mathrm{~h}_{\mathrm{x} \mid \mathrm{cb}-40}\right)$ and then subtracting that from the corresponding values of overall $H T C$ at $x=40 \mathrm{~cm}\left(h_{x \mid 40}\right)$, which was measured from the experiments. Since, the correlation for convective component of HTC was obtained from scientifically accurate and rigorous 2-D CFD simulation of annular flow-boiling, the nucleate boiling component calculated using that 
correlation is assumed to take micro-scale nucleation into account and thus to be more accurate than ad hoc calculations of nucleate boiling components available in the literature - within certain percentage of experimental errors.

Table 5.3: Preliminary comparison of results from experiments (conducted from operating conditions proposed in Table 5.1) and correlation proposed by CFD simulation of annular flowboiling (Eq. (3.2))

\begin{tabular}{|c|c|c|c|c|c|c|c|}
\hline Case & $\begin{array}{c}\text { Inlet } \\
\text { pressure, } \\
\mathrm{p}_{\text {in }}(\mathrm{kPa})\end{array}$ & $\begin{array}{c}\text { Heat-flux at } 40 \\
\mathrm{~cm}, \mathrm{q}_{\mathrm{w} \mid 40}^{\mathrm{m}} \\
\left(\mathrm{W} / \mathrm{cm}^{2}\right)\end{array}$ & $\begin{array}{c}\mathrm{HTC} \text { at } 40 \\
\mathrm{~cm}, \mathrm{~h}_{\mathrm{x} \mid 40} \\
\left(\mathrm{~W} / \mathrm{m}^{2} \mathrm{~K}\right)\end{array}$ & $\begin{array}{c}\text { Convective HTC at } \\
40 \mathrm{~cm}, \mathrm{~h}_{\mathrm{x} \mid \mathrm{cb}-40} \\
\left(\mathrm{~W} / \mathrm{m}^{2} \mathrm{~K}\right)\end{array}$ & $\begin{array}{c}\text { Nucleate boiling } \\
\mathrm{HTC} \text { at } 40 \mathrm{~cm}, \\
\mathrm{~h}_{\mathrm{x} \mid \mathrm{cb}-40}\left(\mathrm{~W} / \mathrm{m}^{2} \mathrm{~K}\right)\end{array}$ & $\% \mu \mathrm{nb}$ & $\%$ nb-KM \\
\hline $\begin{array}{c}\text { Exp } \\
\text { error }\end{array}$ & $\pm 2.48 \%$ & $\pm 3 \%$ & $\pm 11.04 \%$ & -- & -- & -- & -- \\
\hline 1 & 110.04 & 0.136 & 842.11 & 238.84 & 603.27 & 71.64 & 15.02 \\
\hline 2 & 109.94 & 0.124 & 1072.6 & 206.08 & 866.5 & 80.79 & 15.59 \\
\hline 3 & 109.97 & 0.175 & 1264.1 & 187.95 & 1183 & 85.13 & 15.51 \\
\hline 4 & 109.70 & 0.195 & 1378 & 172.14 & 1205.9 & 87.51 & 16.24 \\
\hline 5 & 110.03 & 0.172 & 1208.5 & 183.69 & 1024.8 & 84.8 & 15.97 \\
\hline
\end{tabular}

For the sake of comparison, Table 5.3 also includes nucleate boiling (\% $\mathrm{nb}-\mathrm{KM})$ contributions as predicted by a popular correlation for flow-boiling proposed by Kim and Mudawar [17]. The difference between the nucleate boiling contributions as calculated using correlations from CFD simulation and a popular existing correlation shows the ad hoc nature of decomposition of overall HTC into convective and nucleate boiling contributions in the existing correlations - since it was discussed earlier as to why the nucleate boiling contribution as calculated using correlation from CFD simulation is more accurate. Further, it can be seen that the contribution of micro-nucleation towards overall heat transfer is significantly high and the existing correlation, with ad hoc decomposition of convective and nucleate boiling terms, severely under predicts the nucleate boiling contributions.

It should be noted that this is not a part of the current work and is only discussed here to show the possibility of important fluid-physics understanding that can be discerned from such comparisons. This is part of a larger modeling work undertaken elsewhere. Detailed discussion of experimental data and the 
procedure to compute nucleate boiling contributions in a particular experimental setup are done in [14, 22, 23].

\section{Future Work}

While the work done here has given elucidating picture of processes involved in traditional and annular flow-boiling, there is scope for significant future work that can be built on what has already been done.

(i) The 2-D CFD simulation of annular flow-boiling, discussed in Section 3 and [16], was done for flows involving laminar liquid and laminar (to moderately turbulent) vapor i.e., for low liquid and vapor Reynolds numbers. This CFD work can be extended - with the help of available experimental data - to include suppressed nucleation turbulent flows involving higher values of liquid and vapor Reynolds numbers, which would eventually lead to a convective HTC correlation with higher ranges of parameters.

(ii) Once a correlation for convective HTC is available for turbulent flows, it could be used to assess nucleate boiling contributions for turbulent annular flowboiling cases (similar to use of Table 5.3 for operating conditions proposed in Table 5.1).

(iii) Further, the CFD simulation of annular flow-boiling (and the correlation thus developed in Eq. (3.2)) was done for known wall temperature "method of heating." This can be extended to cover known heat-flux "method of heating."

(iv) The data gathered from the experiments for operating conditions proposed in Tables 5.1 and 5.2 can be used to propose correlations by modifying existing correlations for flow-boiling. These modified correlations would be specific to parameter ranges for which the experiments were conducted and will prove to be useful and accurate tools in designing future experiments (as discussed in Section 4.1 and Section 5.1). 


\section{Conclusion}

The current work achieved its objective of developing a better understanding through modeling and simulation/programming activities - of annular flow-boiling and its applications. This was based on a synthesis of Computational Fluid Dynamics (CFD) simulations, existing correlations, and experiments. Section 1 discussed the importance and relative merits of annular flow-boilers and flowcondensers over traditional flow-boilers and flow condensers - and the need for CFD simulation of annular flow-boiling with hypothetically assumed absence of nucleation.

To provide context for results from CFD simulation of annular flow-boiling, correlation structure(s) for HTC was discussed, in Section 2, using fundamental physics and non-dimensionalization approaches. Discussions in Section 2 also presented a 1-D modeling approach for providing estimates that used available order of magnitude correlations.

In Section 3, the algorithm for 2-D CFD simulation of annular flow-boiling, with assumed absence of nucleation, for flows involving laminar liquid and laminar vapor, was briefly discussed (detailed discussions in [16]) and flow-physics results - and a correlation for convective component of HTC was reported.

In Section 4, a general first order estimates-methodology for design of annular flow-boilers and flow-condensers were presented/discussed. The design methodology for annular flow-boilers assumed known heat-flux "method of heating." For a specific test-section dimensions and operating condition (a combination of inlet pressures $p_{i n}$, total mass fluxes $G$, and mean heat-flux $\bar{q}_{w}^{\prime \prime}$ ), it provided the maximum possible length $\mathrm{L}_{\max }$, inlet and exit qualities along with temperature, HTC and pressure variations over the length of the test-section.

However, for test-sections for which the length is already fixed, such as the one designed for experiments in Dr. Narain's lab, the above general methodology had 
to be modified. The experimental test-section was also designed for known wall temperature "method of heating," thus necessitating more modifications to the design methodology discussed in Section 4 . These modifications were discussed in Section 5 and preliminary experimental designs (with regard to flow variables) were obtained using the modified methodology. These experimental designs were divided into two categories: one involving flows with laminar liquid and primarily laminar vapor near the interface (similar to scenarios for which CFD simulations of annular flow-boiling were conducted) and the other involving flows with laminar or turbulent liquid and turbulent vapor. Preliminary results for the former case were discussed by comparing the experimental results with those obtained from a rigorous laminar/laminar CFD correlation. This comparison yielded first-of-its-kind estimates of the significant role micro-nucleation plays as a heat-transfer mechanism.

Scope for future work, based on extensions of the current work, has been discussed in Section 6. 


\section{Appendix A - Copyright Documentation}

A.1. Copyright permission from Springer International Publishing for reuse of Fig. $1.1-1.2$, Section 1.1, Section 2 and Section 4 (including figures, and tables):

SPRINGER LICENSE TERMS AND CONDITIONS

Dec 02, 2017

This Agreement between Hrishikesh Ranga Prasad ("You") and Springer ("Springer") consists of your license details and the terms and conditions provided by Springer and Copyright Clearance Center.

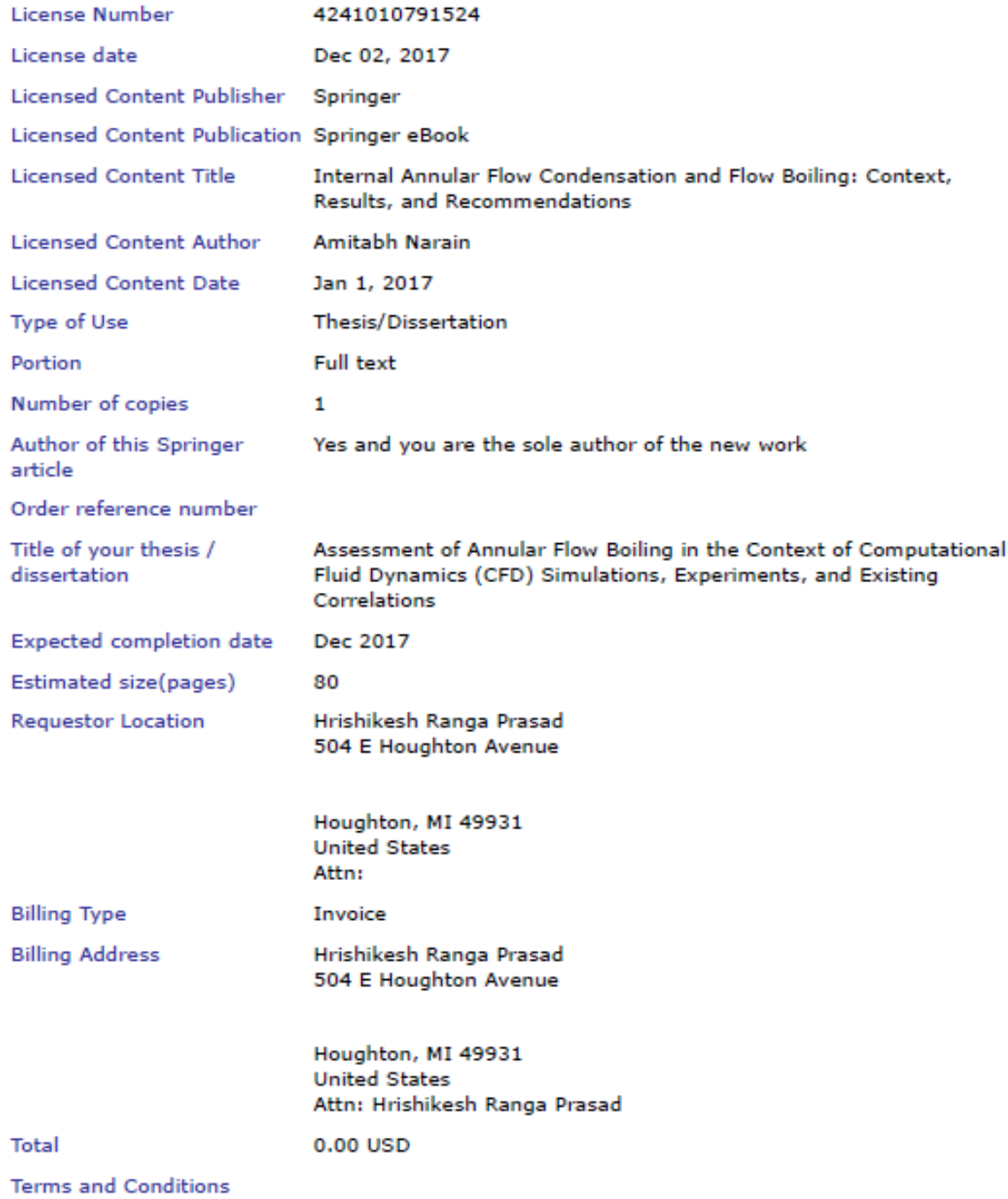


A.2. Email of copyright permission from Old City Publishing for reuse of Section 1.2 and Section 3 (including figures, table and the reported correlation):

Request for Permission:

\section{Re: IJTP manuscript \#: IJTP 16 N0001199 (Invited Article)}

Hrishikesh Ranga Prasad <hrangapr@mtu.edu>

Mon, Dec 4, 2017 at 3:05 PM

To: Journals At Old City Publishing <journals@oldcitypublishing.com>

Cc: Amitabh Narain <narain@mtu.edu>, nook Gorgitrattanagul <pgorgitr@mtu.edu>, info@oldcitypublishing.com

Dear Guy,

I am one of the students working with Dr. Amitabh Narain (and one of the authors of the paper).

I too had sent a request for permission.

Just to clarify, I have summarized the work published in the article in my dissertation and, so, I had asked for permission to reproduce the entire text along with the figures and tables. However, I will only be using the text, figures and tables necessary to effectively summarize the work published in the article.

Can you kindly confirm if this is acceptable and that the email be used as permission (granted by Old City Publishing) to reproduce the necessary text, figures and tables?

Thanks,

Hrishikesh Ranga Prasad

[Quoted text hidden]

\section{Email of Copyright Permission:}

\section{Re: IJTP manuscript \#: IJTP 16N0001199 (Invited Article)}

Journals At Old City Publishing <journals@oldcitypublishing.com>

Mon, Dec 4, 2017 at 3:30 PM

To: Hrishikesh Ranga Prasad shrangapr@mtu.edu>

Cc: Amitabh Narain <narain@mtu.edu>, nook Gorgitrattanagul <pgorgitr@mtu.edu>, info@oldcitypublishing.com

You are welcome to include the article summary for your dissertation. Please be sure to fully cite: Journal Name, volume number, issue number, page range of the article and publication year.

Best of luck with your studies.

\section{Guy}

Guy Griffiths

Old City Publishing

628 North 2nd Street

Philadelphia, PA 19123, USA

Tel: 2159254390

Fax: 2159254371

E-mail: joumals@oldcitypublishing.com

Web: oldcitypublishing.com 


\section{References}

1. Kuo, C.-J. and Y. Peles, Flow boiling of coolant (HFE-7000) inside structured and plain wall microchannels. Journal of Heat Transfer, 2009. 131(12): p. 121011.

2. Li, W., X. Qu, T. Alam, F. Yang, W. Chang, J. Khan and C. Li, Enhanced flow boiling in microchannels through integrating multiple micro-nozzles and reentry microcavities. Applied Physics Letters, 2017. 110(1): p. 014104.

3. Zhu, Y., D.S. Antao, K.-H. Chu, S. Chen, T.J. Hendricks, T. Zhang and E.N. Wang, Surface Structure Enhanced Microchannel Flow Boiling. Journal of Heat Transfer, 2016. 138(9): p. 091501.

4. Kandlikar, S.G. and C.N. Hayner, Liquid Cooled Cold Plates for Industrial High-Power Electronic Devices-Thermal Design and Manufacturing Considerations. Heat Transfer Engineering, 2009. 30(12): p. 918-930.

5. Ghiaasiaan, S.M., Two-phase flow, boiling, and condensation: in conventional and miniature systems. 2007: Cambridge University Press.

6. Faghri, A., Heat Pipe Science and Technology. 1995: Taylor and Francis, Washington D. C.

7. Agostini, B., M. Fabbri, J.E. Park, L. Wojtan, J.R. Thome and B. Michel, State of the art of high heat flux cooling technologies. Heat Transfer Engineering, 2007. 28(4): p. 258-281.

8. Ball, P., Computer engineering: Feeling the heat. Nature, 2012. 492(7428): p. 174-176.

9. Narain, A., H. Ranga Prasad and A. Koca, Internal Annular Flow Condensation and Flow Boiling: Context, Results, and Recommendations, in Handbook of Thermal Science and Engineering, F.A. Kulacki, Editor. 2017, Springer International Publishing. p. 1-88.

10. Qu, W. and I. Mudawar, Measurement and correlation of critical heat flux in two-phase micro-channel heat sinks. International Journal of Heat and Mass Transfer, 2004. 47(10-11): p. 2045-2059.

11. Das, P.K., S. Chakraborty and S. Bhaduri, Critical Heat Flux during Flow Boiling in Mini and Microchannel-a State of the Art Review. Frontiers in Heat and Mass Transfer, 2012. 3(1).

12. Carey, V.P., Liquid-Vapor Phase-Change Phenomena. Series in Chemical and Mechanical Engineering, Hemisphere Publishing Corporation, 1992. 
13. Kivisalu, M.T., P. Gorgitrattanagul and A. Narain, Results for high heat-flux flow realizations in innovative operations of milli-meter scale condensers and boilers. International Journal of Heat and Mass Transfer, 2014. 75: $p$. 381-398.

14. Gorgitrattanagul, P., A. Narain and S. Sepahyar, Investigations of Temperature Controlled Innovative Annular Flow-boiling of FC-72 in Millimeter Scale Ducts - Part I: Experimental Realizations of Steady and Enhanced Pulsatile Cases. International Journal of Heat and Mass Transfer, 2018. To Be Submitted.

15. Chen, J.C., Correlation for boiling heat transfer to saturated fluids in convective flow. Industrial \& engineering chemistry process design and development, 1966. 5(3): p. 322-329.

16. Ranga Prasad, H., A. Narain, S.S. Bhasme and R.R. Naik, Shear-driven Annular Flow-boiling in Millimeter-scale channels: Direct Numerical Simulations for Convective Component of the Overall Heat Transfer Coefficient. International Journal of Transport Phenomena, 2017. 15(1): p. $1-35$

17. Kim, S.-M. and I. Mudawar, Universal approach to predicting saturated flow boiling heat transfer in mini/micro-channels - Part II. Two-phase heat transfer coefficient. International Journal of Heat and Mass Transfer, 2013. 64: p. 1239-1256.

18. Lazarek, G. and S. Black, Evaporative heat transfer, pressure drop and critical heat flux in a small vertical tube with $R-113$. International Journal of Heat and Mass Transfer, 1982. 25(7): p. 945-960.

19. Narain, A., Kivisalu, M., Naik, R., Gorgitrattanagul, N., Mitra, S., Hasan, M. M. Comparative Experimental and Computational Studies for Annular Condensing and Boiling Flows in Milli-meter Scale Horizontal Ducts. in Proceedings of ASME 2012 Summer Heat Transfer Conference. 2012. Rio Grande, Puerto Rico, USA: ASME.

20. Naik, R.R., A. Narain and S. Mitra, Steady and unsteady simulations for annular internal condensing flows, part l: Algorithm and its accuracy. Numerical Heat Transfer, Part B: Fundamentals, 2016: p. 1-22.

21. Naik, R.R. and A. Narain, Steady and unsteady simulations for annular internal condensing flows, part II: Instability and flow regime transitions. Numerical Heat Transfer, Part B: Fundamentals, 2016: p. 1-16.

22. Gorgitrattanagul, P. Temperature controlled innovative flow-boiling of FC72 for thin liquid film annular flows in millimetre scale ducts - investigation 
of steady and pulsatile cases with enhanced micro-nucleation. Ph. D, Michigan Technological University.2017.

23. Narain, A., H. Ranga Prasad, P. Gorgitrattanagul and S. Mehendale, Investigations of Temperature Controlled Innovative Annular Flow-boiling of FC-72 in Millimeter Scale Ducts - Part II: Modeling/simulations for heat transfer coefficient correlations and assessment of convective and nucleate boiling contributions. International Journal of Heat and Mass Transfer, 2018. To Be Submitted.

24. Dalkilic, A.S. and S. Wongwises, Intensive literature review of condensation inside smooth and enhanced tubes. International Journal of Heat and Mass Transfer, 2009. 52(15-16): p. 3409-3426.

25. Kim, S., I.C. Bang, J. Buongiorno and L. Hu, Surface wettability change during pool boiling of nanofluids and its effect on critical heat flux. International Journal of Heat and Mass Transfer, 2007. 50(19): p. 41054116.

26. Shah, M.M., A method for predicting heat transfer during boiling of mixtures in plain tubes. Applied Thermal Engineering, 2015. 89: p. 812-821.

27. White, F.M., Fluid Mechanics. 2003, McGraw-Hill.

28. Thome, J.R., Engineering data book III. Wolverine Tube Inc, 2004. 2010.

29. Narain, A., R.R. Naik, S. Ravikumar and S.S. Bhasme, Fundamental assessments and new enabling proposals for heat transfer correlations and flow regime maps for shear driven condensers in the annular/stratified regime. Journal of Thermal Engineering, 2015. 1(4): p. 307-321.

30. Bergman, T.L., F.P. Incropera, D.P. DeWitt and A.S. Lavine, Fundamentals of heat and mass transfer. 2011: John Wiley \& Sons.

31. Bhasme, S.S. Development of and Simulation Results from: a CFD code for Steady Annular (Suppressed Nucleation) Flow Boiling. M.S, Michigan Technological University.2016.

32. Kivisalu, M.T. Experimental investigation of certain internal condensing and boiling flows: Their sensitivity to pressure fluctuations and heat transfer enhancements. Ph. D, Michigan Technological University.2015.

33. Harirchian, T. and S.V. Garimella, Flow regime-based modeling of heat transfer and pressure drop in microchannel flow boiling. International Journal of Heat and Mass Transfer, 2012. 55(4): p. 1246-1260. 
34. Kim, S.-M. and I. Mudawar, Universal approach to predicting heat transfer coefficient for condensing mini/micro-channel flow. International Journal of Heat and Mass Transfer, 2013. 56(1-2): p. 238-250.

35. Mandhane, J., G. Gregory and K. Aziz, A flow pattern map for gas-liquid flow in horizontal pipes. International Journal of Multiphase Flow, 1974. 1(4): p. 537-553.

36. Zivi, S., Estimation of Steady-State Void Fraction by Means of Principle of Minimum Energy Production. ASME Journal of. Heat Transfer, 1964. 86(2): p. 247-252.

37. Rouhani, S.Z. and E. Axelsson, Calculation of void volume fraction in the subcooled and quality boiling regions. International Journal of Heat and Mass Transfer, 1970. 13(2): p. 383-393.

38. Steiner, D., Heat transfer to boiling saturated liquids VDI-Wärmeatlas (VDI Heat Atlas). VDI-Gesellschaft Verfahrenstechnik und Chemieingenieurswesen (GCV), Düsseldorf, 1993.

39. Friedel, L. Improved friction pressure drop correlations for horizontal and vertical two-phase pipe flow. in European two-phase flow group meeting, Paper E. 1979.

40. Grönnerud, R., Investigation of liquid hold-up, flow-resistance and heat transfer in circulation type evaporators, part IV: two-phase flow resistance in boiling refrigerants. Bull. De l'Inst. Du Froid, Annexe, 1972. 1.

41. Lockhart, R. and R. Martinelli, Proposed correlation of data for isothermal two-phase, two-component flow in pipes. Chem. Eng. Prog, 1949. 45(1): p. 39-48. 